\title{
WestVirginiaUniversity
}

THE RESEARCH REPOSITORY @ WVU

Graduate Theses, Dissertations, and Problem Reports

2005

\section{Finite-element modeling of a composite bridge deck}

\author{
Suraj Suraj \\ West Virginia University
}

Follow this and additional works at: https://researchrepository.wvu.edu/etd

\section{Recommended Citation}

Suraj, Suraj, "Finite-element modeling of a composite bridge deck" (2005). Graduate Theses, Dissertations, and Problem Reports. 1580.

https://researchrepository.wvu.edu/etd/1580

This Thesis is protected by copyright and/or related rights. It has been brought to you by the The Research Repository @WVU with permission from the rights-holder(s). You are free to use this Thesis in any way that is permitted by the copyright and related rights legislation that applies to your use. For other uses you must obtain permission from the rights-holder(s) directly, unless additional rights are indicated by a Creative Commons license in the record and/ or on the work itself. This Thesis has been accepted for inclusion in WVU Graduate Theses, Dissertations, and Problem Reports collection by an authorized administrator of The Research Repository @ WVU. For more information, please contact researchrepository@mail.wvu.edu. 
Finite-Element Modeling of a Composite Bridge Deck

\title{
Suraj Suraj
}

\author{
Thesis submitted to the \\ College of Engineering and Mineral Resources \\ at West Virginia University \\ in partial fulfillment of the requirements \\ for the degree of
}

Master of Science

in

Mechanical Engineering

\author{
Nithi T. Sivaneri, Ph.D., Chair \\ Hota GangaRao, Ph.D., \\ Jacky C. Prucz, Ph.D., \\ Department of Mechanical and Aerospace Engineering \\ Morgantown, West Virginia \\ 2005
}

Keywords: Bridge Deck, Composites, ANSYS, Finite-Element Modeling 


\section{ABSTRACT \\ Finite-Element Modeling of A Composite Bridge Deck \\ Suraj Suraj}

Fiber Reinforced Polymer (FRP) materials are being widely used for structural applications, an example being bridge decks. In this study a finite-element model using the software ANSYS is developed for an 8"-thick low-profile FRP bridge deck (Prodeck 8) made of E-glass fiber and Polyester resin. The bridge deck is subjected to a patch load at the center and the finite-element results obtained in the form of deflections, strains, and equivalent flexural rigidity are compared with experimental results. A good correlation is found to exist between the finite-element results and the experimental results. A failure analysis, based on maximum stress, maximum strain and Tsai-Wu theories of the Prodeck 8 is carried and first ply failure is determined. Finally, the Prodeck 8 is evaluated for critical load by performing a buckling analysis. 


\section{ACKNOWLEDGEMENTS}

First and foremost, I would like to thank God for providing me with an opportunity to pursue higher education at WVU. Also exceeding appreciation is extended to my family for their support and encouragement.

I would like to express my sincere gratitude and appreciation to Dr. Nithi $\mathrm{T}$. Sivaneri, my advisor and committee chairman. His contributions are too numerous to mention, but much of the success of the project is due to his guidance and these indispensable contributions will never be forgotten. I would like to thank the remainder of the advisory committee, Dr. Hota V. GangaRao for his valuable suggestions, feedback and insightful thoughts and Dr. Jacky C. Prucz for his suggestions and advice.

Special thanks are also owed to Vimala Shekar for all her invaluable help and suggestions during the duration of the project. Many additional students and Faculty were very helpful during the course of this project, and their assistance is greatly appreciated.

The Federal Highway Administration, US Department of Transportation (FHWAUSDOT), sponsored this work under the Center of Excellence Project. 


\section{TABLE OF CONTENTS}

ABSTRACT

ACKNOWLEDGEMENTS

LIST OF FIGURES

LIST OF TABLES $\quad$ ix

1 INTRODUCTION 1

1.1 PROBLEM STATEMENT 1

1.2 OBJECTIVES 2

1.3 SCOPE 3

2 LITERATURE REVIEW 4

$3 \quad$ DESCRIPTION OF PRODECK $8 \quad 10$

4 FINITE ELEMENT ANALYSIS 15

$\begin{array}{lll}4.1 & 15 T R O D U C T I O N\end{array}$

$\begin{array}{lll}4.2 & 15\end{array}$

4.3 COMPUTATION OF LAMINA PROPERTIES 17

$\begin{array}{lll}\text { 4.3.1 Material Properties } & 18\end{array}$

4.3.2 Lamina Properties 20

4.3.3 Lamina Material Specifications 22

4.4 MODELING AND MESHING 23

$\begin{array}{lll}4.5 & \text { BOUNDARY CONDITIONS } & 27\end{array}$

$\begin{array}{lll}4.6 & \text { LOADS } & 28\end{array}$

$\begin{array}{ll}4.7 & \text { DESIGN FOR FAILURE }\end{array}$

4.7.1 Strength ratio $(R) \quad 29$

$\begin{array}{lll}4.7 .2 & \text { Failure criteria } & 29\end{array}$

4.7.2.1 Maximum Stress criterion 30

4.7.2.2 Maximum ctrain criterion 31

4.7.2.3 Tsai-Wu failure criterion $\quad 32$ 
4.7.3 Failure criteria Using ANSYS 33

$\begin{array}{lll}\text { 4.7.4 Lamina failure properties } & 34\end{array}$

5 RESULTS AND DISCUSSIONS 36

$\begin{array}{lll}5.1 & \text { INTRODUCTION } & 36\end{array}$

$\begin{array}{lll}5.2 & \text { DEFLECTION ANALYSIS } & 37\end{array}$

5.3. TORSIONAL ANALYSIS OF PRODECK 8

5.4 STRAIN AND STRESS ANALYSIS 48

$\begin{array}{lll}5.5 & \text { FAILURE ANALYSIS } & 73\end{array}$

$\begin{array}{lll}5.6 & \text { BUCKLING ANALYSIS } & 81\end{array}$

6 CONCLUSIONS AND RECOMMENDATIONS 81

$\begin{array}{lll}6.1 & \text { INTRODUCTION } & 81\end{array}$

6.2 CONCLUSIONS 81

$\begin{array}{lll}6.3 & \text { RECOMMENDATIONS } & 82\end{array}$

$\begin{array}{ll}\text { REFERENCES } & 83\end{array}$

APPENDIX A

$\begin{array}{ll}\text { SHEAR MODULUS AND SHEAR CORRECTION } & 87\end{array}$

$\begin{array}{lll}\text { A.1 Shear modulus } & 87\end{array}$

A.2 Shear correction in transverse loading analysis

APPENDIX B

PRODECK 8 SUBJECTED TO PURE BENDING MOMENT 90 


\section{LIST OF FIGURES}

Fig. 2.1 FRP bridge deck cross-sections considered by Henry (1985) and Ahmad and Plecnik (1989) 5

Fig. 2.2 Cross-sections of the FRP decks analyzed by Zurieck 6

Fig. 3.1 Cross-Section of Prodeck 8 [Howard, (2002)] 11

Fig. 3.2 Cross-Section of Prodeck 8 used for the present analysis 11

Fig. 3.3 Global coordinate system for the Prodeck 8

Fig. 3.4 Fiber architecture of polyester component [Howard, (2002)] 13

Fig. 4.1 Element type SOLID46 [2] 16

Fig. 4.2 Solid model of the Prodeck $8 \quad 24$

Fig. 4.3 Schematic representation of the meshed Prodeck 8

Fig. 4.4 Element orientations of individual layers 26

Fig. 4.5 Graphical representation of the element co-ordinate system 26

Fig. 4.6 Schematic representation of the applied boundary conditions on the Prodeck $8 \quad 27$

Fig. 4.7 Schematic representation of a 10" x 20 " patch load applied on the Prodeck $8 \quad 28$

Fig. 5.1 Deformed shape of the Prodeck 8 under central patch load of value 24 kips $\quad 37$

Fig. 5.2 Variation of maximum deflection with load for a central patch load 39

Fig. 5.3 Displacement plot in the $Y$ direction for the Prodeck 8 with fiber volume fraction of $54 \%$ and $24 \mathrm{Kips}$ patch load

Fig. 5.4 Variation of load with maximum deflection for two different fiber volume fractions for a central patch load 42

Fig. 5.5 Prodeck 8 subjected to torsion 46

Fig. 5.6 Contour plot of showing angle of twist of the Prodeck 8 from the torsional analysis 46

Fig. 5.7 Position of strain gages [Howard, (2002)] 48

Fig. 5.8 Variation of $\varepsilon_{Z}$ at gage \#4 location for a central patch load 50 
Fig. 5.9 Variation of $\varepsilon_{Z}$ at the Strain Gage \#1 location for a central patch load

Fig. 5.10 Variation of $\varepsilon_{X}$ (compressive) at the Strain Gage \#2 location for a central patch load

Fig. 5.11 Variation of $\varepsilon_{X}$ (compressive) at the Strain Gage \#5 location for a central load of $24 \mathrm{Kips}$

Fig. 5.12 Variation of $\varepsilon_{Z}$ at the Strain Gage \#6 location for a central patch load

Fig. 5.13 Variation of $\varepsilon_{Z}$ (compressive) at the Strain Gage \#7 location for a central patch load

Fig. 5.14 Variation of $\varepsilon_{X}$ at the Strain Gage \#8 location for a central patch load

Fig. 5.15 Variation of $\varepsilon_{X}$ at the Strain Gage \#11 location for a central patch load

Fig. 5.16 Variation of $\varepsilon_{Z}$ (compressive) at the Strain Gage \#12 location for

a central patch load

Fig. 5.17 Variation of $\varepsilon_{Y}$ at the Strain Gage \#10 location for a central patch load

Fig. 5.18 Contour plot of $\varepsilon_{Z}$ for a central patch load of 24 Kips

Fig. 5.19 Contour plot of $\varepsilon_{Z}$ in side view for a central patch load of 24 Kips

Fig. 5.20 Contour plot of $\varepsilon_{X}$ for a central patch load of $24 \mathrm{Kips}$

Fig. 5.21 Contour plot of $\varepsilon_{X}$ for a section of the Prodeck 8 for a central patch load of 24 Kips

Fig. 5.22 Contour plot of $\varepsilon_{Y}$ for a central patch load of $24 \mathrm{Kips}$

Fig. 5.23 Contour plot of $\varepsilon_{Y}$ in the side view for a central patch load of 24 Kips

Fig. 5.24 Contour plot of $\gamma_{X Y}$ for a central patch load of 24 Kips

Fig. 5.25 Contour plot of $\gamma_{X Y}$ in the side view for a central patch load of $24 \mathrm{Kips}$

Fig. 5.26 Contour plot of $\gamma_{X Z}$ for a central patch load of $24 \mathrm{Kips}$

Fig. 5.27 Contour plot of $\gamma_{X Z}$ in the side view for a central patch load of $24 \mathrm{Kips}$

Fig. 5.28 Contour plot of $\gamma_{Y Z}$ for a central patch load of 24 Kips 
Fig. 5.29 Contour plot of $\gamma_{Y Z}$ in the side view for a central patch load of 24 Kips

Fig. 5.30 Contour plot of $\sigma_{Z}$ in the side view for a central patch load of $24 \mathrm{Kips} \quad 66$

Fig. 5.31 Contour plot of $\sigma_{Z}$ for a central patch load of 24 Kips 66

Fig. 5.32 Contour plot of $\sigma_{X}$ for a central patch load of 24 Kips 67

Fig. 5.33 Contour plot of $\sigma_{X}$ in the side view for a central patch load of $24 \mathrm{Kips} \quad 67$

Fig. 5.34 Contour plot of $\sigma_{Y}$ for a central patch load of 24 Kips $\quad 68$

Fig. 5.35 Contour plot of $\sigma_{Y}$ in the side view for a central patch load of 24 Kips $\quad 68$

Fig. 5.36 Contour plot of $\tau_{X Y}$ for a central patch load of 24 Kips

Fig. 5.37 Contour plot of $\tau_{X Y}$ for a central patch load of 24 Kips 69

Fig. 5.38 Contour plot of $\tau_{X Z}$ for a central patch load of 24 Kips $\quad 70$

Fig. 5.39 Contour plot of $\tau_{X Z}$ for a central patch load of 24 Kips $\quad 70$

Fig. Fig. 5.40 Contour plot of $\tau_{Y Z}$ for a central patch load of 24 Kips 71

Fig. 5.41 Contour plot of $\tau_{Y Z}$ for a central patch load of 24 Kips $\quad 71$

Fig. 5.42 Failure plot of the Prodeck 8 using maximum stress criterion 74

Fig. 5.43 Failure plot for a part of the Prodeck 8 using maximum stress criterion $\quad 74$

Fig. 5.44 Failure plot of the Prodeck 8 using maximum strain criterion 75

Fig. 5.45 Failure plot for a part of the Prodeck 8 using maximum strain criterion $\quad 76$

Fig. 5.46 Failure plot of the Prodeck 8 using Tsai-Wu Criterion 76

Fig. 5.47 Failure plot for a section of the Prodeck 8 using Tsai-Wu criterion $\quad 77$

Fig. 5.48 Failure plot of the Prodeck 8 using maximum stress criterion $\begin{array}{ll}\text { subjected to a patch load of 14'x 20" } & 78\end{array}$

Fig. 5.49 Failure plot for a part of the Prodeck 8 using maximum stress criterion subjected to a patch load of 14'x 20" 79

Fig. 5.50 Failure plot of the Prodeck 8 using maximum strain criterion subjected to a patch load of 14'x 20" 79

Fig. 5.51 Failure plot for a part of the Prodeck 8 using maximum strain criterion subjected to a patch load of 14'x 20" 
Fig. 5.52 Failure plot of the Prodeck 8 using Tsai-Wu criterion subjected to a patch load of 14'x 20"

Fig. 5.53 Failure plot for a part of the Prodeck 8 using Tsai-Wu criterion

Fig. 5.54 Buckled shape of the Prodeck 8

Fig. 5.55 Buckled shape of the web

Fig. A-1 Linear fit of the angle of twist for the web of the Prodeck 8

Fig. A-2 Linear fit of the angle of twist for the flange of the Prodeck 8

Fig. B-1 Prodeck 8 subjected to pure bending moment 90

Fig. B-2 Contour plot of displacement in the $Y$ direction 


\section{LIST OF TABLES}

Table 3.1-TVM-3408/Version 1001 Product Specifications 14

Table 3.2-NEMP 120/2001 Product Specifications 14

Table 4.1 Lamina properties with fiber volume fraction of $0.64 \quad 23$

Table 4.2 Lamina Properties with fiber volume fraction of 0.54

Table 4.3 Strength values for Rovings, TVM and NEMP 35

Table 4.4 Ultimate strain values for Rovings, TVM and NEMP 35

Table 5.1 Maximum deflection of Prodeck 8 for a central load of 24 Kips 38

Table 5.2 Maximum deflection of Prodeck 8 for two different fiber volume fractions for a central load of 24 Kips 41

Table 5.3 Equivalent flexural rigidity and Young's modulus in the longitudinal direction based on maximum deflection $\quad 44$

Table 5.4 Strain values at the Strain Gage \#4 location for a central load of 24 Kips 49

Table 5.5 Strain values at the locations of Strain Gages \#1, \#2, \#5 and \#6 for a central load of 24 Kips 51

Table 5.6 Strain values at the locations of Strain Gages \#7, \#8, \#11 and \#12 for a central load of $24 \mathrm{Kips}$

Table 5.7 Strain values at the locations of Strain Gage \#10 a central load of 24 Kips 53

Table 5.8 Equivalent flexural rigidity and Young's modulus in the cell direction based on strain 


\section{CHAPTER 1}

\section{INTRODUCTION}

\subsection{PROBLEM STATEMENT}

The engineering world is constantly striving to come up with new materials that can improve the efficiency, enhance the performance, and increase the durability of structures. One such material being investigated and researched is the Fiber Reinforced Polymer (FRP) material for structural applications, specifically bridges. According to the Federal Highway Administration publications ${ }^{*}, 28.6 \%$ of the total inventories of highway bridges are structurally deficient and over $\$ 55$ billion funding has been allocated for bridge replacement and rehabilitation programs to improve the condition of the nation's bridges.

Over the past few years a considerable amount of research work has been carried out on FRP materials for bridge deck systems and a couple of all-composite bridge decks are already in use: Laurel Lick Bridge in Lewis County, WV and Wickwire Run Bridge in Taylor County, WV [GangaRao et.al (1999)]

Composites are primarily made of fibers and matrix. While fibers account for most of the stiffness and strength, the matrix binds the fibers together enabling the transfer of loads. Composite materials have superior properties like light weight, high strength to weight ratio, good corrosion and fatigue resistance and ease of manufacturing,

\footnotetext{
* (www.fhwa.gov/policy/2002cpr/ch11)
} 
compared to steel and concrete, the traditional construction materials. Though steel and concrete are widely used for structural applications, they require routine maintenance and should have to be replaced eventually compared to FRP's, which have a longer life span.

However the application of composite materials to infrastructure applications has been limited due to the lack of industry recognized design criteria and standards and standardized test methods. One key reason is due to the lack of a reliable failure theory; or more precisely, a consistent failure analysis methodology. This happens despite of the fact that advanced composites have been widely used in aerospace and other strength critical structures for nearly half a century [Wang, (2004)]. Also the design of composite structures is quite complicated and needs specialized training.

\subsection{OBJECTIVES}

- The primary objective of this research is to develop a finite-element model using the software ANSYS for a composite bridge deck subjected to a patch load of 10 " $\mathrm{x} 20$ " in three point bending.

- To determine the equivalent flexural rigidity and Young's Modulus of the deck.

- To carry out a failure analysis and determine the first ply failure.

- To carry out a buckling analysis and determine the critical load. 


\subsection{SCOPE}

Chapter 2 contains a brief review of published literature relating to composite bridge decks.

Chapter 3 gives a detail description of the composite bridge deck being analyzed.

Chapter 4 deals with the finite-element model generation, the loading conditions and the types of solution.

Chapter 5 contains the results generated, comparison with existing experimental results and a discussion of the results.

Chapter 6 lists the conclusions and also contains some recommendations for future work. 


\section{CHAPTER 2}

\section{LITERATURE REVIEW}

In 1983 the US department of transportation initiated a research project named, "Transfer of Composite Technology to Design and Construction of Bridges", which marked the beginning of research on FRP decks. Since then, a number of research works has been conducted on FRP decks and a number of papers have been published. This chapter presents a brief review of the relevant references pertaining to experimental and numerical modeling of FRP decks. It should be noted that the magnitude of research work conducted on the analytical front is smaller compared to that of the experimental work.

McGhee et al. (1991) have performed a numerical analysis on FRP decks of different shapes as shown in Fig. 2.1, based on the experimental studies carried out by Henry (1985) and Ahmad and Plecnik (1989). The purpose of the research conducted by McGhee et al. is to determine the shape that would be the best fit for practical application. Based on the mathematical formulation and a finite element analysis, the authors conclude that the FRP deck with Type III cross-section is the most efficient shape.

Mongi (1991) has conducted experimental and numerical studies for determining the deflections of an FRP bridge deck system with different sizes, joint types, and loading conditions. On comparing the experimental and numerical results the author concludes that there exists a good correlation between the two and finds that the FRP bridge deck system made of 2 cellular box sections connected by an I-beam to be the best fit. 

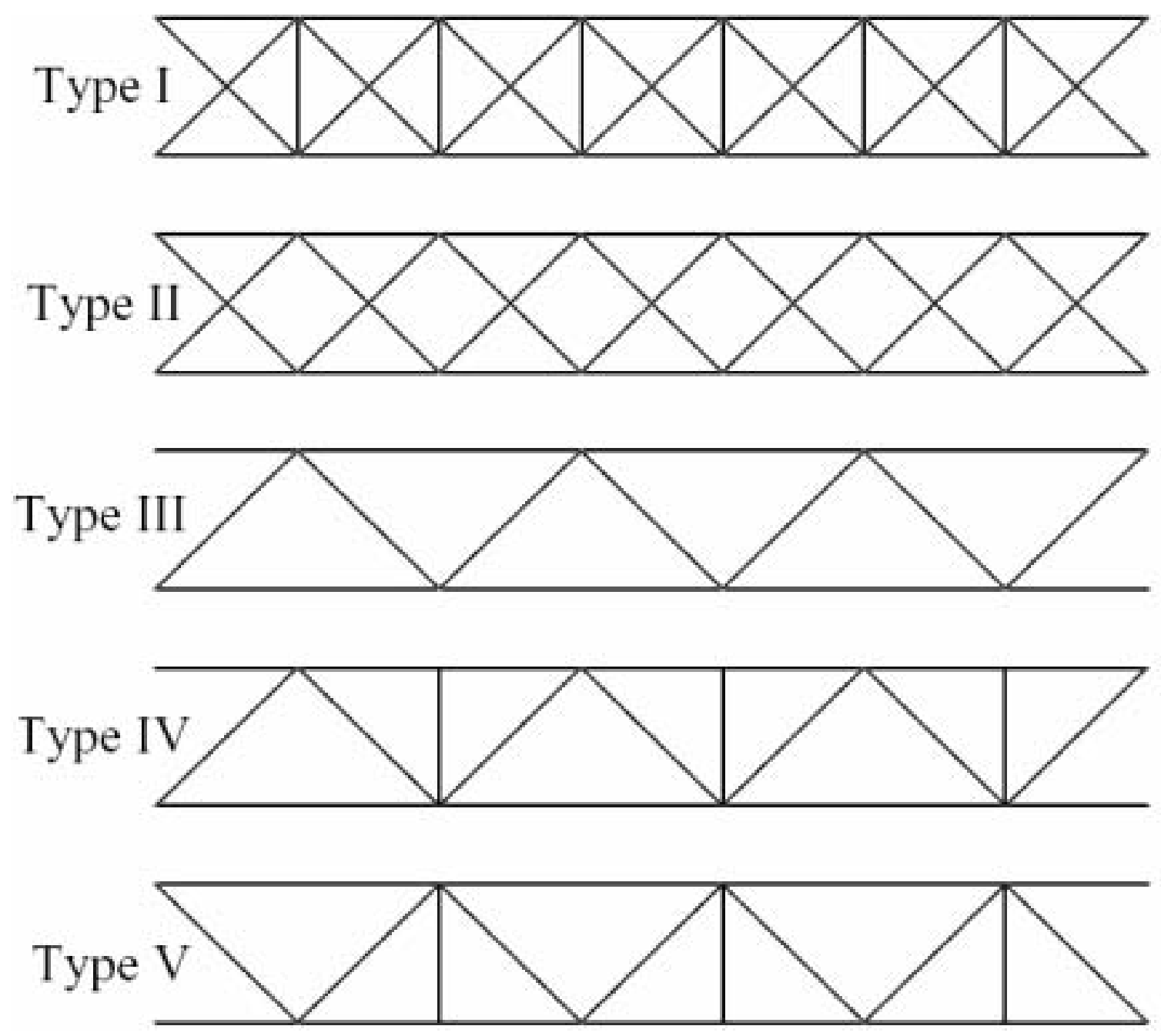

Fig. 2.1 FRP bridge deck cross-sections considered by Henry (1985) and Ahmad and Plecnik (1989)

Zurieck (1997) has conducted a finite-element analysis on simply supported FRP decks (40' long, 8' wide and 11' deep) with two stringers and subjected to a patch load. Decks with four different shaped cells as shown in Fig. 2.2 have been analyzed for deflections. The author concludes that the box shaped cell and V shaped cell deflected less compared to the trapezoidal and cross-shaped cells 




Deck 1: box-shaped cells

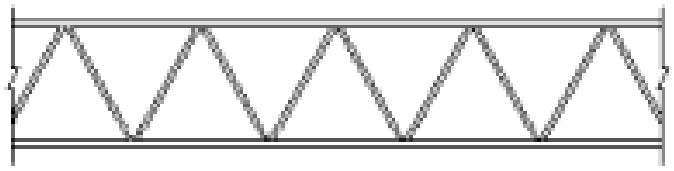

Deck 3: V-shaped cells

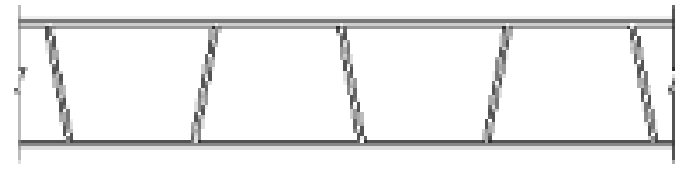

Deck 2: trapezoidal-shaped cells

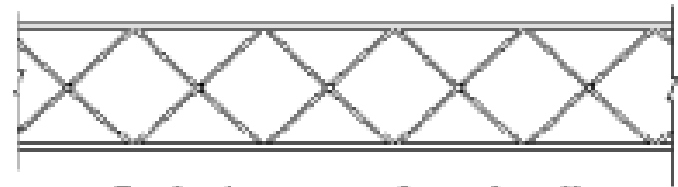

Deck 4: cross-shaped cells

Fig. 2.2 Cross-sections of the FRP decks analyzed by Zurieck (1997)

Brown (1998) has conducted experimental and analytical studies of FRP bridge decks consisting of cellular box decks and wide flange I-beam as stringer. FRP decks of two different shapes have been tested. The first deck tested had dimensions of 5'x 5'x 5" and consisted of box beams that are 5"x 5"x 3/8". The second deck tested has dimensions of $10^{\prime} \times 10^{\prime} \times 8^{\prime \prime}$ and consists of bonded box beams that are 4"x 8"x 1/4" and the decks are in turn placed on FRP wide flange I-beams (12"x 12"x 1/2") and tested as a deck and stringer bridge system. Simplified design equations are developed for the analysis of FRP beams under bending and compared with experimental and finite-element results. The author finds a good correlation between experimental and analytical results and concludes that the simplified design approach developed could be effectively used in the systematic analysis and design of FRP deck and stringer bridge systems.

Shekar (2000) has conducted 3-point bending tests on second-generation trapezoidal and hexagonal FRP bridge decks. The outer dimension of the component cross-section is 12 "x 8 " with a clear span of 108 ". The equivalent flexural rigidity is found to be $8.28 \times 10^{8}\left(\mathrm{lb} \mathrm{x} \mathrm{in}^{2}\right)$ and the ultimate bending stress is found to be $30.8 \mathrm{ksi}$. 
The author reports the failure mode to be the web flange separation. The stiffness and ultimate bending stress are also calculated using approximate classical lamination theory and the results are compared to experimental results.

Chandrashekhara and Nanni (2000) have conducted an extensive experimental study and a finite-element analysis to evaluate the performance of an all-composite bridge deck. They have stiffness and strength properties and failure modes for a deck with the dimensions $30^{\prime} \times 9^{\prime}$ consisting of 3" square box cells 0.25 ". The authors report a good correlation between their experimental results and finite-element results. Based on their study they conclude that all-composite bridge decks made of pultruded glass and carbon FRP tubes to be a suitable replacement for short span bridges made of conventional materials.

Temeles (2001) has conducted an experimental research on two 7"-thick FRP deck panels, 15'x 5' rectangular panes comprising of ten 15'-long, 6"х 6"x 3/8" standard pultruded FRP tubes. The deck is made of E-glass fiber with Polyester matrix. The deck is tested for fatigue and bending loads. For bending the deck is subjected to AASHTO (American Association of State Highway and Transportation Officials) design loads under simulated HS25 axle with impact effects. The maximum deflection of the deck is found to be $L / 470$ (where $L$ is the clear span of the deck). For the fatigue analysis the deck is subjected to approximately 4 million load cycles over a period of 8 months and the author reports no loss in stiffness.

Zhou (2002) has conducted an experimental and analytical study on FRP bridge decks and determined their strength and stiffness. The FRP bridge deck is 15' 3" long and 5 ' wide comprising of 6" x 6" x 3/8" orthotropic box beams. An analysis procedure based 
on classical lamination plate theory (CLPT) using the method of elastic equivalence (MEE) is developed for the stiffness analysis of the FRP bridge deck. The author concludes that while this method predicts the bending deflections reasonably well for uniformly distributed load and rectangular patch loads, the bending deflection of the deck under the point load could not be accurately predicted and suggests the use of finiteelement analysis or higher order plate theories. Also a deck failure function method is developed for the failure analysis of FRP decks and concludes that the failure function method gives a good damage and failure predictions for central loading compared to Tsai-Wu and Tsai Hill criteria.

Howard (2002) has conducted experimental tests on an FRP bridge deck called Prodeck 8 with a fiber volume fraction of $54 \%$. The bridge deck is evaluated for for its adequacy under AASHTO's HS25 loading case with minimum stringer spacing of 5'. Two different multicellular decks (E-glass fiber with polyester and vinyl ester resins) is designed and tested. Testing has been performed to determine both elastic and failure response at the component level and elastic response at the system level. The experimental results are compared with theoretical results obtained using a micromechanics approach. Also buckling test is carried out on 12" long FRP decks to determine the ultimate load and failure modes. From the buckling tests the author concludes that the vinyl ester specimen outperformed polyester specimens pertaining to both the ultimate load and the failure values. Bending tests have been performed on polyester and vinyl ester specimens of width 24 " and clear span of 120 " loaded with a patch loads of 10 "x 20 " and 15 "x 24 " at the center. Linear behavior until failure is 
reported and punching shear failure is observed for the 10 "x 20 " patch load and failure due to web flange separation is observed for the 15 "x 24 " patch load.

Punyamurthula (2004) has conducted experimental tests on 4"-deep FRP bridge decks made of E-glass fiber and vinyl ester resin with a fiber volume fraction of $50 \%$. The decks are evaluated for structural performance to determine their adequacy under AASHTO's HS25 loading. Failure strength and stiffness of the deck are determined experimentally and the experimental results are compared with theoretical results obtained using CLPT. The author concludes that the FRP bridge decks could resist AASHTO's HS25 type of loading with a stringer spacing of 48 ".

The work described in this chapter gives a brief overview of the kind of research work that has been carried our on FRP bridge decks. It is evident from the published work that the suitability of Prodeck 8 for bridge deck application has been evaluated experimentally. Structural analysis of the Prodeck 8 has not yet been performed using a finite-element model. The present study aims to fill this need for a numerical modeling and analysis of the Prodeck8. 


\section{CHAPTER 3}

\section{DESCRIPTION OF PRODECK 8}

The composite bridge deck being analyzed is named Prodeck 8 and is made of Eglass/Polyester. Figure 3.1 shows the cross section of the deck used for experimental tests. Figure 3.2 shows the cross section of the deck used for the finite-element model in present research. As shown in Fig. 3.1 the deck is 8 " in height and 24" in width. The thickness of top and bottom flange is 0.5 ", while that of the diagonal stiffener and the two webs are $0.25 "$ and $0.35 "$ respectively. While the top and bottom flange are made of 50

layers of $0^{0}$ fibers, $\pm 45^{\circ}$ fibers, continuous strand mat (CSM) and 56-Yield Rovings (3 per inch), the web and stiffener have 36 and 22 layers, respectively.

For the Prodeck 8 being analyzed the material properties obtained from the manufacturer is:

Modulus of elasticity of fiber $\left(E_{f}\right)=10.5 \times 10^{6} \mathrm{psi}$

Modulus of elasticity of matrix $\left(E_{m}\right)=4.9 \times 10^{5} \mathrm{psi}$

Shear modulus of fiber $\left(G_{f}\right)=4.18 \times 10^{6} \mathrm{psi}$

Shear modulus of matrix $\left(G_{m}\right)=2.37 \times 10^{5} \mathrm{psi}$ 


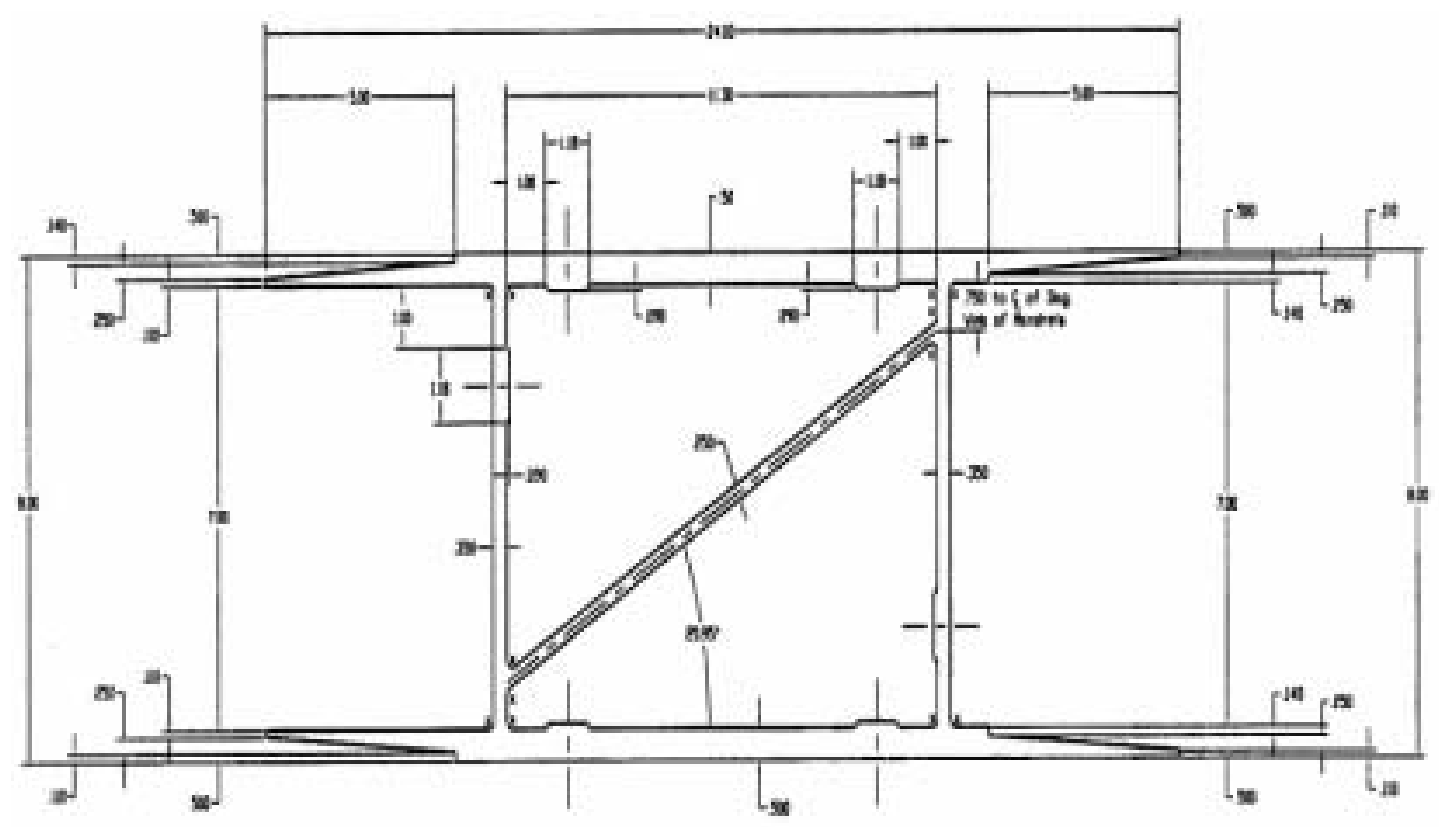

Fig. 3.1 Cross-Section of Prodeck 8 [Howard, (2002)]

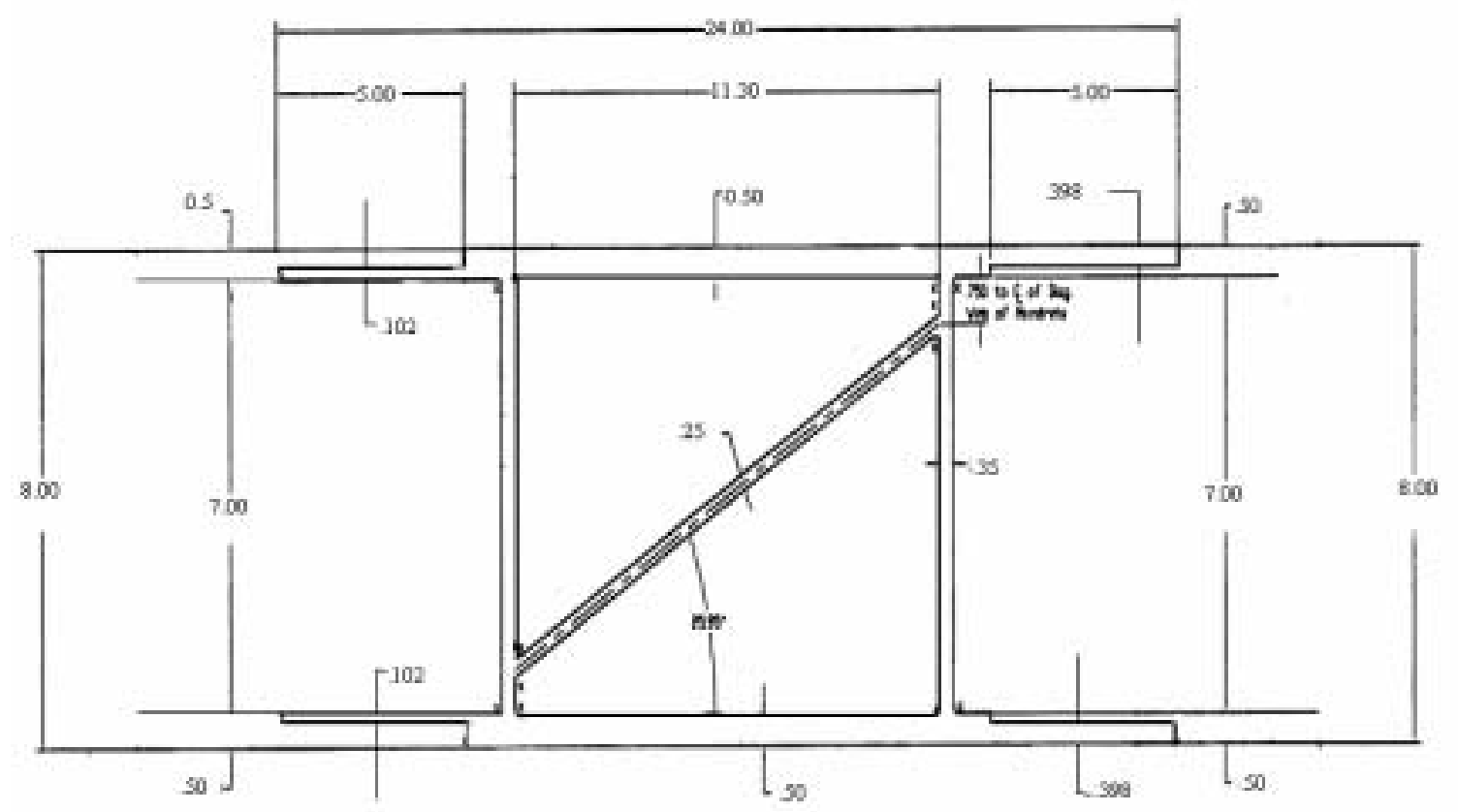

Fig. 3.2 Cross-Section of Prodeck 8 used for the present analysis 


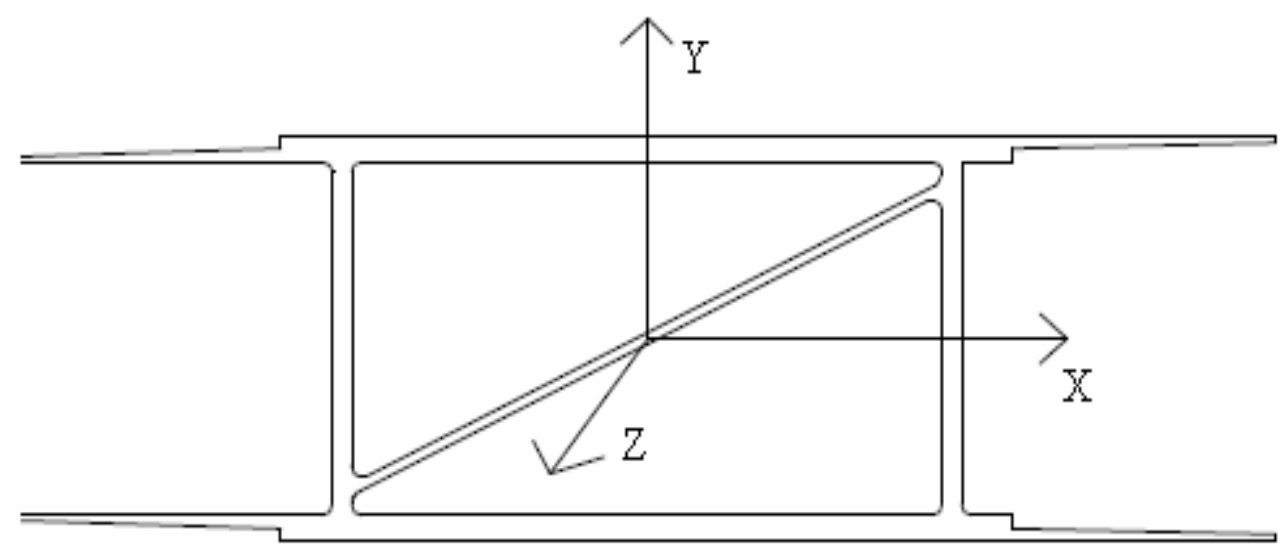

Fig. 3.3 Global coordinate system for the Prodeck 8

Figure 3.3 shows the global coordinate system for the Prodeck 8 . The traffic direction is along the $X$-axis in the global coordinate system. The $0^{0}$ fibers run along the $X$-axis in the material coordinate system, i.e. is perpendicular to the traffic direction. The fiber architecture for the Prodeck 8 is shown in Fig. 3.4. 


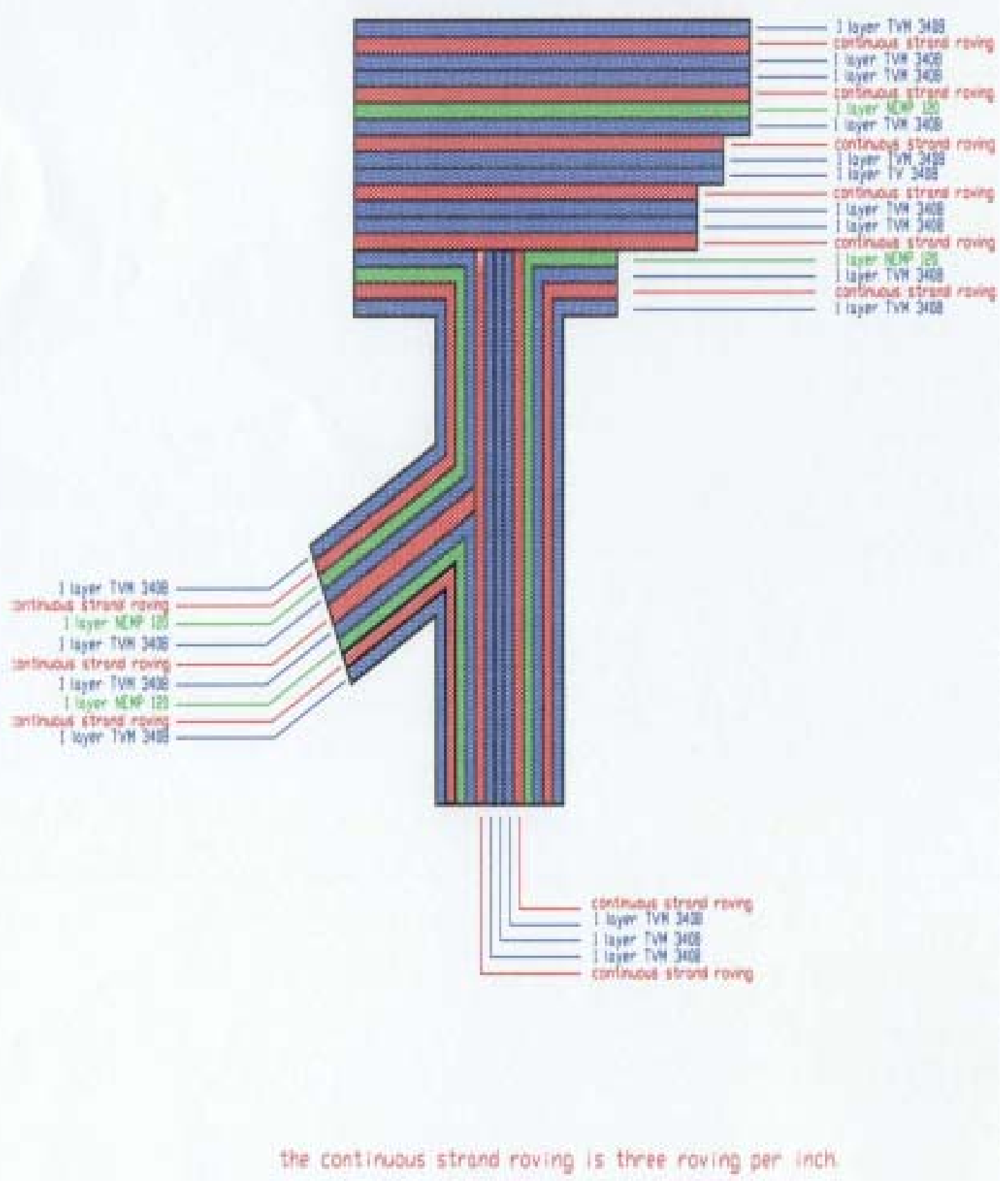

Fig. 3.4 Fiber architecture of polyester component [Howard, (2002)] 
The detailed product specifications for the $0^{0}$ fibers and $\pm 45^{\circ}$ fibers and the mat (CSM) are summarized in Tables 3.1 and 3.2.

Table 3.1 TVM-3408/Version 1001 product Specifications

\begin{tabular}{|c|c|c|c|c|}
\hline Fiber Type & $\begin{array}{c}\text { Nominal Wt. } \\
\left(\mathbf{o z}^{\prime} \mathrm{yd}^{2}\right)\end{array}$ & $\begin{array}{c}\text { Thickness } \\
\text { (in) }\end{array}$ & $\begin{array}{c}\boldsymbol{W}_{\boldsymbol{f}} \\
\mathbf{( l b )}\end{array}$ & $\begin{array}{c}\boldsymbol{L v} \\
\left.\mathbf{( i n}^{\mathbf{3}}\right)\end{array}$ \\
\hline $0^{0}$ Fabrics & 16.90 & 0.0135 & 0.1174 & 1.94 \\
\hline$+45^{0}$ Fabrics & 9.05 & 0.0073 & 0.0629 & 1.05 \\
\hline$-45^{0}$ Fabrics & 9.19 & 0.0074 & 0.0638 & 1.06 \\
\hline Mat (CSM) & 6.75 & 0.0054 & 0.0469 & 0.778 \\
\hline Totals & $\mathbf{4 1 . 8 9}$ & $\mathbf{0 . 0 3 3 6}$ & $\mathbf{0 . 2 9 1 0}$ & $\mathbf{4 . 8 3}$ \\
\hline
\end{tabular}

Table 3.2 NEMP-120/2001 product Specifications

\begin{tabular}{|c|c|c|c|c|}
\hline Fiber Type & $\begin{array}{c}\text { Nominal Wt. } \\
\left(\mathbf{o z} / \mathrm{yd}^{2}\right)\end{array}$ & $\begin{array}{c}\text { Thickness } \\
\text { (in) }\end{array}$ & $\begin{array}{c}\boldsymbol{W}_{f} \\
(\mathbf{l b})\end{array}$ & $\begin{array}{c}\boldsymbol{L} \boldsymbol{v} \\
\left.\mathbf{( i n}^{\mathbf{3}}\right)\end{array}$ \\
\hline$+45^{0}$ Fabrics & 6.11 & 0.005 & 0.0423 & 0.72 \\
\hline$-45^{0}$ Fabrics & 6.11 & 0.005 & 0.0423 & 0.72 \\
\hline Totals & $\mathbf{1 2 . 2 2}$ & $\mathbf{0 . 0 1}$ & $\mathbf{0 . 0 8 4 6}$ & $\mathbf{1 . 4 4}$ \\
\hline
\end{tabular}

Where,

$W_{f}=$ Weight of CSM/fabric per square foot $(\mathrm{lb}) / \mathrm{ft}^{2}$

$L_{v}=$ Volume of 1' x 1' composite laminate $\left(\mathrm{in}^{3}\right)$ 


\section{CHAPTER 4}

\section{FINITE ELEMENT ANALYSIS}

\subsection{INTRODUCTION}

This chapter contains the finite-element model generation of the Prodeck 8 in the general-purpose finite element software $A N S Y S$. In the following sections a detailed description of the element type, computation of the lamina properties, solid modeling, meshing, boundary conditions and failure criteria is presented.

\subsection{ELEMENT TYPE}

The SOLID46 element from ANSYS 7.1 is used for the finite-element analysis of the deck. To begin with, both solid elements (SOLID46) and shell elements (SHELL99) have been considered for the layered composite bridge deck. The SHELL99 is an 8-node, 3-D shell element with six degrees of freedom at each node. It is designed to model thin to moderately thick plates (ANSYS Ref. Manual v7.1) and simple shell structures. While the SHELL99 is good for simple shell structures, solid elements are preferred for structures with complex shapes. The Prodeck 8 has a complex shape and SHELL99 does not very well simulate the web-flange connectivity. As a result SOLID46 is chosen over SHELL99 and this solid element is explained in detail in this section. 


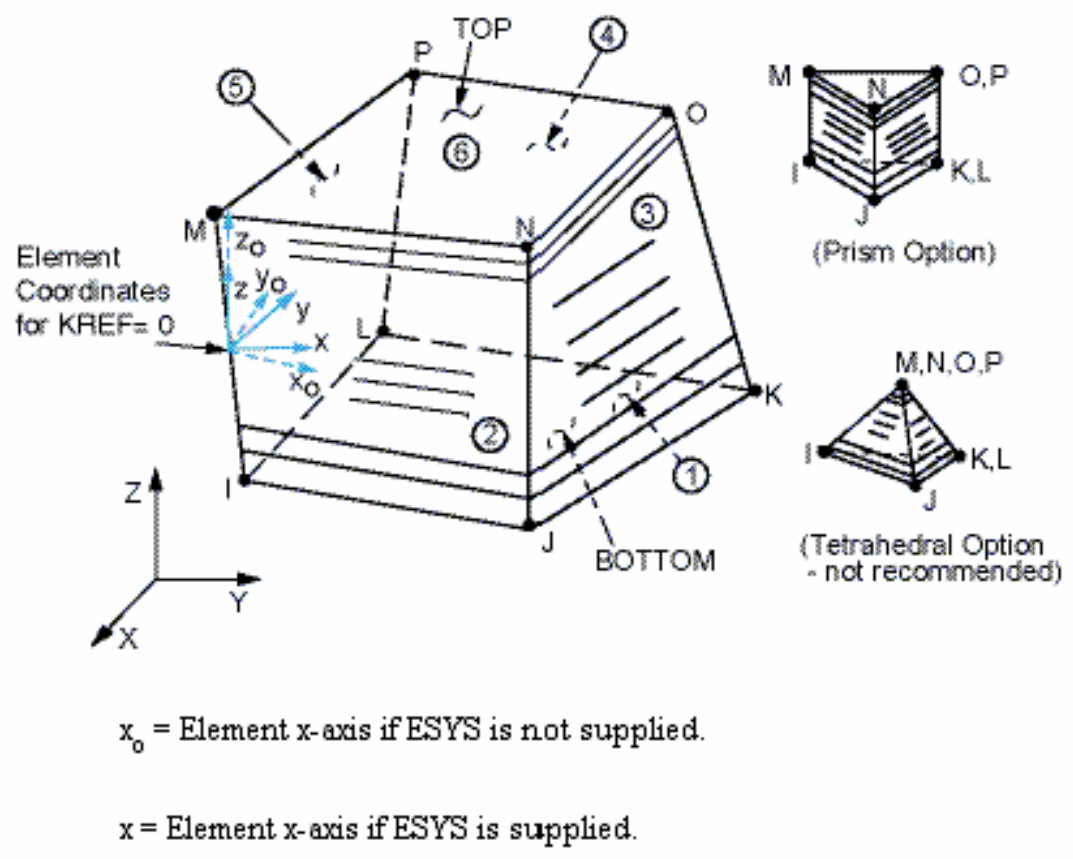

Fig. 4.1 Element type SOLID46 (ANSYS Ref. Manual v7.1)

The element type SOLID46 has 8 nodes, one at each corner, and three degrees of freedom at each node: translations in the global $X, Y$, and $Z$ directions $\left(U_{X}, U_{Y}\right.$ and $\left.U_{Z}\right)$. The geometry, node locations, and the coordinate system for this element are shown in Fig. 4.1. Eight nodes, layer thickness, layer material axis orientation, and orthotropic material properties define the element. Every element type has a default element coordinate system. The default element $x$-axis for SOLID46 is the projection of side I-J and side M-N. The material $x$ direction corresponds to the local layer $x$ direction. The default element coordinate system can be changed for area and volume elements by previously defined local coordinate systems before and/or after meshing.

The material properties may be input either in matrix form or layer form; since failure criteria are not available with matrix input, the layer input option is chosen. The 
material properties of each layer may be orthotropic or isotropic or anisotropic in the plane of the element. For isotropic materials only Young's Modulus $(E)$ and Poisson's ratio $(v)$ need to be defined. The layer configuration is defined layer-by-layer from bottom to top. The bottom layer is designated as layer 1, and additional layers are stacked from bottom to top in the positive $z$ (normal) direction of the element coordinate system.

For each orthotropic layer, the following properties are specified

- Material properties $\left(E_{1}, E_{2}, E_{3}, v_{12}, v_{23}, v_{13}, G_{12}, G_{23}, G_{13}\right)$

where

$E_{1}, E_{2}$ and $E_{3}$ represent the Modulus of elasticity in the $x, y$, and $z$ directions of the element co-ordinate system.

$v_{12}, v_{23}$ and $v_{13}$ represent the Poisson's ratio in the $x y, y z$ and $x z$ directions, respectively.

$G_{12}, G_{23}$ and $G_{13}$ represent the Shear modulus in the $x y, y z$ and $x z$ directions, respectively.

- Layer orientation angle (THETA): this defines the fiber orientation of the layer, in degrees with respect to the element coordinate system

- Layer thickness (THK) in the positive $z$ direction.

\subsection{COMPUTATION OF LAMINA PROPERTIES}

Micro-mechanics is used to calculate the lamina properties. These properties are calculated taking into account the interaction of the constituent materials in detail. The equations that are used for the computation of the lamina properties are presented in the following sections. The component cross-section details and fiber architecture have been presented in Chapter 3. 


\subsubsection{Material Properties}

The basic fiber (E-glass) and matrix (polyester) properties, i.e., Modulus of elasticity $(E)$, Shear Modulus $(G)$ and Poisson's ratio $(v)$ that are needed in order to compute the lamina properties are obtained from the manufacturer. For the Prodeck 8 being analyzed the properties obtained from the manufacturer is:

$$
\begin{aligned}
& \text { Modulus of elasticity of fiber }\left(E_{f}\right)={ }_{10.5} \times 10^{6} \mathrm{psi} \\
& \text { Modulus of elasticity of matrix }\left(E_{m}\right)=4.9 \times 10^{5} \mathrm{psi} \\
& \text { Shear modulus of fiber }\left(G_{f}\right)=4.18 \times 10^{6} \mathrm{psi} \\
& \text { Shear modulus of matrix }\left(G_{m}\right)=2.37 \times 10^{5} \mathrm{psi}
\end{aligned}
$$

From the above properties, Poisson's ratio for both the fibers and matrix can be obtained as

$$
\begin{array}{lc}
\text { Poisson's ratio of fiber: } & v_{f}=\frac{E_{f}}{2 G_{f}}-1 \\
\text { Poisson' s ratio of matrix : } & v_{\mathrm{m}}=\frac{E_{m}}{2 G_{m}}-1
\end{array}
$$

These equations result in $v_{f}=0.22$ and $v_{m}=0.38$.

\section{Fiber Volume Fraction}

The fiber volume fraction $\left(V_{f}\right)$ is defined as the ratio of volume of fiber to the total volume of the layer. The Prodeck 8 has rovings, mat and fabrics. A roving is a collection of parallel continuous strands; a strand is an untwisted bundle of continuous fibers used as a unit [Barbero, (1998)]. A mat is formed by randomly oriented chopped filaments (chopped strand mat), short fibers, or swirled filaments (continuous strand mat, CSM) loosely held together with a very small amount of adhesive [Barbero, (1998)]. 
Depending on whether the fiber reinforcement is in the form of rovings, mats or fabrics, the fiber volume fraction is calculated as follows:

\section{$\underline{\text { For Rovings }}$}

$$
V_{f}=\frac{n \pi D^{2}}{4 b t}
$$

where,

$n=$ Number of bundles

$b=$ Width of lamina (in)

$t=$ Thickness of composite layer (in)

$D=$ Diameter of fiber $=\sqrt{\frac{1}{\rho_{f} Y 9 \pi}}$

$\rho_{f}=$ Density of fiber.

$Y=$ yield (a number in yards which weighs $1 \mathrm{lb}$ )

The values for $n, \rho_{\mathrm{f}}$, and $\mathrm{Y}$ are typically obtained from the manufacturer.

\section{For CSM (Continuous Strand Mat) and Fabric}

$$
V_{f}=\frac{W_{f}}{\rho_{f} L_{v}}
$$

where,

$W_{f}=$ Weight of CSM/fabric per square foot (lb)

$L_{v}=$ Volume of 1' x 1' composite laminate $\left(\mathrm{in}^{3}\right)$

$\rho_{f}=$ Density of CSM or fabric.

Once the fiber volume fractions for the fiber, rovings and mat have been calculated, the Lamina properties can be calculated as shown in the next section. 


\subsubsection{Lamina Properties}

\section{Properties for Fabric and Rovings}

\section{Longitudinal Modulus:}

The Longitudinal modulus $\left(E_{1}\right)$ can be calculated using the rule of mixtures (ROM) formula. The ROM formula assumes that the strains in the direction of fibers are the same in the matrix and fiber, implying that fiber-matrix bond is perfect [Barbero, (1998)].

$E_{1}=E_{f} V_{f}+E_{m}\left(1-V_{f}\right)$

\section{Transverse Modulus}

The transverse modulus $\left(E_{2}\right)$ that is the modulus in the direction transverse to the fibers can be calculated using inverse ROM formula. The inverse ROM assumes that the transverse stress is same in the fiber and matrix implying that the fiber-matrix bond is perfect [Barbero, (1998)].

$$
E_{2}=\frac{E_{f} E_{m}}{E_{f}\left(1-V_{f}\right)+E_{m} V_{f}}
$$

The inverse ROM does not accurately predict the transverse modulus in general and may not be used for design calculations. An accurate prediction would be the Periodic Microstructure Model (PMM) [Barbero, (1998)]. Since the PMM formula is relatively complex, it is not represented here. 


\section{Inplane Shear Modulus}

The inplane shear modulus $\left(G_{12}\right)$ can be calculated using the inverse ROM formula.

$$
G_{12}=\frac{G_{f} G_{m}}{G_{f}\left(1-V_{f}\right)+G_{m} V_{f}}
$$

Once again the inverse ROM does not accurately predict the transverse modulus in general and may not be used for design calculations. An accurate prediction would be the Periodic Microstructure Model (PMM)

\section{Interlaminar Shear Modulus}

The interlaminar shear modulus $\left(G_{23}\right)$ is also calculated by PMM.

\section{In-plane Poisson's Ratio}

The Inplane major Poisson's ratio $\left(v_{12}\right)$ is calculated using the ROM formula, which is an accurate prediction and is sufficient for design calculations.

$$
v_{12}=v_{f} V_{f}+v_{m}\left(1-V_{f}\right)
$$

Then the minor Poisson's ratio $\left(v_{21}\right)$ can be calculated as

$$
v_{21}=\frac{v_{12} E_{2}}{E_{1}}
$$

\section{For Continuous Strand Mat}

Continuous Strand Mat (CSM) consists of randomly placed continuous rovings held together by a binder. The CSM is used to obtain bi-directional properties. The material properties of CSM are determined assuming them as random composites. A layer of composite with randomly oriented fibers can be idealized as a laminate with a

large number of thin unidirectional layers, each with a different orientation from $0^{0}$ to $180^{0}$ [Barbero, (1998)]. 
Elastic Modulus

Shear Modulus

$$
E_{c s m}=\frac{3}{8} E_{1}+\frac{5}{8} E_{2}
$$

$$
G_{c s m}=\frac{1}{8} E_{1}+\frac{1}{4} E_{2}
$$

Where $E_{1}$ and $E_{2}$ are the longitudinal and transverse moduli of a fictitious unidirectional layer having the same volute fraction as the CSM layer [Barbero, (1998)].

Poisson's Ratio

$$
v_{r a n}=\left(\frac{E_{c s m}}{2 G_{c s m}}\right)-1
$$

Note: Continuous Strand Mats are assumed to behave in an isotropic manner; so only one modulus value is needed.

\subsubsection{Lamina Material Specifications}

The Prodeck 8 being analyzed contains three different types of lamina:

56-Yield Rovings (3 per inch)

TVM-3408/Version 1001

NEMP 120/2001

Both the TVM-3408/Version 1001 and NEMP 120/2001 contains different types of fiber configurations. For example, TVM-3408/Version 1001 contains both fabrics and a mat. Using the micro-mechanics approach, the material properties for each layer are calculated separately using the equations that have been describe above. The material properties so calculated are input for each kind of fiber. The following tables summarize the lamina properties for the Prodeck 8. 
Table 4.1 Lamina properties with fiber volume fraction of 0.64

\begin{tabular}{|c|c|c|c|c|c|c|c|}
\hline Fiber type & $V_{f}$ & $\begin{array}{c}E_{1} \times 10^{6} \\
(\mathbf{p s i})\end{array}$ & $\begin{array}{c}\boldsymbol{E}_{\mathbf{2}} \mathbf{x 1 0} \\
(\mathbf{p s i})\end{array}$ & $V_{\mathbf{1 2}}$ & $V_{\mathbf{2 3}}$ & $\begin{array}{c}\boldsymbol{G}_{12} \times \mathbf{x 1 0}^{\mathbf{6}} \\
(\mathbf{p s i})\end{array}$ & $\begin{array}{c}\boldsymbol{G}_{\mathbf{2 3}} \times \mathbf{x 1 0}^{\mathbf{6}} \\
(\mathbf{p s i})\end{array}$ \\
\hline Fibers/rovings & 0.64 & 6.936 & 2.373 & 0.343 & 0.549 & 0.703 & 0.704 \\
\hline Mat (CSM) & 0.64 & 4.05 & & 0.399 & & 1.449 & \\
\hline
\end{tabular}

It should be noted that the fiber volume fraction $\left(V_{f}\right)$ obtained using the formulas previously described yields a value of 0.64 as shown in Table 4.1, which is high compared to the fiber volume fraction of 0.54 [Howard, (2002)] obtained from the burnout test conducted on an element of the Prodeck 8. As a result the analysis is also run using fiber volume fraction of 0.54 and the corresponding results have been presented in chapter 5. For the fiber volume fraction of 0.54 the material properties calculated separately using micro-mechanics approach is summarized in Table 4.2.

Table 4.2 Lamina Properties with fiber volume fraction of 0.54

\begin{tabular}{|c|c|c|c|c|c|c|c|}
\hline Fiber type & $\boldsymbol{V}_{\boldsymbol{f}}$ & $\begin{array}{c}\boldsymbol{E}_{\mathbf{1}} \times \mathbf{x 1 0}^{\mathbf{6}} \\
(\mathbf{p s i})\end{array}$ & $\begin{array}{c}\boldsymbol{E}_{\mathbf{2}} \mathbf{\times 1 0} \\
(\mathbf{p s i})\end{array}$ & $v_{\mathbf{1 2}}$ & $V_{\mathbf{2 3}}$ & $\begin{array}{c}\boldsymbol{G}_{\mathbf{1 2}} \times \mathbf{x 1 0}^{\mathbf{6}} \\
(\mathbf{p s i})\end{array}$ & $\begin{array}{c}\boldsymbol{G}_{\mathbf{2 3}} \times \mathbf{x 1 0}^{\mathbf{6}} \\
(\mathbf{p s i})\end{array}$ \\
\hline Fibers/rovings & 0.54 & 5.795 & 1.642 & 0.36 & 0.58 & 0.525 & 0.531 \\
\hline Mat (CSM) & 0.54 & 3.37 & & 0.404 & & 0.12 & \\
\hline
\end{tabular}

\subsection{MODELING AND MESHING}

After defining the material properties, a finite element model for the Prodeck 8 is generated. The finite element model is generated as a solid model, i.e., the model is 
generated using volumes and then map-meshed. The volumes are created using key points, which are defined in the global co-ordinate system. After meshing the volumes, the orientation of the layers are checked manually and reoriented if needed as desired.

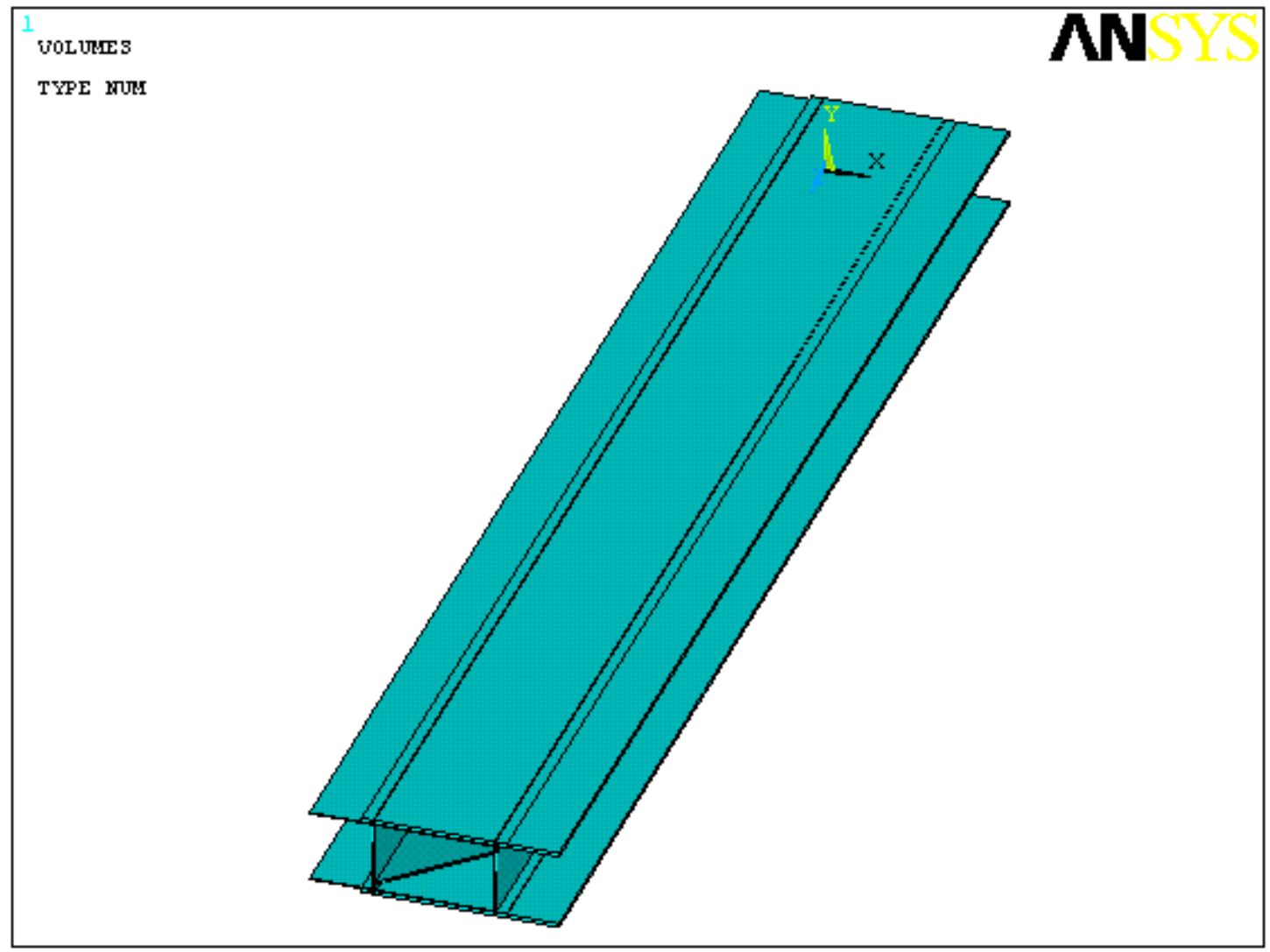

Fig. 4.2 Solid model of the Prodeck 8

The solid model of the Prodeck 8 (Fig. 4.2) consists of 34 volumes, which are glued together. The gluing operation redefines the volume so that the volumes share areas resulting in the merging of key-points, nodes, elements and areas along their common boundaries. Also it enables the transfer of load to all the volumes. Local co-ordinates are defined for all the volumes to enable the proper orientation of the elements after meshing.

After the solid modeling, the Prodeck 8 is map-meshed resulting in a total of 8008 elements with 12560 nodes. Figure 4.3 shows the mesh for the Prodeck 8. The elements generated have their own co-ordinate systems and proper care should be taken to make 
sure that the resulting orientation is as desired in order to align fiber directions. Those elements, which are not oriented as desired, are manually reoriented. The process for checking and reorienting the co-ordinate system is explained next.

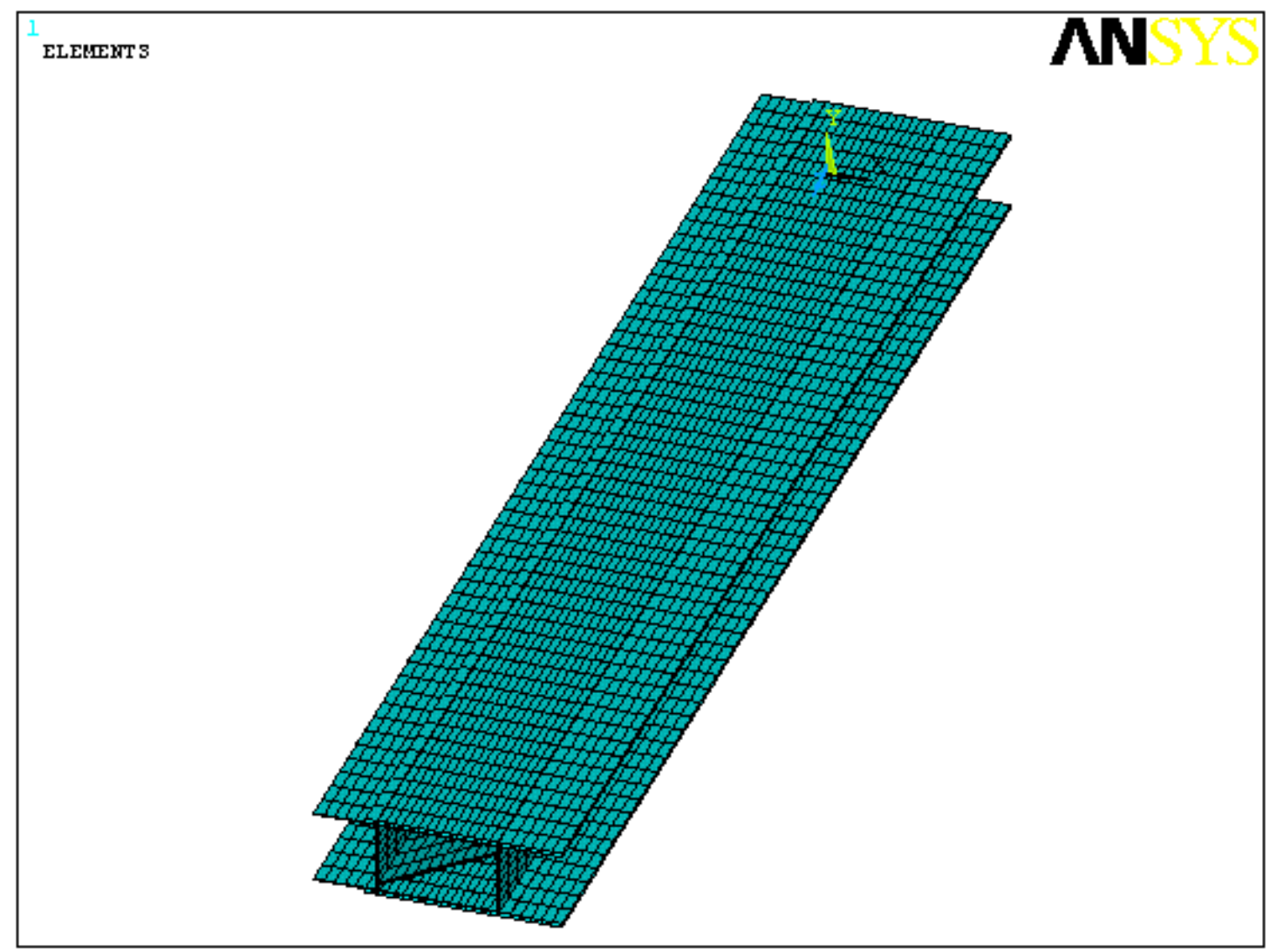

Fig. 4.3 Meshed Prodeck 8

Figure 4.4 depicts the orientation of each layer for a randomly selected element and the material number assigned to it. The element orientations are with respect to the locally defined co-ordinate systems for all the elements.

Finally for each volume the element co-ordinate systems are graphically checked and reoriented if needed in the desired direction. Figure 4.5 shows the graphical representation of the element co-ordinate system for the Prodeck 8. 


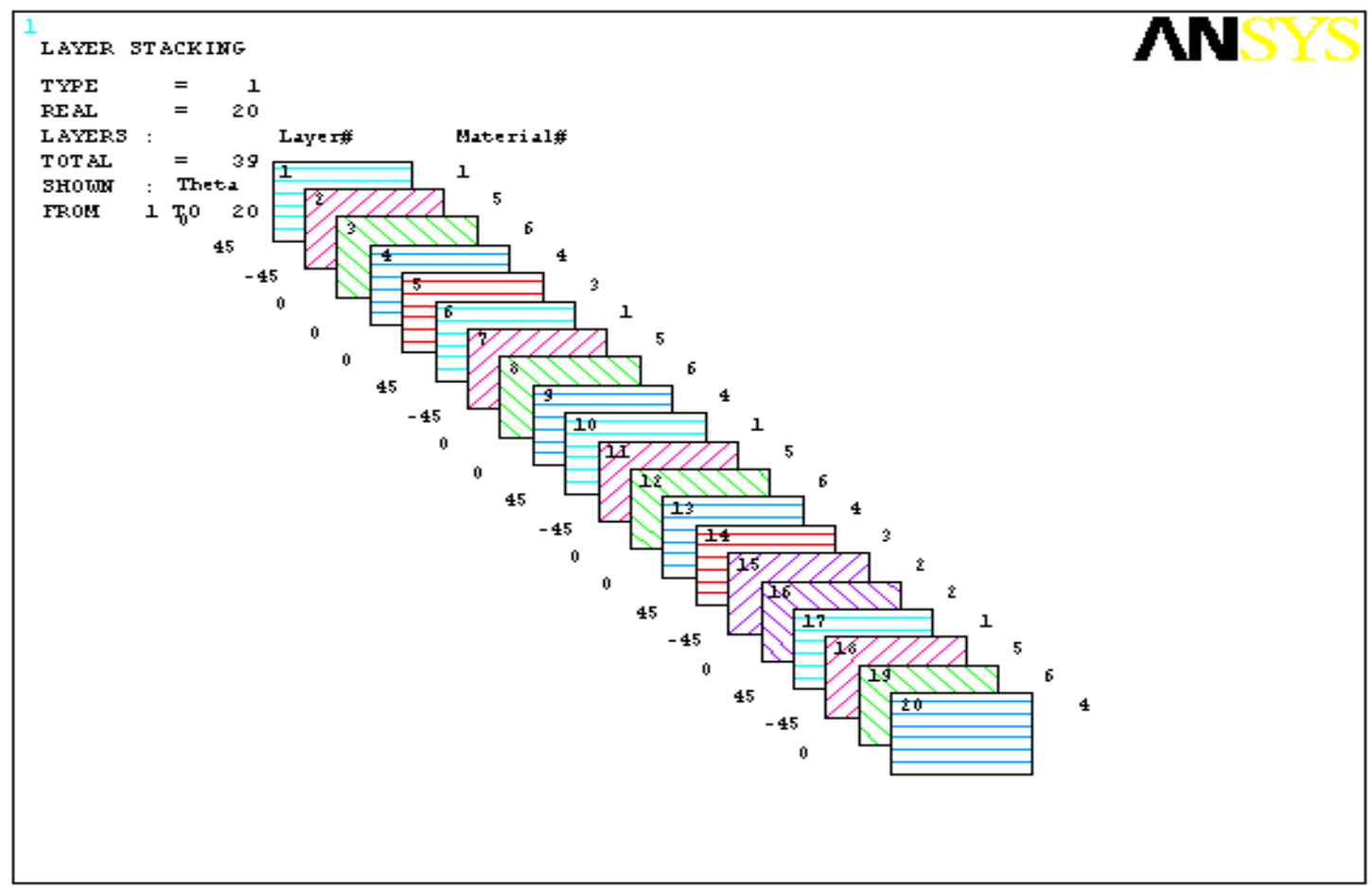

Fig. 4.4 Element orientations of individual layers

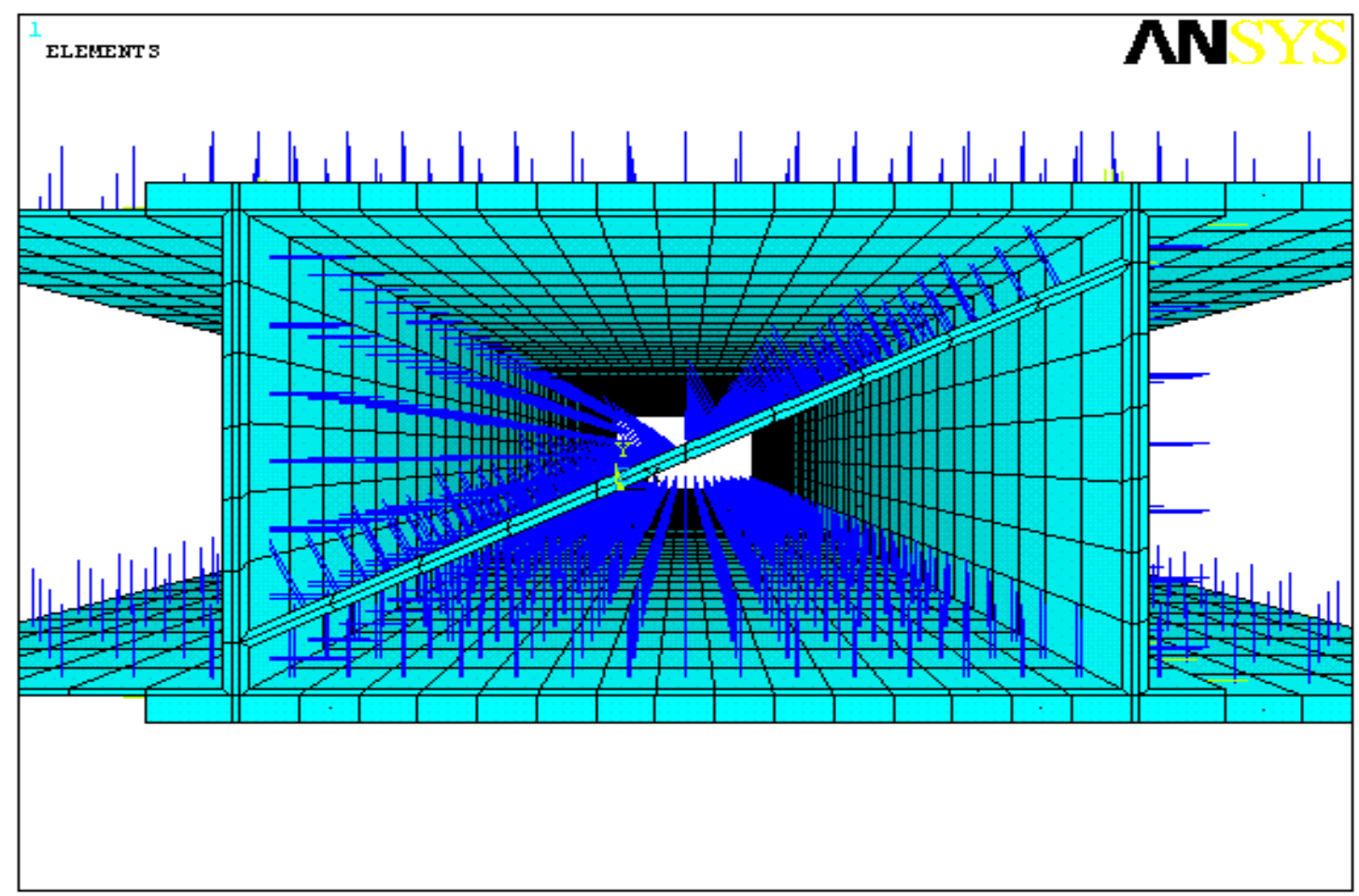

Fig. 4.5 Graphical representation of the element co-ordinate system 


\subsection{BOUNDARY CONDITIONS}

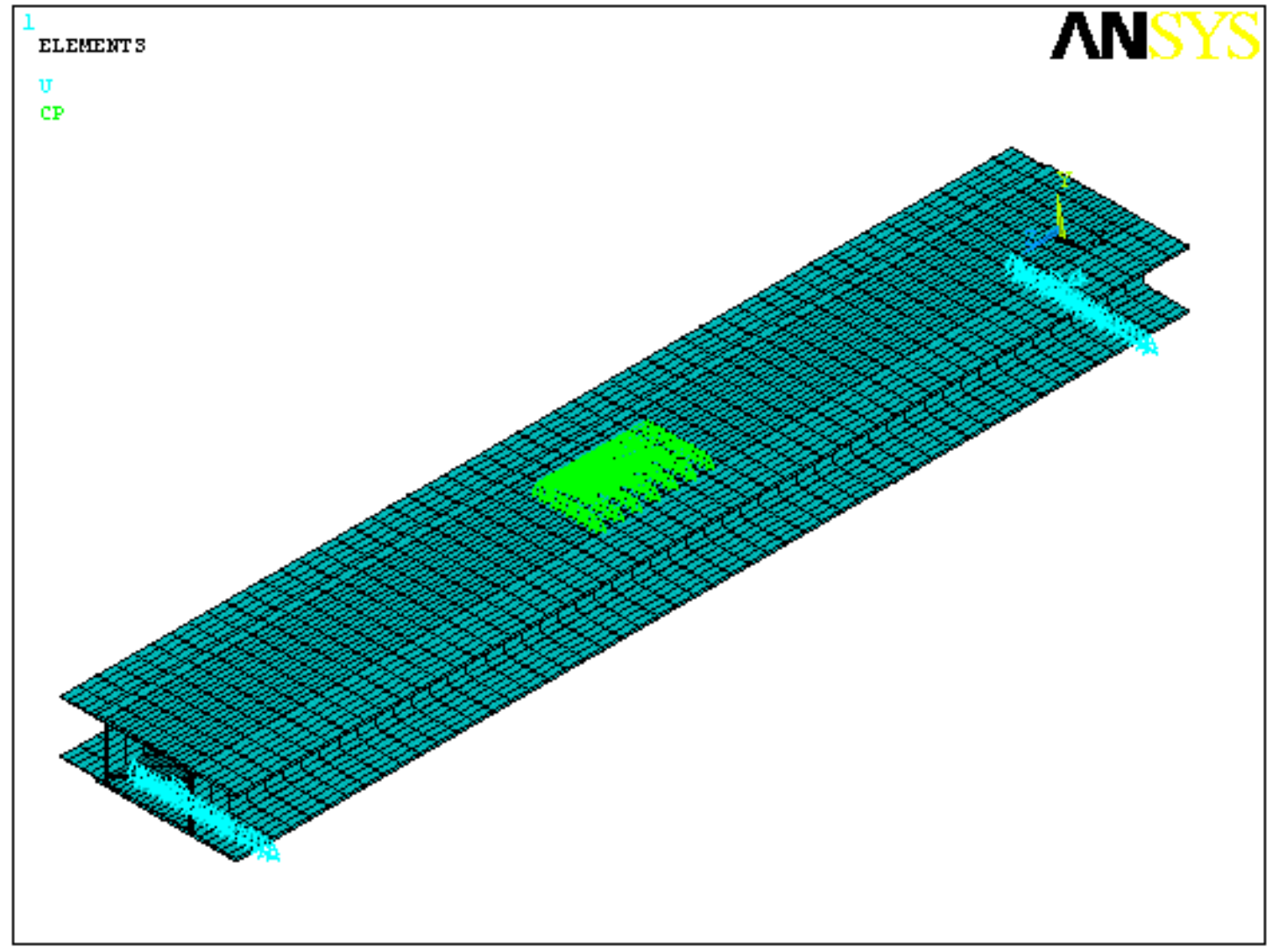

Fig. 4.6 Schematic representation of the applied boundary conditions on the Prodeck 8

The Prodeck 8 is simply supported as shown with a clear span of 120”. Coupling restraints are applied at the center of the top flange with a cross-section of 10 " $\mathrm{x} 20$ " to get equal displacement in the $Y$ direction, $Y$ being the loading direction. This is done with the assumption that the steel plate, which is used for patch loading, is considered to be rigid and doesn't deform on being loaded. Figure 4.6 shows the boundary conditions applied on the Prodeck 8 . 


\subsection{LOADS}

A surface load is applied across a cross-section of 10 " x 20 " at the center of the Prodeck 8. For Experimental testing, a steel plate of 10 " x 20 " size is used to simulate the tire. For the finite-element model using ANSYS this is achieved by restricting those elements in contact with the steel plate to have the same deflection in the loading direction. This is based on the assumption that the steel plate acts as a rigid body and is always in contact with the deck. Figure 4.7 shows the applied load at the center of the Prodeck 8.



Fig. 4.7 Schematic representation of the 10 " x 20 " patch load applied on the Prodeck 8 


\subsection{DESIGN FOR FAILURE}

A Structural element can be considered as failed, when it no longer performs the intended function, even though the structure might not have collapsed, partially damaged structures can still be considered as failed. Several failure theories exist for predicting the failure of composite materials, but none can be considered to predict the failure accurately at all times particularly at the component level. Therefore great care must be taken for failure design of composite structures and if possible the results should be experimentally verified. There are many contributing factors for the lack of a good failure theory because the internal constitutions of composites are complex, endowed with micron-scale entities materially and geometrically [Wang, (2004)].

\subsubsection{Strength Ratio $(R)$}

The failure criteria can be expressed in terms of strength ratio defined as the ratio of ultimate stress to applied stress. Also in terms of strain it can be defined as the ratio of ultimate strain to applied strain.

$$
R=\frac{\sigma_{\text {ultimate }}}{\sigma_{\text {applied }}} \quad \text { Or } \quad R=\frac{\varepsilon_{\text {ultimate }}}{\varepsilon_{\text {applied }}}
$$

\subsubsection{Failure Criteria}

Failure criteria are used to assess the possibility of failure of a material. Determining the mode of failure or failure strength for composite materials is very different from that of isotropic materials. For isotropic materials two constants are 
sufficient to determine the failure strength, because they do not have any preferential orientation, implying they have the same properties in all the directions. For composite materials, however, the stresses in all the directions must be examined before arriving at any conclusion on the possible causes of failure. This allows the consideration of orthotropic materials, which might be much weaker in one direction than another. The determination of strength using failure criteria is based on the assumption that the material is homogeneous and its strength can be experimentally measured with simple tests [Tsai and Hahn, (1980)].

\subsubsection{Maximum Stress Criterion}

According to this criterion, Failure occurs when one of the following equalities is met [Barbero, (1998)].

$$
\begin{array}{ll}
\sigma_{1}>F_{1 t} & \text { if } \sigma_{1}>0 \\
\operatorname{abs}\left(\sigma_{1}\right)>F_{1 c} & \text { if } \sigma_{1}<0 \\
\sigma_{2}>F_{2 t} & \text { if } \sigma_{2}>0 \\
\operatorname{abs}\left(\sigma_{2}\right)>F_{2 c} & \text { if } \sigma_{2}<0 \\
\operatorname{abs}\left(\sigma_{4}\right)>F_{4} & \\
\operatorname{abs}\left(\sigma_{5}\right)>F_{5} & \\
\operatorname{abs}\left(\sigma_{6}\right)>F_{6} &
\end{array}
$$

where,

$\sigma_{1}, \sigma_{2}, \sigma_{3}, \sigma_{4}, \sigma_{5}, \sigma_{6}$ are the stresses in the material coordinates.

$F_{1 t}, F_{1 c}, F_{2 t}, F_{2 c}, F_{4}, F_{5}, F_{6}$ are the failure stress values. 
In terms of strength ratio the maximum stress criterion can be defined as follows [Barbero, (1998)].

$$
\begin{array}{ll}
R_{1}=F_{1 t} / \sigma_{1} & \text { if } \sigma_{1}>0 \\
R_{1}=-F_{1 d} / \sigma_{1} & \text { if } \sigma_{1}<0 \\
R_{2}=F_{2 t} / \sigma_{2} & \text { if } \sigma_{2}>0 \\
\mathrm{R}_{2}=-\mathrm{F}_{2 c} / \sigma_{2} & \text { if } \sigma_{2}<0 \\
R_{4}=F_{4} /\left|\left(\sigma_{4}\right)\right| & \\
R_{5}=F_{5} /\left|\left(\sigma_{5}\right)\right| & \\
R_{6}=F_{6} /\left|\left(\sigma_{6}\right)\right| &
\end{array}
$$

The strength ratio for the layer is the minimum of all the $R_{i}$.

\subsubsection{Maximum strain criterion}

If the material is linear elastic up to failure, the strains to failure are directly related to the ultimate strengths as follows [Barbero, (1998)].

$$
\begin{aligned}
& \varepsilon_{1 t}=F_{1 t} / E_{1} \\
& \varepsilon_{1 c}=F_{1 c} / E_{1} \\
& \varepsilon_{2 t}=F_{2 t} / E_{2} \\
& \varepsilon_{2 c}=F_{2 c} / E_{2} \\
& \gamma_{4 u}=F_{5} / G_{13} \\
& \gamma_{6 u}=F_{4} / G_{23} \\
& \gamma_{4 u}=F_{6} / G_{12}
\end{aligned}
$$

Where $\varepsilon_{1 t}, \varepsilon_{1 c}, \varepsilon_{2 t}, \varepsilon_{2 c}, \gamma_{4 u}, \gamma_{5 u}, \gamma_{6}$ are the failure strains. 
In terms of strength ratio the maximum strain criterion can be defined as follows

$$
\begin{array}{ll}
R_{1}=\varepsilon_{1 t} / \varepsilon_{1} & \text { if } \varepsilon_{1}>0 \\
R_{1}=-\varepsilon_{1 d} / \varepsilon_{1} & \text { if } \varepsilon_{1}<0 \\
R_{2}=\varepsilon_{2 t} / \varepsilon_{2} & \text { if } \varepsilon_{2}>0 \\
R_{2}=-\varepsilon_{2 d} / \varepsilon_{2} & \text { if } \varepsilon_{2}<0 \\
R_{4}=\gamma_{4 u} /\left|\left(\varepsilon_{4}\right)\right| & \\
R_{5}=\gamma_{5 u} /\left|\left(\varepsilon_{5}\right)\right| & \\
R_{6}=\gamma_{6} /\left|\left(\varepsilon_{6}\right)\right| &
\end{array}
$$

The strength ratio for the layer is the minimum of all the $R_{\mathrm{i}}$.

\subsubsection{Tsai-Wu failure criterion}

This criterion can be represented using the following quadratic equation [Barbero, (1998)].

$$
\begin{gathered}
f_{1}{\sigma_{1}}^{f}+f_{2} \sigma_{2}{ }^{f}+f_{11}\left(\sigma_{1}^{f}\right)^{2}+f_{22}\left(\sigma_{2}^{f}\right)^{2}+2 f_{12}\left(\sigma_{1}^{f} \sigma_{2}{ }^{f}\right)+f_{22}\left(\sigma_{2}{ }^{f}\right)^{2} \\
+f_{66}\left(\sigma_{6}{ }^{f}\right)^{2}+f_{55}\left(\sigma_{5}{ }^{f}\right)^{2}+f_{44}\left(\sigma_{4}{ }^{f}\right)^{2}-1=0
\end{gathered}
$$

where,

$\sigma_{1}^{f}, \sigma_{2}^{f}, \sigma_{6}^{f}, \sigma_{4}^{f}, \sigma_{5}^{f}$ are the components of stress at any point of the failure envelope.

$$
\begin{aligned}
& f_{1}=\frac{1}{F_{1 t}}-\frac{1}{F_{1 c}} \\
& f_{2}=\frac{1}{F_{2 t}}-\frac{1}{F_{2 c}} \\
& f_{11}=\frac{1}{F_{1 t} F_{1 c}}
\end{aligned}
$$




$$
\begin{aligned}
& f_{22}=\frac{1}{F_{2 t} F_{2 c}} \\
& f_{66}=\frac{1}{\left(F_{6}\right)^{2}} \\
& f_{44}=\frac{1}{\left(F_{4}\right)^{2}} \\
& f_{55}=\frac{1}{\left(F_{5}\right)^{2}}
\end{aligned}
$$

\subsubsection{Failure Criteria using $A N S Y S$}

Using ANSYS possible failure of a material (first ply failure) can be evaluated by up to six different criteria. Three failure criteria are predefined in $A N S Y S$; they are maximum strain, maximum stress and Tsai-Wu failure criteria. Each of these failure criteria is evaluated at the top and bottom (or middle) of each layer at each of the in-plane integration points. Since the criteria are orthotropic, the failure stress or failure strain values for all directions are input, i.e. if we do not want the failure stress or strain to be checked in a particular direction, a large number in that direction is to be specified. The maximum stress, maximum strain, and Tsai-Wu failure criteria are predefined in ANSYS and the failure values are calculated in terms of $\xi$,

where

$$
\xi=1 / R
$$

The properties that are required to define the above mentioned failure criteria are explained next. 


\subsubsection{Lamina failure properties}

\section{Longitudinal Tensile Strength $\left(F_{1 t}\right)$}

The longitudinal Tensile strength is calculated using the formula

$F_{1 \mathrm{t}}=\sigma_{f a}\left[V_{f}+\frac{E_{m}}{E_{f}}\left(1-V_{f}\right)\right]$

$\sigma_{f a}$ is the fiber average strength

This equation assumes that the strain in the matrix and the fibers are the same [Barbero, (1998)].

\section{Longitudinal Compressive Strength $\left(F_{1 c}\right)$}

The longitudinal compressive strength is calculated using the formula

$$
F_{1 c}=\left(\frac{\chi}{a}+1\right)^{b} G_{12}
$$

where,

$\chi=\frac{G_{12} \Omega}{F_{6}}$, a dimensionless quantity and a and $\mathrm{b}$ are two constants chosen to fit Eq.

(4.23): $\mathrm{a}=0.21$ and $\mathrm{b}=-0.69$.

\section{Transverse Tensile Strength $(F 2 t)$}

The transverse tensile strength is a matrix dominated property and is calculated using the formula

$$
F_{2 t}=\sigma_{m u}\left[1-\sqrt{\frac{4 V_{v}}{\pi\left(1-V_{f}\right)}}\right]\left[1-V_{f}^{1 / 3}\right] \frac{E_{2}}{E_{m}}
$$

Where

$\sigma_{\mathrm{mu}}$ is the tensile strength of the bulk matrix and $V_{\nu}$ is the void volume fraction 


\section{Transverse Compressive Strength $\left(F_{2 c}\right)$}

The transverse compressive strength can be calculated using the same formula as Eq. (4.25), replacing $\sigma_{m u}$ by $\sigma_{m u c}$ where $\sigma_{m u c}$ is the compressive strength of the bulk matrix.

\section{Inplane Shear Strength $\left(F_{6}\right)$}

Inplane shear strength is calculated using the formula

$$
F_{6}=\tau_{m u} C_{v}\left[1+\left(V_{f}-\sqrt{V_{f}}\right)\left(1-\frac{G_{m}}{G_{f}}\right)\right]
$$

Where $\tau_{m u}$ is the bulk shear strength of the matrix.

The strain values are calculated using equation 2.16 and the failure strength and failure strain values for the fibers are summarized in Tables 4.3 and 4.4 .

Table 4.3 Strength values for Rovings, TVM and NEMP

\begin{tabular}{|c|c|c|c|c|c|}
\hline Fiber type & $\boldsymbol{F}_{\mathbf{1} \boldsymbol{t}}(\mathrm{ksi})$ & $\boldsymbol{F}_{\mathbf{1} \boldsymbol{c}}(\mathrm{ksi})$ & $\boldsymbol{F}_{\mathbf{2} \boldsymbol{t}} \mathbf{( k s i )}$ & $\boldsymbol{F}_{\mathbf{2} \boldsymbol{c}}(\mathbf{k s i})$ & $\boldsymbol{F}_{\mathbf{6}}(\mathrm{ksi})$ \\
\hline Fibers/rovings & 130.969 & 51.778 & 5.81 & 9.862 & 5.801 \\
\hline Mat (CSM) & 22.9 & 22.9 & 22.9 & 22.9 & 11.0 \\
\hline
\end{tabular}

Table 4.3 Ultimate strain values for Rovings, TVM and NEMP

\begin{tabular}{|c|c|c|c|c|c|}
\hline Fiber type & $\varepsilon_{1 t}$ & $\varepsilon_{1 c}$ & $\varepsilon_{2 t}$ & $\varepsilon_{2 c}$ & $\varepsilon_{6}$ \\
\hline Fibers/rovings & $2.26 \times 10^{-2}$ & $8.93 \times 10^{-3}$ & $3.53 \times 10^{-3}$ & $6.01 \times 10^{-3}$ & $1.12 \times 10^{-2}$ \\
\hline Mat (CSM) & $6.79 \times 10^{-3}$ & $6.79 \times 10^{-3}$ & $6.79 \times 10^{-3}$ & $6.79 \times 10^{-3}$ & $9.17 \times 10^{-3}$ \\
\hline
\end{tabular}




\section{CHAPTER 5}

\section{RESULTS AND DISCUSSIONS}

\subsection{INTRODUCTION}

The results obtained from the finite element model of the Prodeck 8 are presented in this chapter. The first set of results corresponds to a static analysis performed on the Prodeck 8 under a patch load; two different fiber volume fractions are considered. The values of maximum deflection and strains at selected locations and directions are obtained and compared with earlier experimental results. The load versus maximum deflection and load versus strain plots and contour plots of stress and strain are provided. Also, tables and plots showing a comparison between the finite element and experimental results are presented.

The results of a failure analysis, using maximum stress criterion, maximum strain criterion and Tsai-Wu criterion of the Prodeck 8 are presented. A description of the buckling analysis performed on the Prodeck 8 and an isolated web section of the deck is provided. 


\subsection{DEFLECTION ANALYSIS}

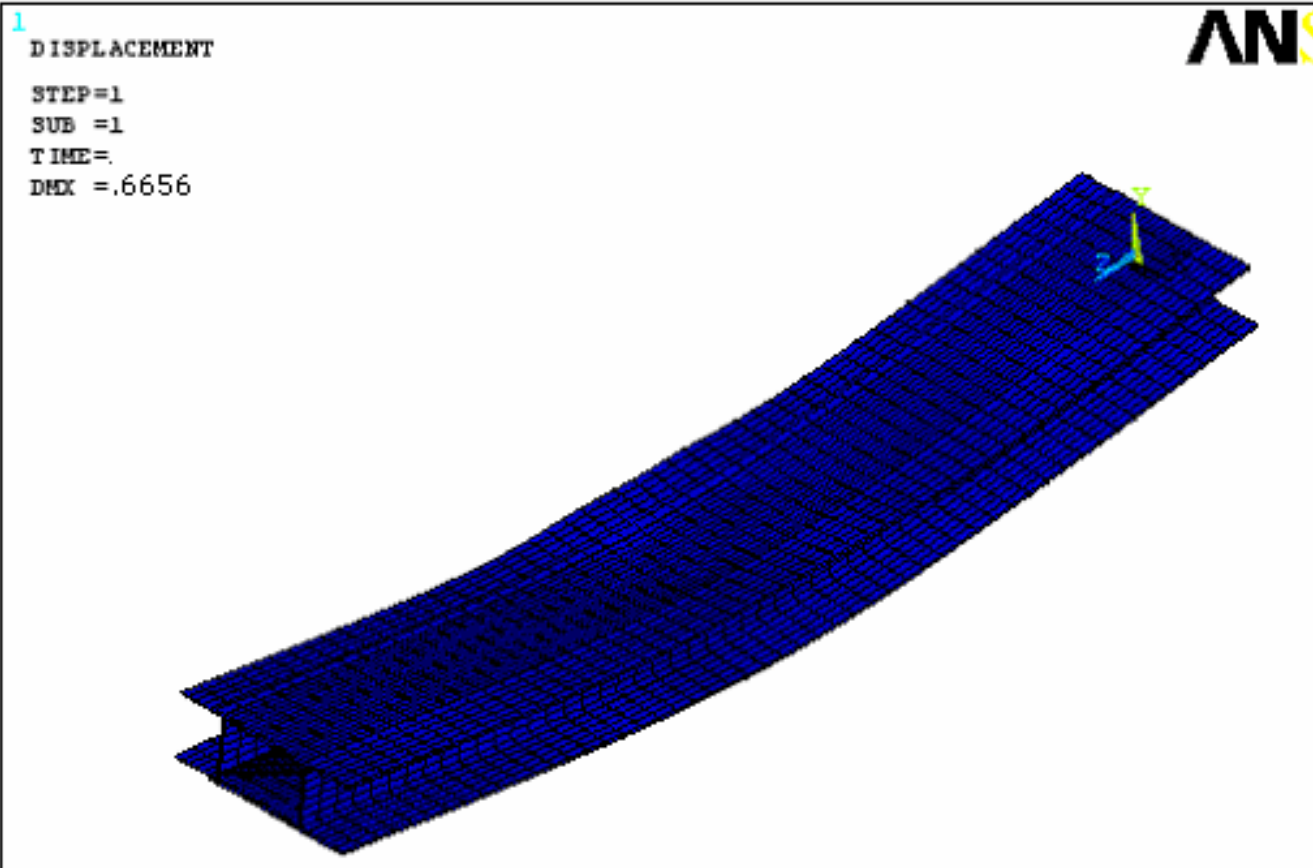

Fig. 5.1 Deformed shape of the Prodeck 8 under central patch load of value 24 kips

The finite-element model generated in ANSYS (see Fig. 4.5) is simulated as simply supported (along the entire width of the deck) at two symmetrically located positions with a span of 120 ". This is subjected to a central patch load over an area of 10"x 20". The deflected shape at a resultant load value of 24 Kips is shown in Fig. 5.1 and the maximum deflection is seen at the center of the span, as expected. 
Table 5.1 Maximum deflection of Prodeck 8 for a central patch load

\begin{tabular}{|c|c|c|}
\hline $\begin{array}{c}\text { Resultant } \\
\text { load } \\
\text { (kips) }\end{array}$ & $\begin{array}{c}\text { Maximum } \\
\text { deflection } \\
\text { (in.) }\end{array}$ & $\begin{array}{c}\text { Maximum } \\
\text { deflection } \\
\text { (in.) }\end{array}$ \\
\hline present & $\begin{array}{c}\text { experiment } \\
\text { (Howard) }\end{array}$ \\
\hline 0 & 0.0000 & 0.0000 \\
\hline 2 & 0.0555 & 0.0720 \\
\hline 4 & 0.1109 & 0.1360 \\
\hline 6 & 0.1664 & 0.2120 \\
\hline 8 & 0.2219 & 0.2950 \\
\hline 10 & 0.2774 & 0.3570 \\
\hline 12 & 0.3328 & 0.4210 \\
\hline 14 & 0.3883 & 0.4970 \\
\hline 16 & 0.4438 & 0.5630 \\
\hline 18 & 0.4992 & 0.6360 \\
\hline 20 & 0.5547 & 0.7140 \\
\hline 22 & 0.6102 & 0.7750 \\
\hline 24 & 0.6656 & 0.8530 \\
\hline 26 & 0.7211 & 0.9240 \\
\hline 28 & 0.7766 & 0.9970 \\
\hline 30 & 0.8321 & 1.0810 \\
\hline 32 & 0.8875 & 1.1600 \\
\hline 34 & 0.9430 & 1.2640 \\
\hline 36 & 0.9985 & 1.3670 \\
\hline
\end{tabular}




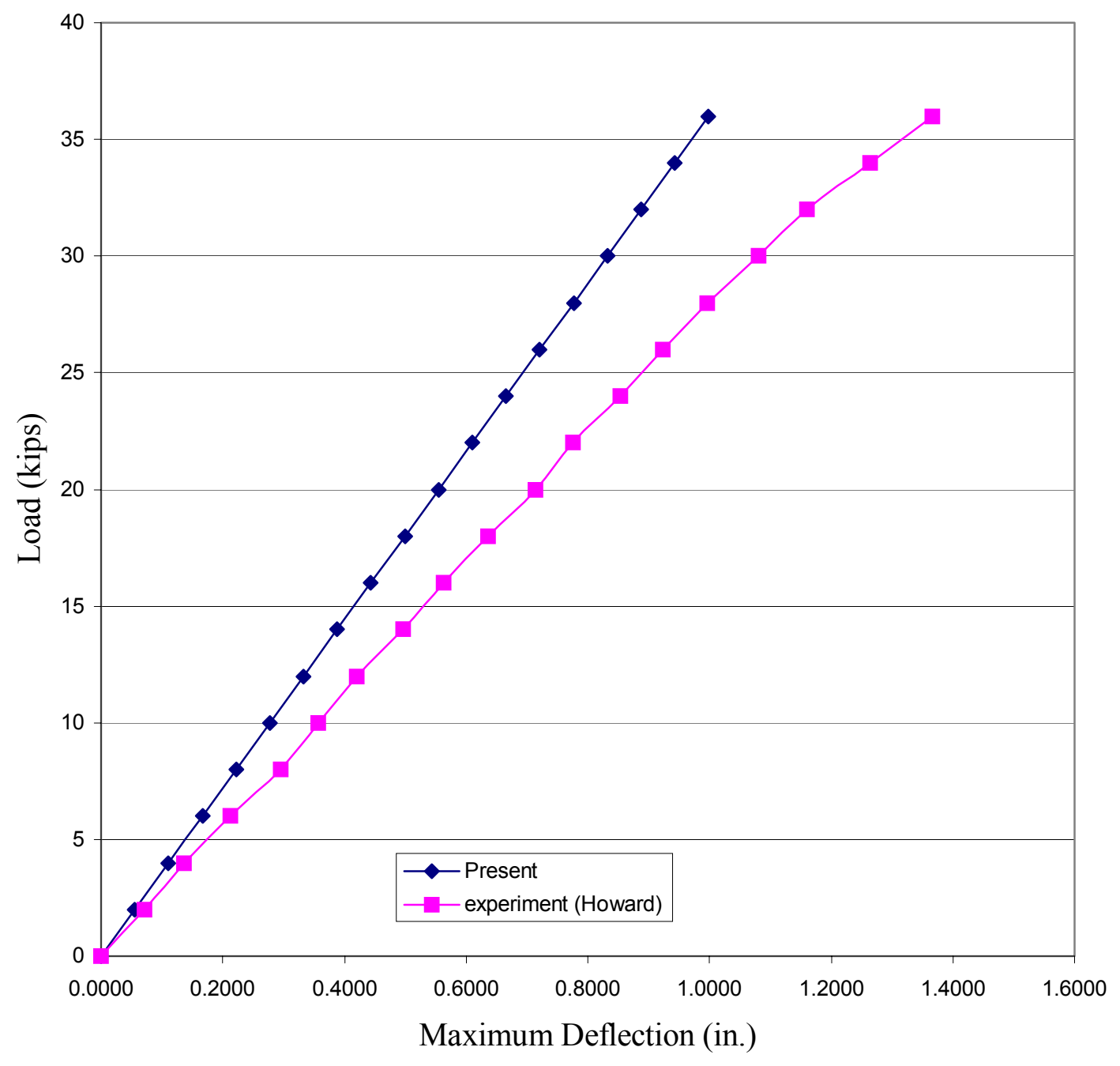

Fig. 5.2 Variation of maximum deflection with load for a central patch load

The values of the maximum deflection of the deck at different load levels are shown in Table 5.1 and Fig. 5.2. The corresponding experimental results generated by Howard (2002) are also presented in this table and the figure for the sake of comparison. As seen from Table 5.1 and Fig. 5.2 the present finite element results are consistently lower than the experimental ones indicating that the finite element model is stiffer. The finite element plot from the present analysis is linear as expected whereas the experimental curve is basically linear upto 32 kips and then begins to 
exhibit nonlinearity. This nonlinearity is probably attributable to accumulation of damage as the load increases. One possible reason for the difference in the deflection values between the numerical and experimental results is the fact that the fiber volume fraction $\left(v_{f}\right)$ used in the present analysis of 0.64 (see Section 4.3) is based on theoretical calculations, which is higher than the fiber volume fraction of 0.54 obtained from a burn-out test [Howard, 2002]. To test this hypothesis the analysis is run with a fiber volume fraction of 0.54 and the contour plot of the transverse deflection at a resultant load of 24 Kips is shown in Fig. 5.3.

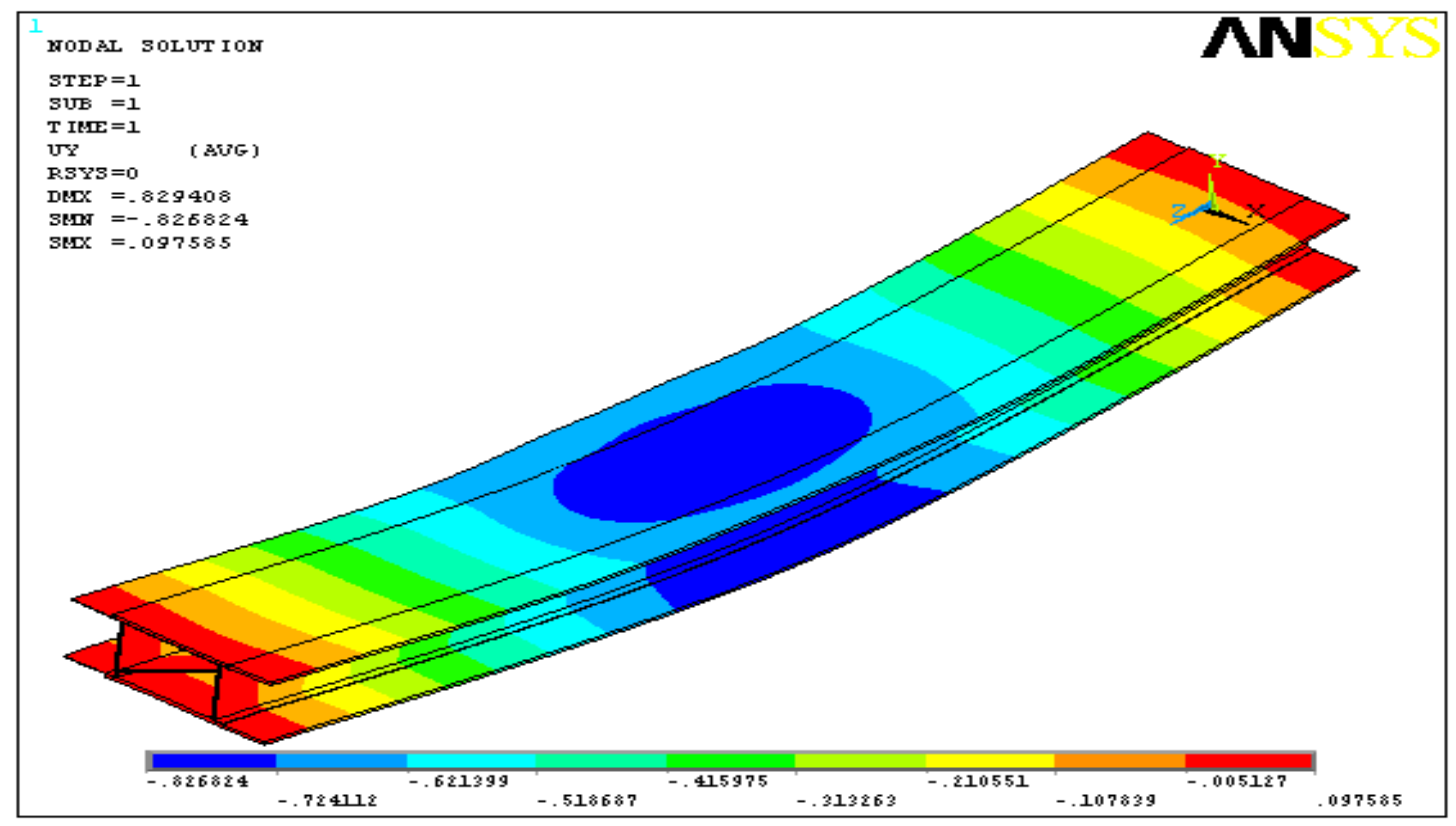

Fig. 5.3 Displacement plot in the $Y$ direction for the Prodeck 8 with fiber volume fraction of $54 \%$ and 24 Kips patch load 
Table 5.2 Maximum deflection of Prodeck 8 for two different fiber volume fractions under a central patch load

\begin{tabular}{|c|c|c|c|}
\hline $\begin{array}{l}\text { load } \\
\text { (kips) }\end{array}$ & \begin{tabular}{|c} 
Maximum \\
deflection \\
(in.)
\end{tabular} & \begin{tabular}{|c} 
Maximum \\
deflection \\
(in.)
\end{tabular} & $\begin{array}{c}\text { Maximum } \\
\text { deflection } \\
\text { (in.) }\end{array}$ \\
\hline & $v_{f}=0.54$ & $v_{f}=0.64$ & $\begin{array}{l}\text { experiment } \\
\text { (Howard) }\end{array}$ \\
\hline 0 & 0.0000 & 0.0000 & 0.0000 \\
\hline 2 & 0.0691 & 0.0555 & 0.0720 \\
\hline 4 & 0.1382 & 0.1109 & 0.1360 \\
\hline 6 & 0.2073 & 0.1664 & 0.2120 \\
\hline 8 & 0.2765 & 0.2219 & 0.2950 \\
\hline 10 & 0.3456 & 0.2774 & 0.3570 \\
\hline 12 & 0.4147 & 0.3328 & 0.4210 \\
\hline 14 & 0.4838 & 0.3883 & 0.4970 \\
\hline 16 & 0.5529 & 0.4438 & 0.5630 \\
\hline 18 & 0.6221 & 0.4992 & 0.6360 \\
\hline 20 & 0.6912 & 0.5547 & 0.7140 \\
\hline 22 & 0.7603 & 0.6102 & 0.7750 \\
\hline 24 & 0.8295 & 0.6656 & 0.8530 \\
\hline 26 & 0.8986 & 0.7211 & 0.9240 \\
\hline 28 & 0.9677 & 0.7766 & 0.9970 \\
\hline 30 & 1.0370 & 0.8321 & 1.0810 \\
\hline 32 & 1.1059 & 0.8875 & 1.1600 \\
\hline 34 & 1.1750 & 0.9430 & 1.2640 \\
\hline 36 & 1.2442 & 0.9985 & 1.3670 \\
\hline
\end{tabular}




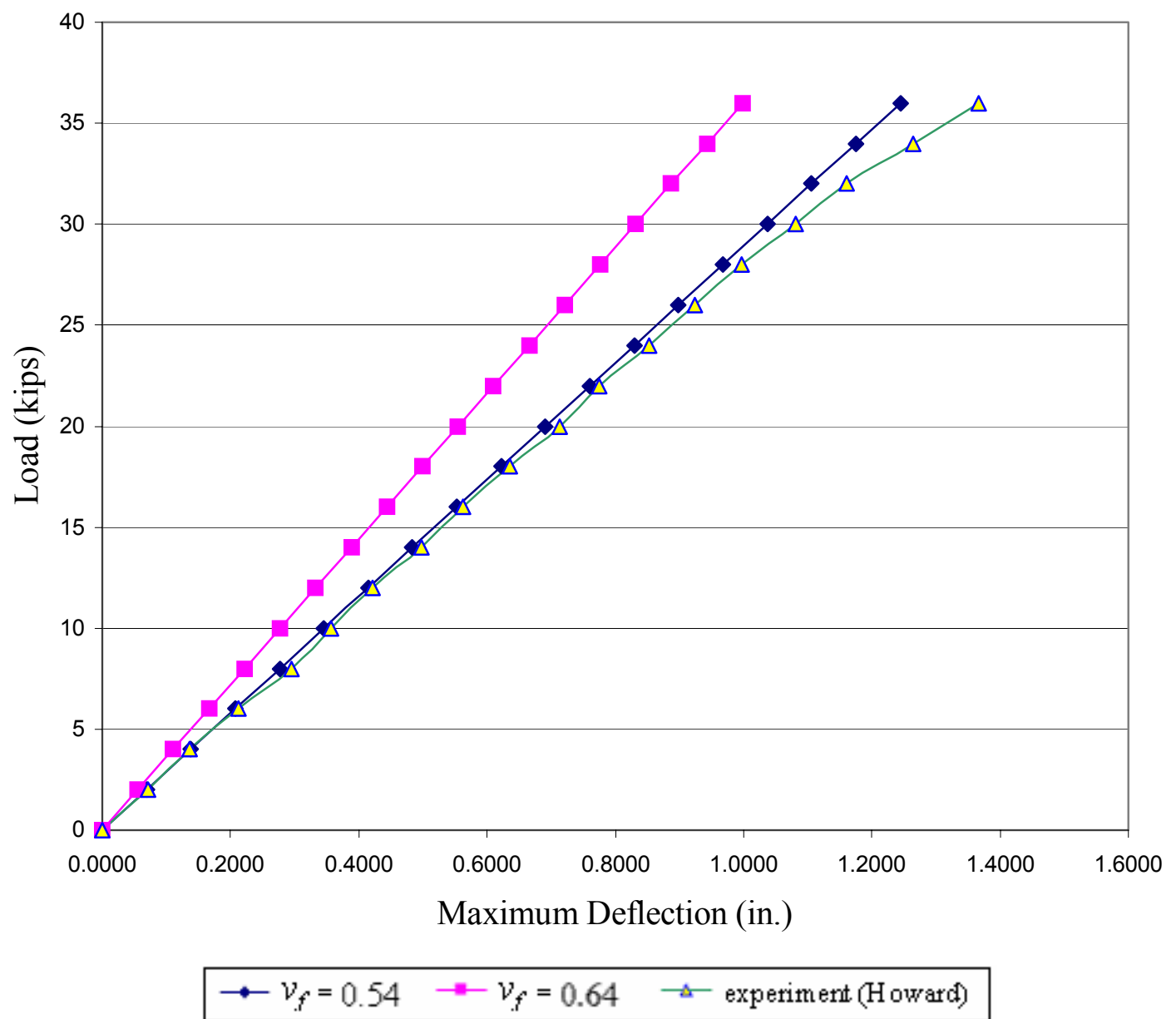

Fig. 5.4 Variation of load with maximum deflection for two different fiber volume fractions under a central patch load

The mid-span deflection for different load levels for $v_{f}=0.54$ and $v_{f}=0.64$ are presented in Table 5.2. The corresponding experimental results from Howard (2002) are also included in this table. The data from Table 5.2 is plotted in Fig. 5.4. It is seen from Fig. 5.4 that the plot corresponding to a fiber volume fraction of 0.54 closely matches the experimental one. For the load values of 0 kips to 32 kips (linear portion of the experimental curve), the maximum difference in the maximum deflection values between 
the finite element result with a fiber volume fraction of 0.64 and experimental result is about $23 \%$, whereas when the analysis is run with a fiber volume fraction of 0.54 , the maximum difference between the two is only about $6 \%$.

The equivalent flexural rigidity and Young's Modulus are calculated based on the fundamental principles of mechanics of materials for bending and Hooke's law. The formulas used for the calculation are presented below.

$$
\begin{aligned}
& \delta=\frac{P L^{3}}{48 E I} \\
& \sigma=E \varepsilon=\frac{M c}{I}
\end{aligned}
$$

Solving (5.1) and (5.2) for EI and substituting $M=\frac{P L}{4}$ we get,

$$
E I=\left(\frac{P}{\delta}\right)\left(\frac{L^{3}}{48}\right)
$$

or

$$
E I=\left(\frac{P}{\varepsilon}\right)\left(\frac{L c}{4}\right)
$$

where,

$$
\begin{aligned}
& \frac{P}{\delta}=\text { Slope of the load versus maximum deflection curve } \\
& \frac{P}{\varepsilon}=\text { Slope of the load versus strain curve } \\
& L=\text { Clear span }=120 " \\
& E=\text { Young's modulus or modulus of elasticity } \\
& I=\text { Moment of inertia of deck cross section }=300 \text { in. }^{4} \\
& c=\text { Distance from the neutral axis to the outermost fiber }=4 "
\end{aligned}
$$


Using Eq. (5.3) and slopes from Fig. 5.4 the equivalent flexural rigidity and Young's modulus are calculated and shown in Table 5.3. The corresponding experimental results generated by Howard (2002) are also presented in this table. As seen from Table 5.3, for the present analysis using maximum deflection, Young's Modulus is calculated as $4.30 \times 10^{6} \mathrm{psi}$, whereas the experimental Young's Modulus reported from Howard (2002) is $3.30 \times 10^{6} \mathrm{psi}$. And when the analysis is performed using a fiber volume fraction of 0.54 , the Young's Modulus is calculated to be $3.47 \times 10^{6}$ psi. This shows that the fiber volume fraction used for calculating the material properties makes a considerable difference to the equivalent flexural rigidity and Young's modulus values and hence great care should be taken in computing the fiber volume fraction. It should be noted that all the results presented hereafter for the Prodeck 8 are based on a fiber volume fraction of 0.54

Table 5.3 Equivalent flexural rigidity and Young's modulus in the longitudinal direction based on maximum deflection

\begin{tabular}{|c|c|c|}
\hline Type & $\begin{array}{c}\text { Equivalent Flexural } \\
\text { Rigidity } \\
\boldsymbol{E}_{\boldsymbol{Z}} \boldsymbol{I}_{\boldsymbol{X}}\left(\mathbf{1 0}^{\mathbf{9}} \mathbf{l b} \cdot \mathbf{i n}^{\mathbf{2}}\right)\end{array}$ & $\begin{array}{c}\text { Equivalent Young's } \\
\text { Modulus } \\
\boldsymbol{E}_{\boldsymbol{z}}\left(\mathbf{1 0}^{\mathbf{6}} \mathbf{~ p s i}\right)\end{array}$ \\
\hline$v_{f}=0.64$ (present) & 1.29 & 4.30 \\
\hline$v_{f}=0.54$ (present) & 1.042 & 3.47 \\
\hline Experiment (Howard) & 0.99 & 3.30 \\
\hline
\end{tabular}




\subsection{TORSIONAL ANALYSIS OF PRODECK 8}

The transverse deflection analysis included in the previous section has not accounted for shear effects, which may be important for composite structures. To quantify the shear effect, a torsional analysis of the Prodeck 8 is carried out. First the torsional constant of the cross section of the deck (Fig. 3.2) is computed. The torsional constants of the closed $\left(J_{c}\right)$ and open $\left(J_{o}\right)$ segments of the section are given, respectively, by

$$
\begin{aligned}
& J_{c}=\frac{4 \bar{A}^{2}}{\oint \frac{d s}{t}} \\
& J_{o}=\sum \frac{1}{3} b t^{3}
\end{aligned}
$$

and $\quad J=J_{c}+J_{o}$

where $\bar{A}=$ enclosed area of the closed segment.

The calculated values for the Prodeck 8 cross section are $J_{c}=341.36$ in. ${ }^{4}, J_{o}=0.658$ in. ${ }^{4}$, and $J=342.02$ in. $^{4}$ Now the Prodeck 8 is simulated for the torsional analysis as follows. 


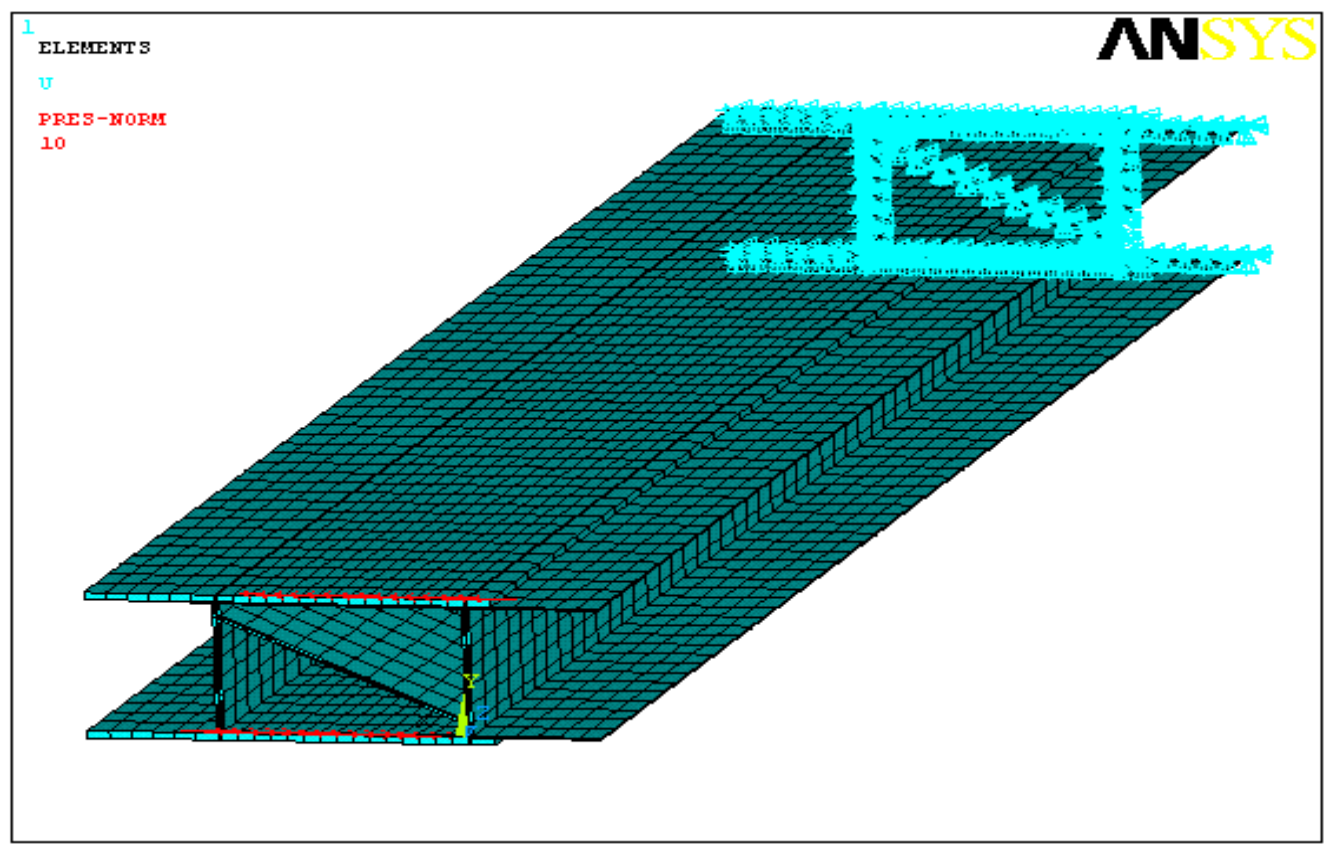

Fig. 5.5 Prodeck 8 subjected to torsion

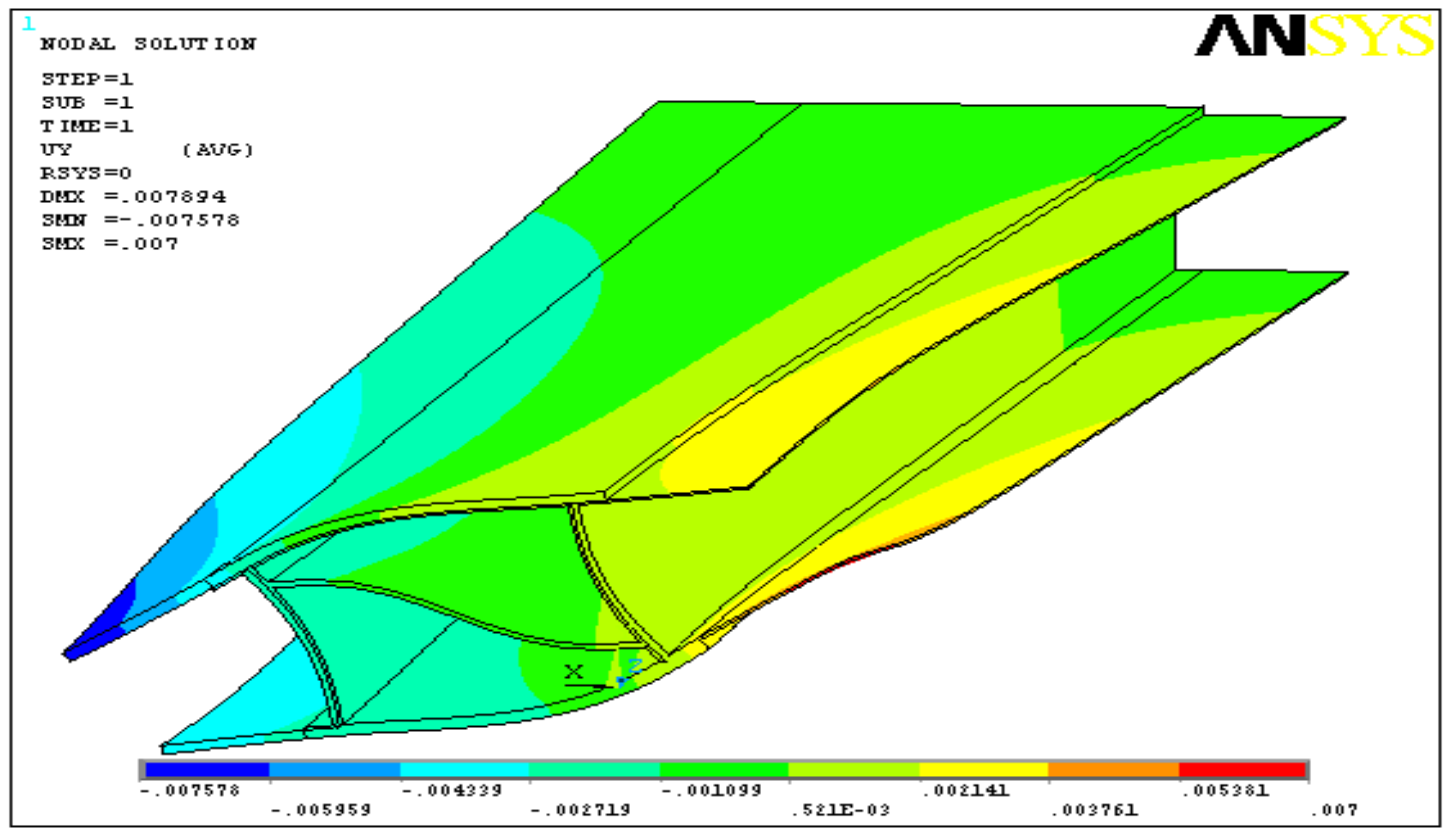

Fig. 5.6 Contour plot of showing angle of twist of the Prodeck 8 from the torsional analysis 
One end of the deck of length 128.75 in. is fixed and on the other end equal and opposite distributed shear loads are applied to the top and bottom flanges as shown in Fig. 5.5. Figure 5.6 shows the angle of twist of the Prodeck 8 under the torsional load. As shown in Appendix A, the twist angle of the free end is computed as $4.5125 \times 10^{-5} \mathrm{rad}$. Then the equivalent shear modulus $G$ is calculated from the equation,

$$
G=\frac{T L}{J \theta}
$$

where

$$
\begin{aligned}
& L=\text { Length of the fixed-free deck } \\
& T=\text { Torque applied to the free end } \\
& J=\text { Torsional constant of the deck cross section } \\
& \theta=\text { Twist angle of the free end. }
\end{aligned}
$$

The calculated value of the equivalent shear modulus is $0.9465 \times 10^{6} \mathrm{psi}$; this value is in close agreement with the $G_{Y Z}$ value of $0.9 \times 10^{6}$ psi calculated by Howard (2002). Then the deflection, $\delta_{s}$ due to the transverse shear strain can be obtained from

$$
\delta_{s}=\frac{P L}{4 G A}
$$

where

$P=$ Magnitude of the applied central load on a simply-supported beam

$L=$ Span of the simply-supported beam $=120 "$

$G=$ Equivalent shear modulus of the cross section

$A=$ Area of cross section of the deck $=27.04$ in. $^{2}$

The calculated central shear deflection for a resultant load of 24 kips is 0.02813 in. and when this is added to the corresponding bending deflection obtained using the 
ANSYS model of 0.2895 in., the total deflection is 0.8576 in. This deflection is used in Eq. (5.3) to obtain the equivalent flexural rigidity of the deck as $1.007 \times 10^{9} \mathrm{lb} \bullet \mathrm{in}^{2}$ Note this value is very close to the value of $0.99 \times 10^{9} \mathrm{lb} \cdot$ in. $^{2}$ obtained experimentally by Howard (2002). The shear-corrected equivalent Young's modulus in the longitudinal direction is computed to be $3.358 \times 10^{6}$ psi, which is nearly identical to Howard's (2002) value of $3.30 \times 10^{6} \mathrm{psi}$.

A cantilever model of the Prodeck 8 is constructed and subjected to a pure bending moment at the top (see Appendix B). Based on this model the equivalent flexural rigidity is calculated to be $1.277 \times 10^{9} \mathrm{lb} \cdot$ in. $^{2}$ and this is comparable to the theoretical value of $1.36 \times 10^{9} \mathrm{lb} \bullet$ in. $^{2}$ found by Howard (2002).

\subsection{STRAIN AND STRESS ANALYSIS}
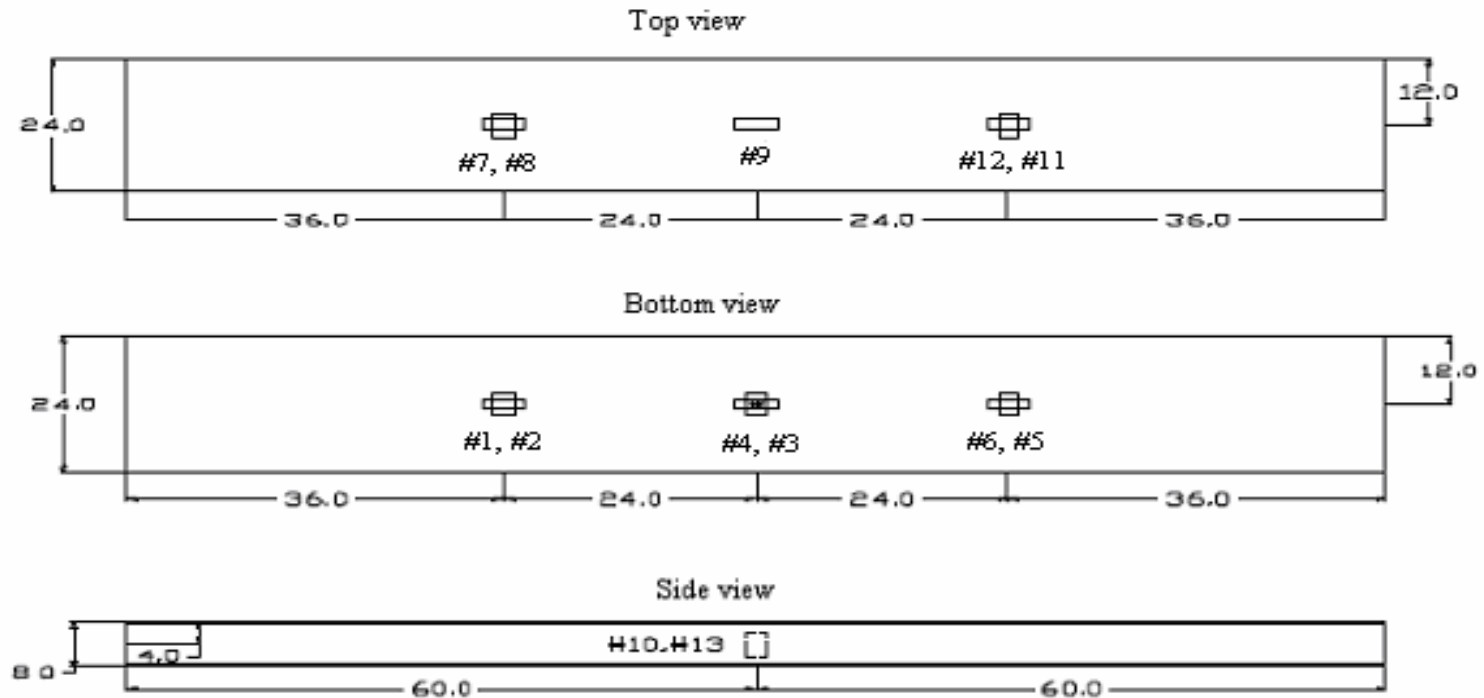

Strain Gages \#1, \#4, \#6, \#7, \#9, and \#12 measure strain in the 120" direction (Z)

Strain Gages \#2, \#3, \#5, \#8, and \#11 measure strain in the 24" direction $(X)$

All Units are in inches, not to scale.

Fig. 5.7 Position of strain gages [Howard, (2002)] 
Figure 5.7 shows the positioning of strain gages from the experimental set up by Howard (2002). The strains have been measured in the top and bottom flanges in the $X$ and $Z$ directions and in the webs. Table 5.4 summarizes the strain values from the present ANSYS model and the experimentally measured quantities by Howard (2002) in the bottom flange in the $Z$ direction (cell direction) at the Gage \# 4 location.

Table 5.4 Strain values at the Strain Gage \#4 location for a central patch load

\begin{tabular}{|c|c|c|}
\hline $\begin{array}{l}\text { load } \\
\text { (kips) }\end{array}$ & $\begin{array}{c}\varepsilon_{z} \\
\text { (micro-strains) }\end{array}$ & $\begin{array}{c}\varepsilon_{z} \\
\text { (micro-strains) } \\
\end{array}$ \\
\hline & Bottom & Bottom \\
\hline & Present & $\begin{array}{c}\text { Experiment } \\
\text { (Howard) }\end{array}$ \\
\hline 0 & 0 & 0 \\
\hline 2 & 181 & 201 \\
\hline 4 & 363 & 406 \\
\hline 6 & 544 & 628 \\
\hline 8 & 726 & 845 \\
\hline 10 & 907 & 1059 \\
\hline 12 & 1088 & 1261 \\
\hline 14 & 1270 & 1482 \\
\hline 16 & 1451 & 1688 \\
\hline 18 & 1633 & 1901 \\
\hline 20 & 1814 & 2119 \\
\hline 22 & 1996 & 2320 \\
\hline 24 & 2177 & 2535 \\
\hline 26 & 2358 & 2740 \\
\hline 28 & 2540 & 2939 \\
\hline 30 & 2721 & 3160 \\
\hline 32 & 2903 & 3365 \\
\hline 34 & 3084 & 3605 \\
\hline 36 & 3265 & 3831 \\
\hline
\end{tabular}




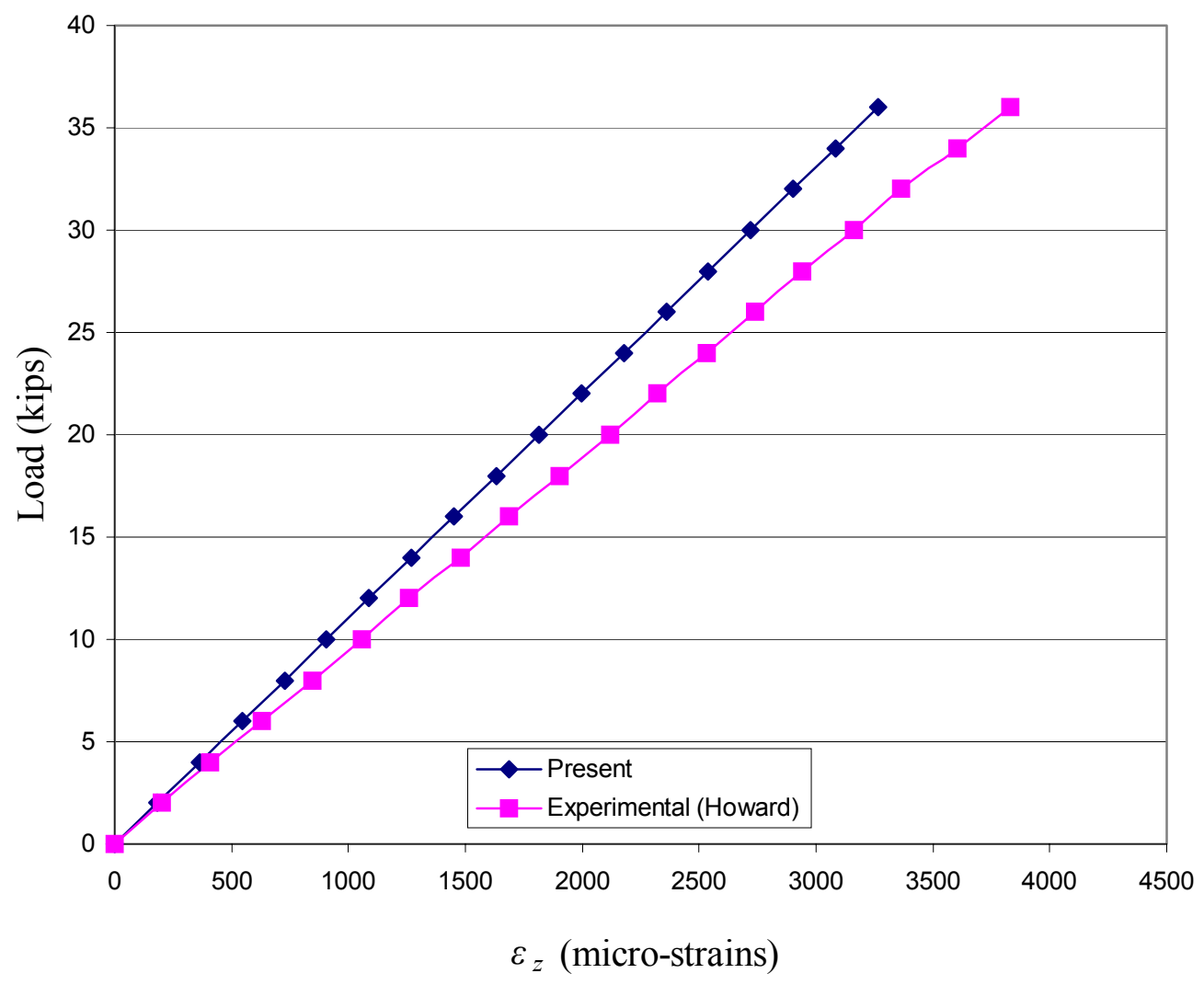

Fig. 5.8 Variation of $\varepsilon_{Z}$ at Gage \#4 location for a central patch load

Figure 5.8 shows the load versus strain plot of the data in Table 5.4. As seen from the plot the present finite element results are linear, as expected, and the experimental strains can also be considered to exhibit mostly linear behavior. Tables 5.5 -5.7 and Figs. $5.9-5.17$ show the strain values at the other gage locations Fig. (5.7) on the Prodeck 8 . 
Table 5.5 Strain values at the locations of Strain Gages \#1, \#2, \#5 and \#6 for a central patch load

Note: Expt. denotes experiment.

\begin{tabular}{|c|c|c|c|c|c|c|c|c|}
\hline \multirow{2}{*}{$\begin{array}{l}\text { Load } \\
\text { (Kips) }\end{array}$} & \multicolumn{2}{|c|}{$\mu \varepsilon_{z} \quad(\# 1)$} & \multicolumn{2}{|c|}{$\mu \varepsilon_{x}(\# 2)$} & \multicolumn{2}{|c|}{$\mu \varepsilon_{x} \quad(\# 5)$} & \multicolumn{2}{|c|}{$\mu \varepsilon_{z} \quad(\# 6)$} \\
\hline & Present & $\begin{array}{c}\text { Expt. } \\
\text { (Howard) }\end{array}$ & Present & $\begin{array}{c}\text { Expt. } \\
\text { (Howard) }\end{array}$ & Present & $\begin{array}{c}\text { Expt. } \\
\text { (Howard) }\end{array}$ & Present & $\begin{array}{c}\text { Expt. } \\
\text { (Howard) }\end{array}$ \\
\hline 0 & 0 & 0 & 0 & 0 & 0 & 0 & 0 & 0 \\
\hline 2 & 111 & 126 & -53 & -42 & -53 & -57 & 111 & 138 \\
\hline 4 & 221 & 252 & -106 & -91 & -105 & -111 & 221 & 274 \\
\hline 6 & 332 & 384 & -159 & -140 & -158 & -173 & 332 & 421 \\
\hline 8 & 443 & 513 & -212 & -186 & -211 & -237 & 443 & 567 \\
\hline 10 & 554 & 642 & -264 & -231 & -264 & -300 & 554 & 720 \\
\hline 12 & 664 & 763 & -317 & -279 & -316 & -361 & 664 & 848 \\
\hline 14 & 775 & 893 & -370 & -329 & -369 & -432 & 775 & 990 \\
\hline 16 & 886 & 1017 & -423 & -379 & -422 & -496 & 886 & 1126 \\
\hline 18 & 997 & 1141 & -476 & -430 & -475 & -568 & 997 & 1270 \\
\hline 20 & 1107 & 1268 & -529 & -484 & -527 & -642 & 1107 & 1415 \\
\hline 22 & 1218 & 1392 & -582 & -541 & -580 & -715 & 1218 & 1555 \\
\hline 24 & 1329 & 1518 & -635 & -598 & -633 & -794 & 1329 & 1711 \\
\hline 26 & 1439 & 1640 & -687 & -661 & -685 & -871 & 1439 & 1849 \\
\hline 28 & 1550 & 1763 & -740 & -724 & -738 & -949 & 1550 & 1987 \\
\hline 30 & 1661 & 1892 & -793 & -797 & -791 & -1035 & 1661 & 2131 \\
\hline 32 & 1772 & 2017 & -846 & -865 & -844 & -1124 & 1772 & 2288 \\
\hline 34 & 1882 & 2167 & -899 & -969 & -896 & -1249 & 1882 & 2484 \\
\hline 36 & 1993 & 2281 & -952 & -1074 & -949 & -1355 & 1993 & 2710 \\
\hline
\end{tabular}


Table 5.6 Strain values at the locations of Strain Gages \#7, \#8, \#11 and \#12 for a central patch load

Note: Expt. denotes experiment.

\begin{tabular}{|c|c|c|c|c|c|c|c|c|}
\hline \multirow{2}{*}{$\begin{array}{l}\text { Load } \\
\text { (Kips) }\end{array}$} & \multicolumn{2}{|c|}{$\mu \varepsilon_{z} \quad(\# 7)$} & \multicolumn{2}{|c|}{$\mu \varepsilon_{x}(\# 8)$} & \multicolumn{2}{|c|}{$\mu \varepsilon_{x} \quad(\# 11)$} & \multicolumn{2}{|c|}{$\mu \varepsilon_{z} \quad(\# 12)$} \\
\hline & Present & $\begin{array}{c}\text { Expt. } \\
\text { (Howard) }\end{array}$ & Present & $\begin{array}{c}\text { Expt. } \\
\text { (Howard) }\end{array}$ & Present & $\begin{array}{c}\text { Expt. } \\
\text { (Howard) }\end{array}$ & Present & $\begin{array}{c}\text { Expt. } \\
\text { (Howard) }\end{array}$ \\
\hline 0 & 0 & 0 & 0 & 0 & 0 & 0 & 0 & 0 \\
\hline 2 & -105 & -127 & 36 & 9 & 36 & 20 & -105 & -122 \\
\hline 4 & -210 & -255 & 71 & 24 & 72 & 35 & -210 & -242 \\
\hline 6 & -314 & -389 & 107 & 49 & 107 & 61 & -314 & -367 \\
\hline 8 & -419 & -521 & 143 & 78 & 143 & 92 & -419 & -485 \\
\hline 10 & -524 & -650 & 179 & 110 & 179 & 126 & -524 & -606 \\
\hline 12 & -629 & -769 & 214 & 144 & 215 & 154 & -629 & -713 \\
\hline 14 & -734 & -898 & 250 & 193 & 251 & 194 & -734 & -829 \\
\hline 16 & -838 & -1021 & 286 & 245 & 287 & 233 & -839 & -937 \\
\hline 18 & -943 & -1147 & 321 & 310 & 322 & 281 & -943 & -1043 \\
\hline 20 & -1048 & -1274 & 357 & 387 & 358 & 333 & -1048 & -1150 \\
\hline 22 & -1153 & -1392 & 393 & 465 & 394 & 387 & -1153 & -1250 \\
\hline 24 & -1257 & -1513 & 429 & 563 & 430 & 450 & -1258 & -1354 \\
\hline 26 & -1362 & -1628 & 464 & 653 & 466 & 506 & -1363 & -1443 \\
\hline 28 & -1467 & -1733 & 500 & 771 & 501 & 566 & -1467 & -1511 \\
\hline 30 & -1572 & -1849 & 536 & 902 & 537 & 633 & -1572 & -1585 \\
\hline 32 & -1677 & -1951 & 572 & 1050 & 573 & 703 & -1677 & -1646 \\
\hline 34 & -1781 & -2037 & 607 & 1217 & 609 & 744 & -1782 & -1681 \\
\hline 36 & -1886 & -2145 & 643 & 1462 & 645 & 939 & -1887 & -1739 \\
\hline
\end{tabular}


Table 5.7 Strain values at the location of Strain Gage \#10 for a central patch load

\begin{tabular}{|r|r|r|}
\hline \multicolumn{1}{|c|}{$\begin{array}{c}\text { load } \\
\text { (kips) }\end{array}$} & \multicolumn{1}{c|}{$\begin{array}{c}\varepsilon_{Y} \\
\text { (micro-strains) }\end{array}$} & $\begin{array}{c}c \\
\varepsilon_{Y} \\
\text { (micro-strains) }\end{array}$ \\
\hline & \multicolumn{1}{|c|}{ Present } & $\begin{array}{c}\text { Experiment } \\
\text { (Howard) }\end{array}$ \\
\hline 0 & 0 & 0 \\
\hline 2 & 18 & 15 \\
\hline 4 & 37 & 35 \\
\hline 6 & 55 & 72 \\
\hline 8 & 74 & 118 \\
\hline 10 & 92 & 157 \\
\hline 12 & 111 & 190 \\
\hline 14 & 129 & 220 \\
\hline 16 & 148 & 241 \\
\hline 18 & 166 & 257 \\
\hline 20 & 185 & 264 \\
\hline 22 & 203 & 267 \\
\hline 24 & 222 & 272 \\
\hline 26 & 240 & 280 \\
\hline 28 & 259 & 284 \\
\hline 30 & 277 & 419 \\
\hline 32 & 296 & 510 \\
\hline 34 & 314 & 554 \\
\hline 36 & 333 & 270 \\
\hline & & \\
\hline
\end{tabular}




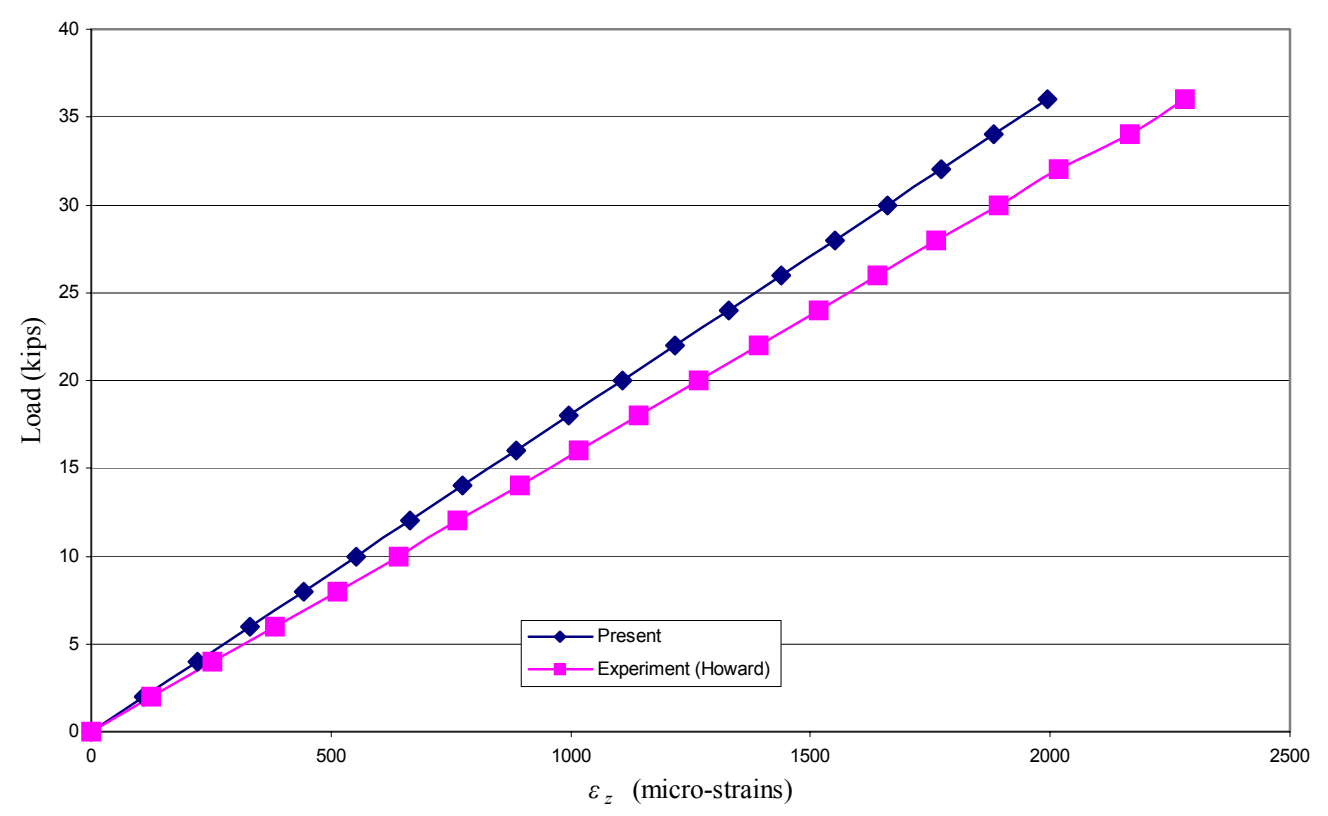

Fig. 5.9 Variation of $\varepsilon_{Z}$ at the Strain Gage \#1 location for a central patch load



Fig. 5.10 Variation of $\varepsilon_{X}$ (compressive) at the Strain Gage \#2 location for a patch load 


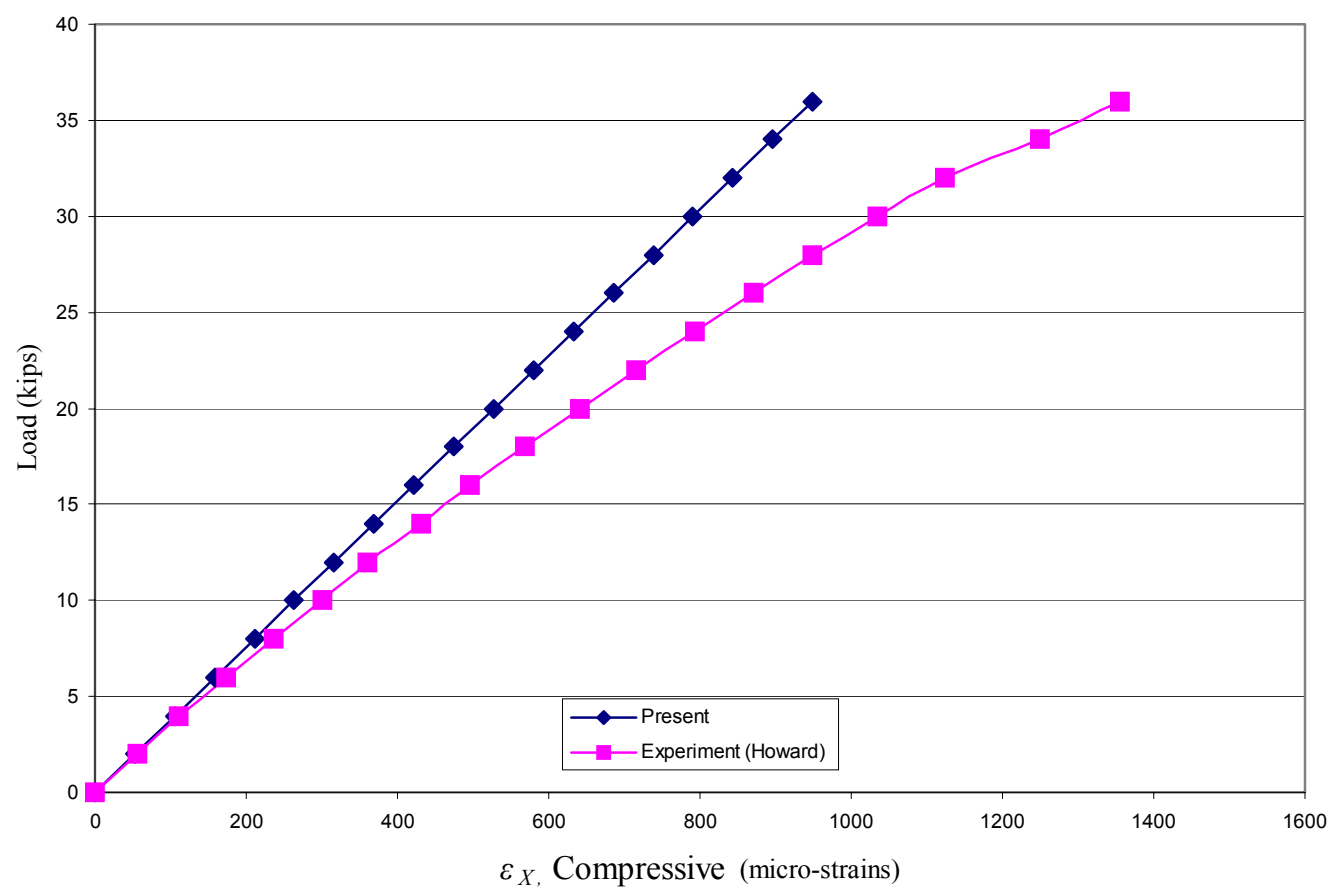

Fig. 5.11 Variation of $\varepsilon_{X}$ (compressive) at the Strain Gage \#5 location for a central patch load

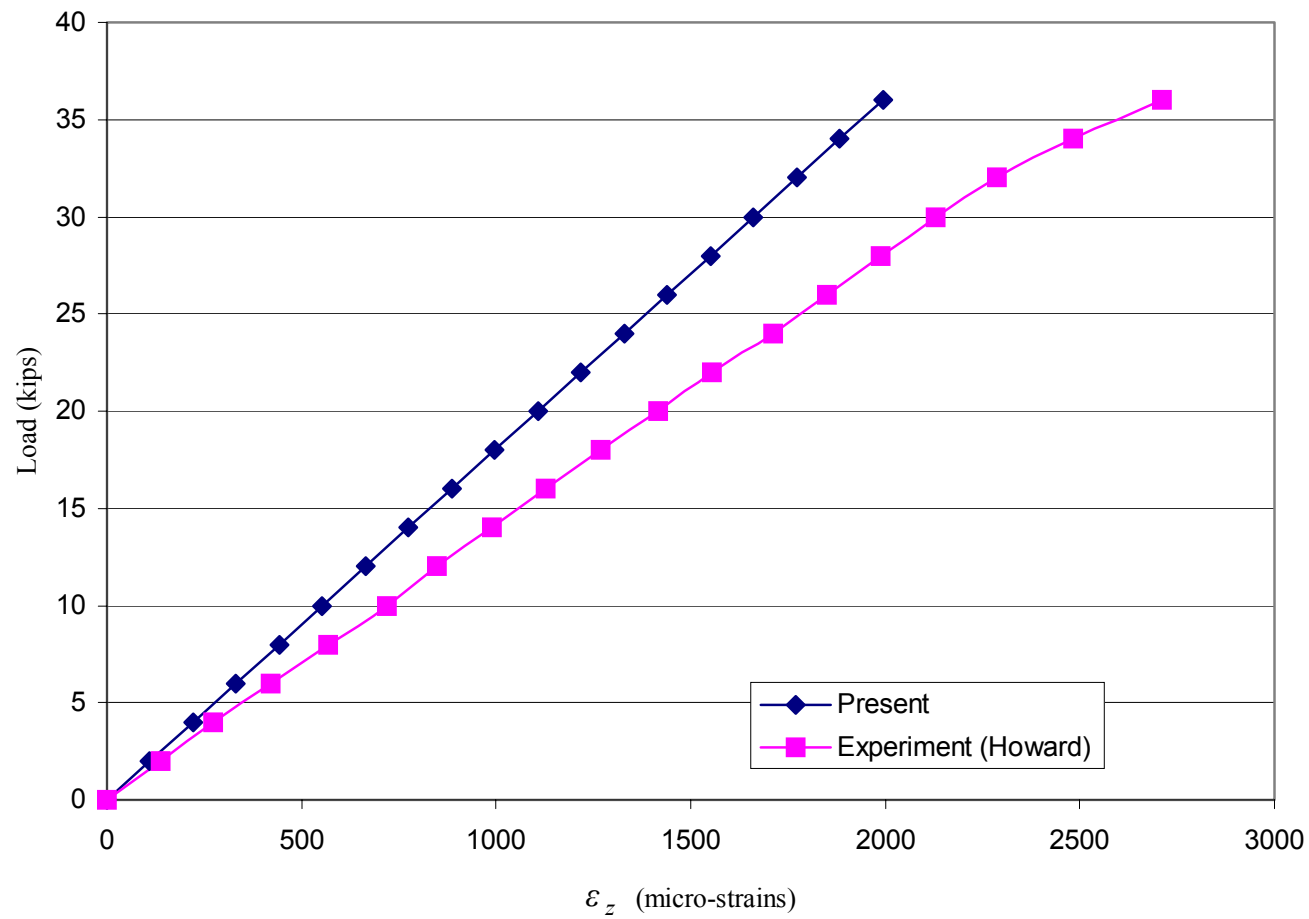

Fig. 5.12 Variation of $\varepsilon_{Z}$ at the Strain Gage \#6 location for a central patch load 


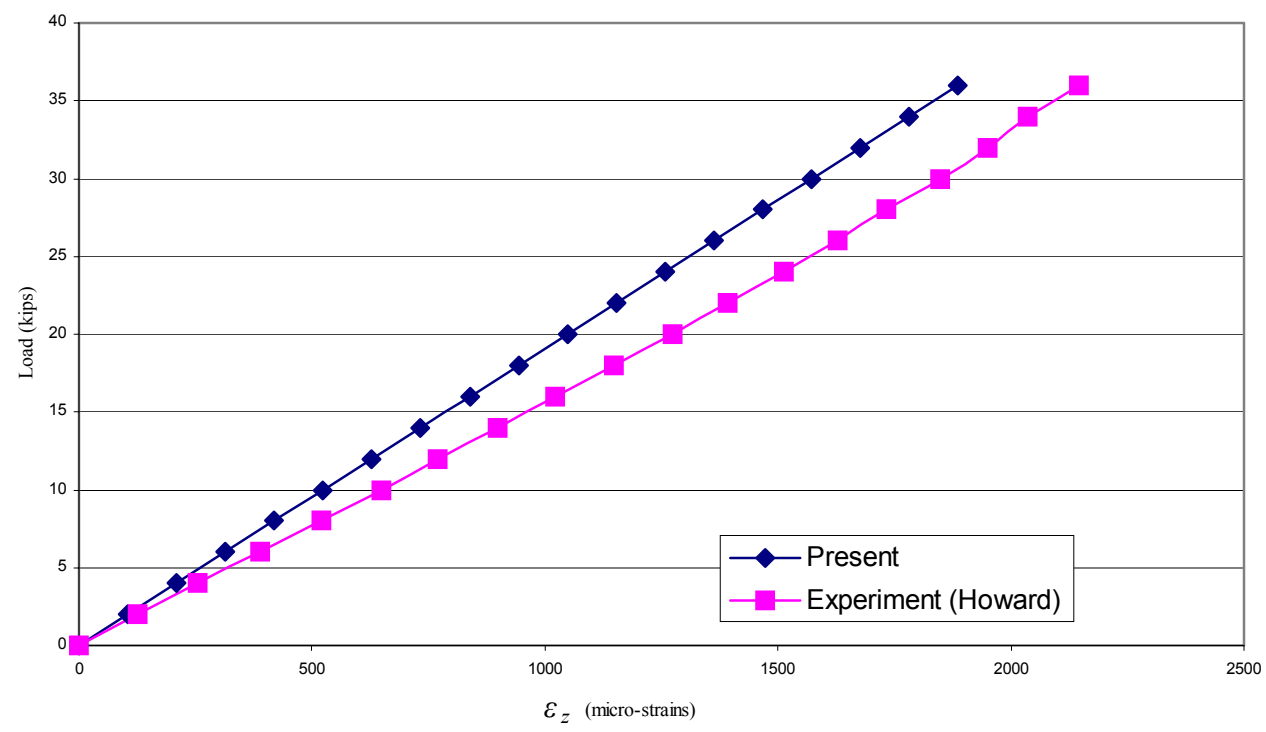

Fig. 5.13 Variation of $\varepsilon_{Z}$ (compressive) at the Strain Gage \#7 location for a central patch

load

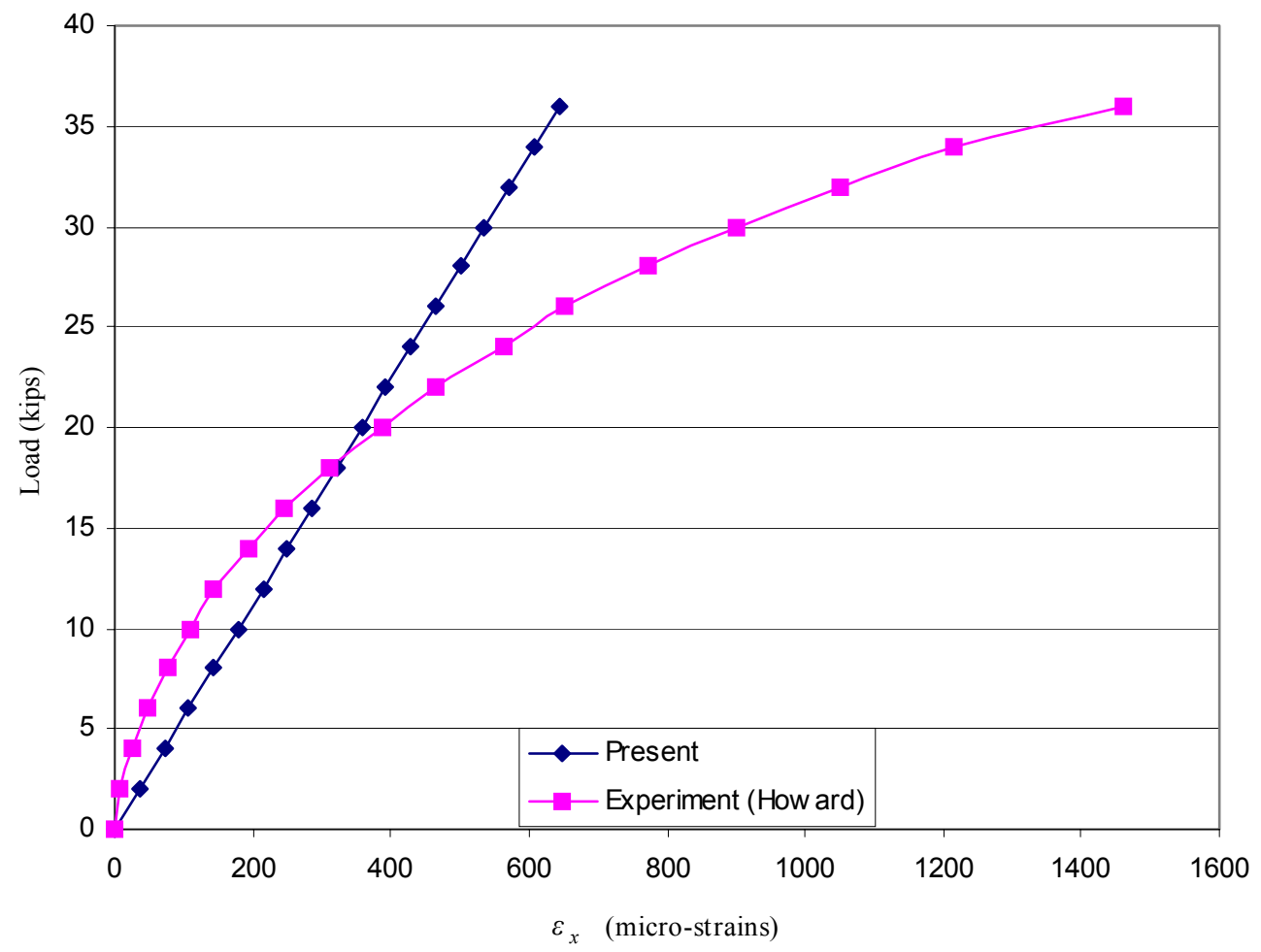

Fig. 5.14 Variation of $\varepsilon_{X}$ at the Strain Gage \#8 location for a central patch load 


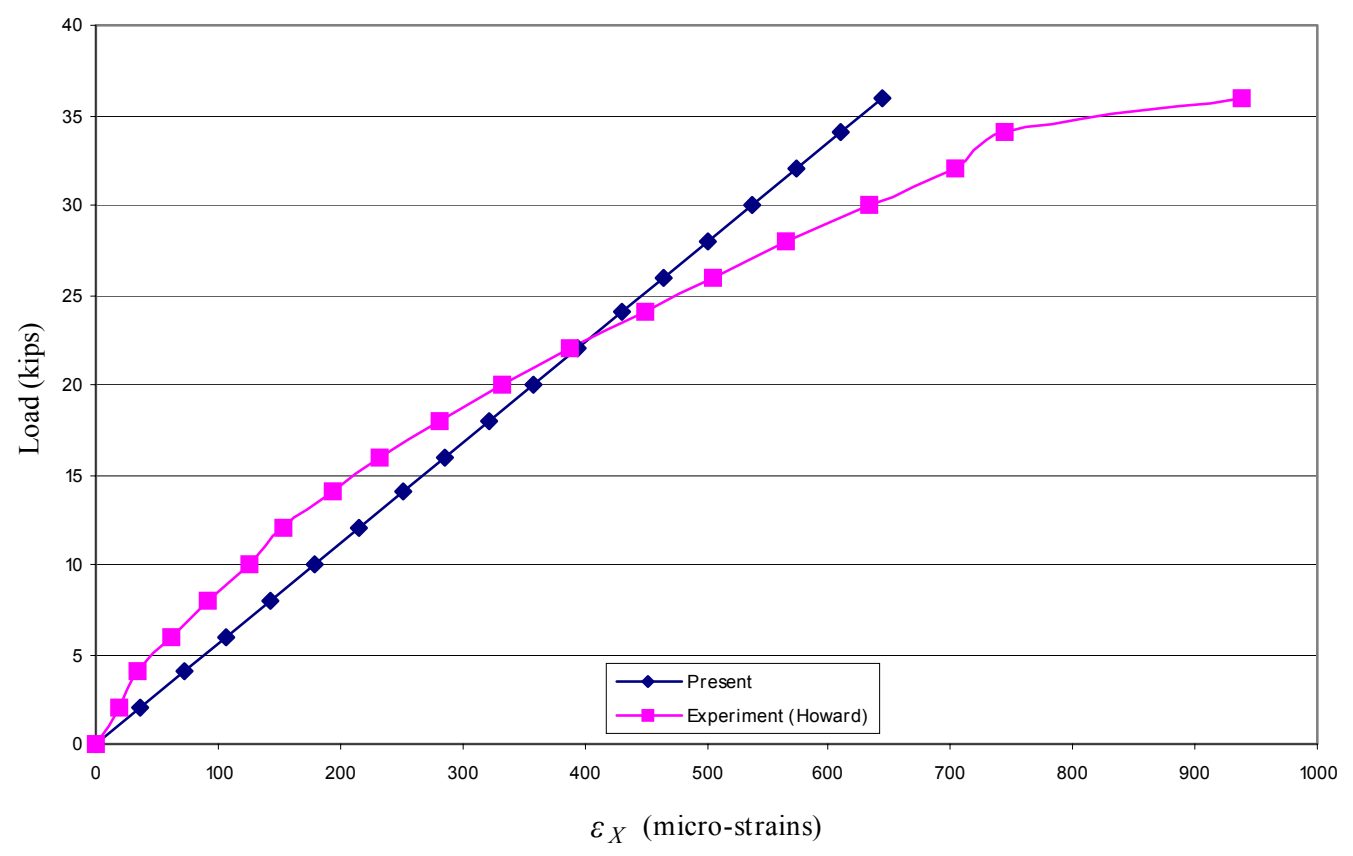

Fig. 5.15 Variation of $\varepsilon_{X}$ at the Strain Gage \#11 location for a central patch load

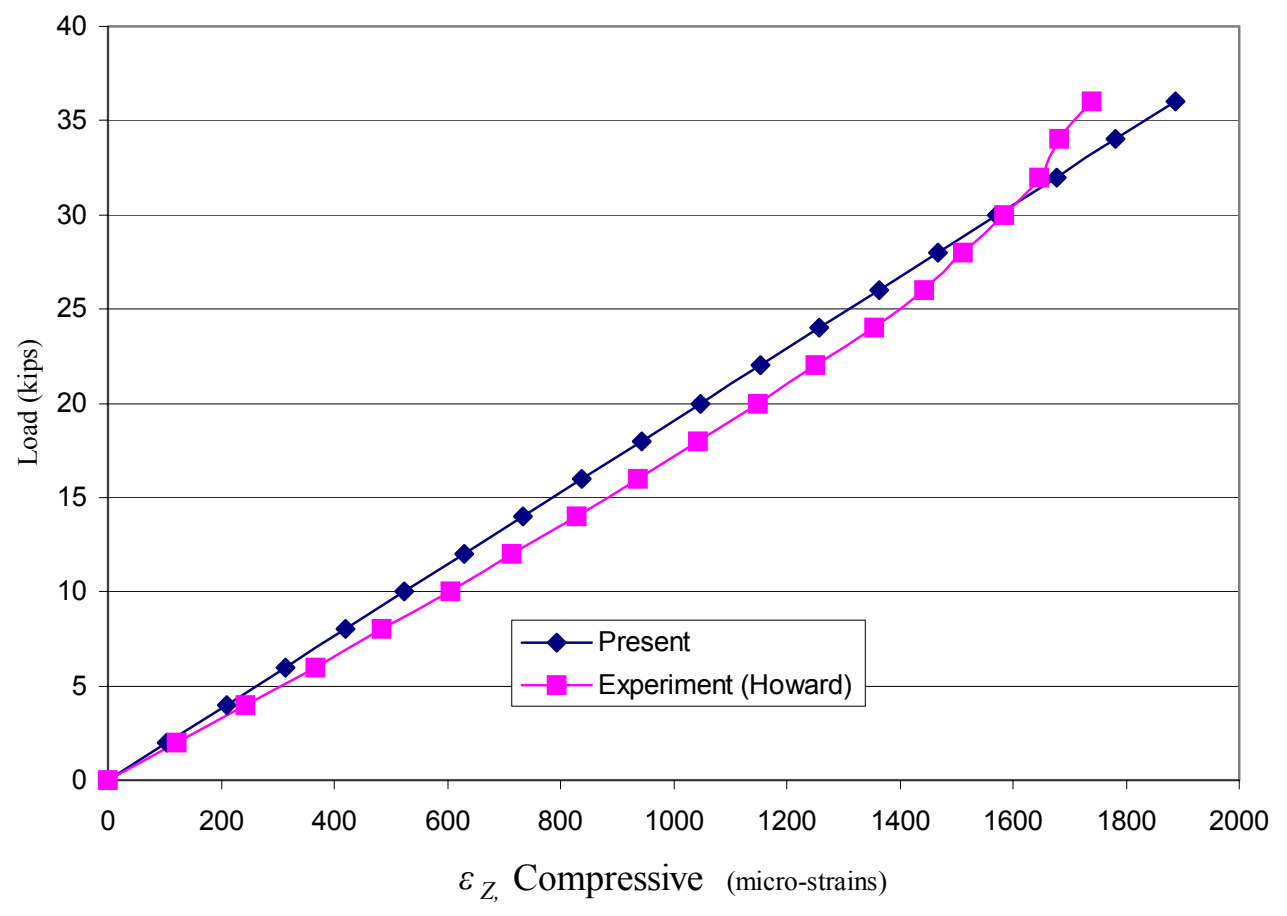

Fig. 5.16 Variation of $\varepsilon_{Z}$ (compressive) at the Strain Gage \#12 location for a central patch load 


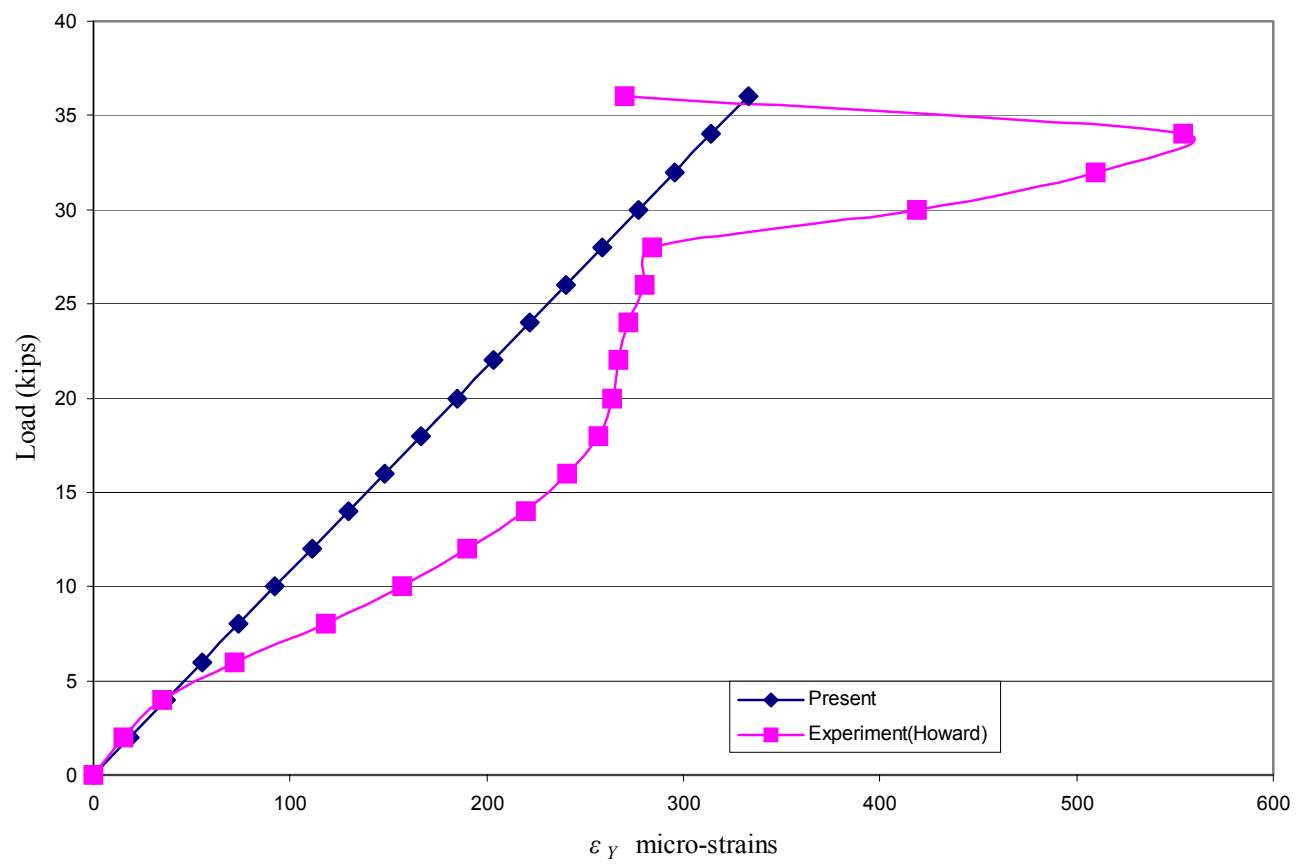

Fig. 5.17 Variation of $\varepsilon_{Y}$ at the Strain Gage \#10 location for a central patch load

Figures 5.9, 5.11, and 5.16 represent the longitudinal direction $(Z)$ strains, $\varepsilon_{Z}$. The

finite-element plots in all cases of $\varepsilon_{Z}$ are in very good agreement with the experimental curves. The experimental plots are linear for the most part. The inplane transverse direction $(X)$ strains, $\varepsilon_{X}$, are shown in Figs. 5.10, 5.11, 5.14 and 5.15. There is very good agreement between the present and experimental results in three of the four $\varepsilon_{X}$ plots; the one exception is Fig. 5.14, which shows a large discrepancy, particularly at loads of 24 kips and higher. Strain Gage \# 8 (Fig. 5.14) is at the mirror-image location of Strain Gage \# 11 (Fig. 5.15) and thus should have identical strain values. In fact, Table 5.6 confirms this as regards to the present (ANSYS) results; but the experimental results for Gages \# 8 and \#11 are far apart and thus Gage \# 8 is most likely a bad one and its readings should be discarded. In general the $\varepsilon_{X}$ plots tend to become nonlinear at low load levels whereas 
the $\varepsilon_{Z}$ plots stay mostly linear until about 32 Kips. Figure 5.17 represents the transverse direction strains $\varepsilon_{Y}$ for the web. It is seen that the experimental strain starts to diverge after a load of 5 kips.

Using Eq. (5.4) and the slope from Fig. 5.8, the equivalent flexural rigidity $\left(E_{Z} I_{X}\right)$ and Young's modulus of the Prodeck 8, based on strain are presented in Table 5.8 and compared with the corresponding values obtained experimentally by Howard (2002). It is seen that the equivalent flexural rigidity of $1.32 \times 10^{9} \mathrm{lb} \cdot$ in. $^{2}$ based on strain is $15.8 \%$ higher than that of Howard (2002). Also, comparing with Table 5.3 the present $E_{Z} I_{X}$ based on strain is $26.9 \%$ higher than that based on deflection.

Table 5.8 Equivalent flexural rigidity and Young's modulus in the cell direction based on strain

\begin{tabular}{|c|c|c|}
\hline Туре & $\begin{array}{c}\text { Equivalent Flexural } \\
\text { Rigidity } \\
E_{Z} I_{X}\left(10^{9} \mathrm{lb} \cdot \text { in. }^{2}\right) \\
\end{array}$ & $\begin{array}{c}\text { Equivalent Young's } \\
\text { Modulus } \\
E_{z}\left(\mathbf{1 0}^{6} \mathrm{psi}\right) \\
\end{array}$ \\
\hline Present & 1.32 & 4.40 \\
\hline Experiment (Howard) & 1.14 & 3.8 \\
\hline
\end{tabular}




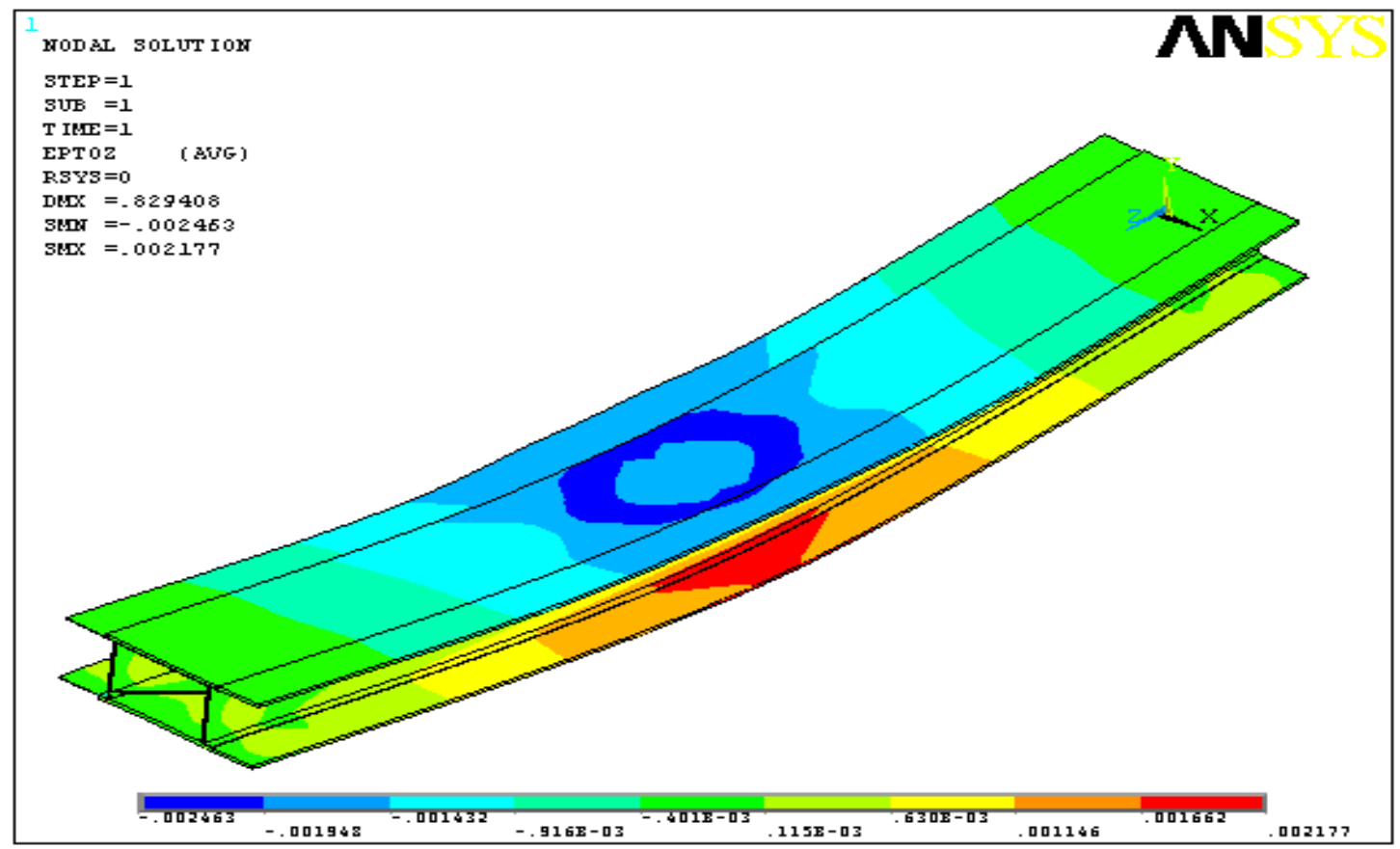

Fig. 5.18 Contour plot of $\varepsilon_{Z}$ for a central patch load of 24 Kips

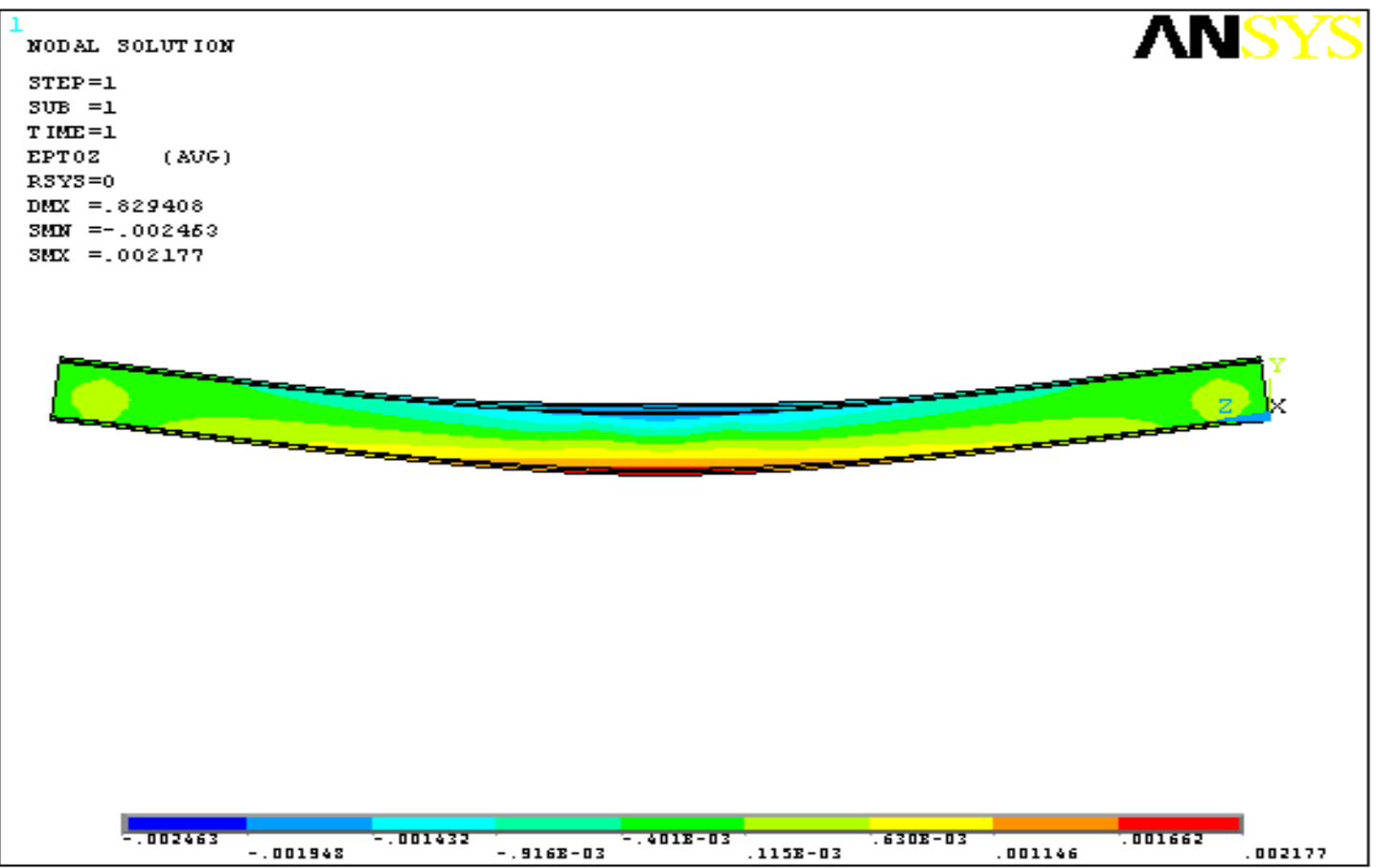

Fig. 5.19 Contour plot of $\varepsilon_{Z}$ in side view for a central patch load of $24 \mathrm{Kips}$ 


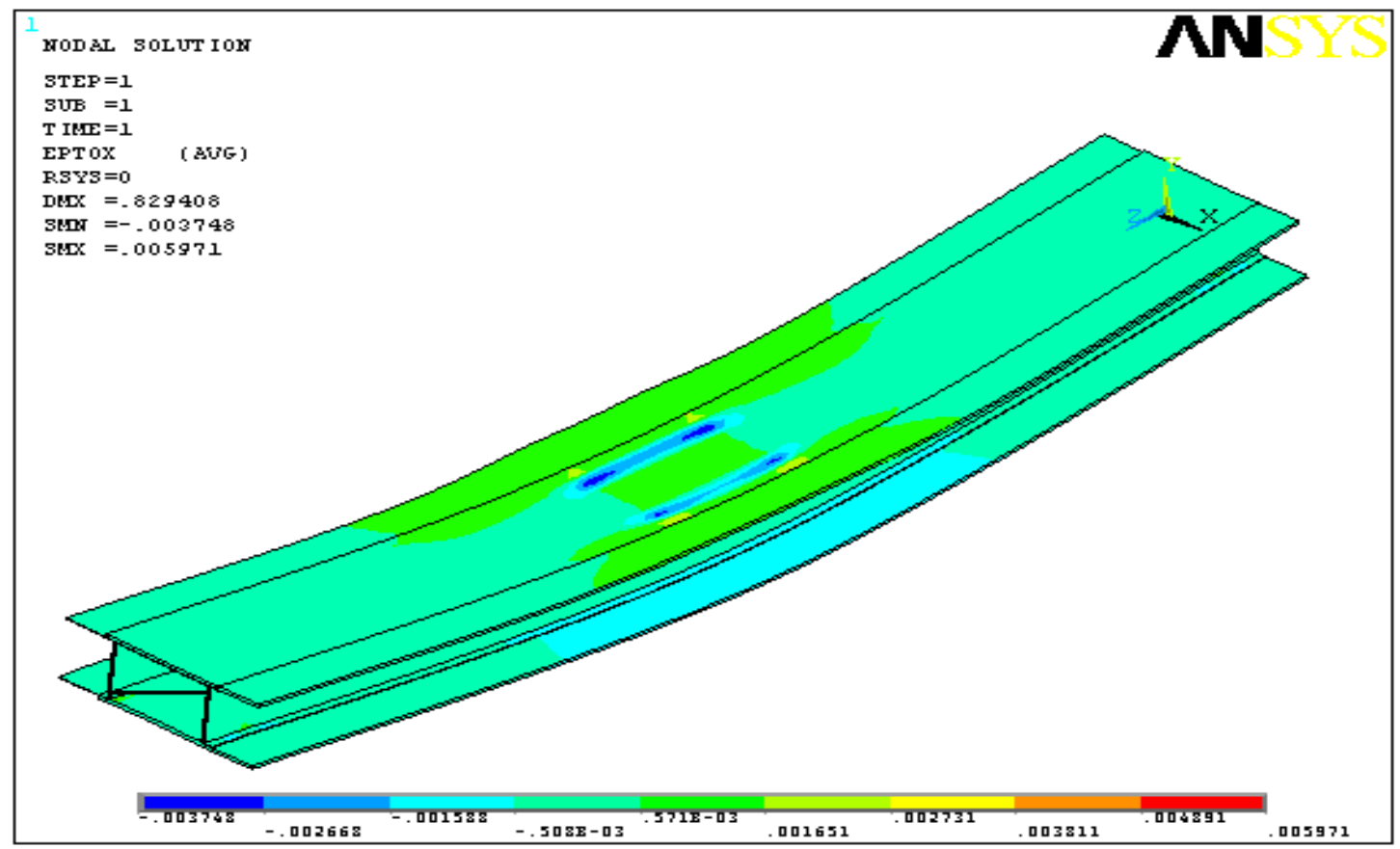

Fig. 5.20 Contour plot of $\varepsilon_{X}$ for a central patch load of 24 Kips

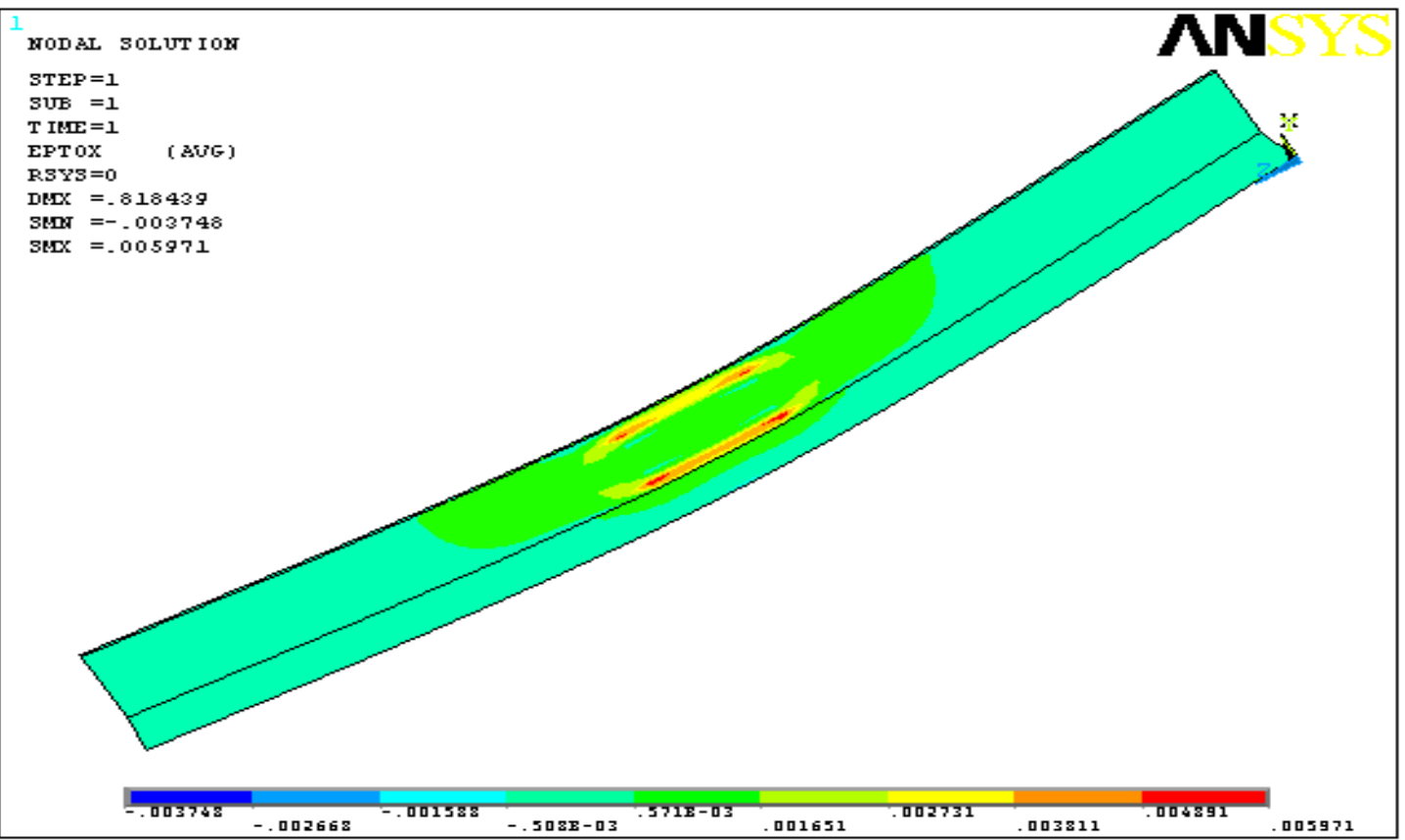

Fig. 5.21 Contour plot of $\varepsilon_{X}$ for a section of the Prodeck 8 for a central patch load of 24

Kips 


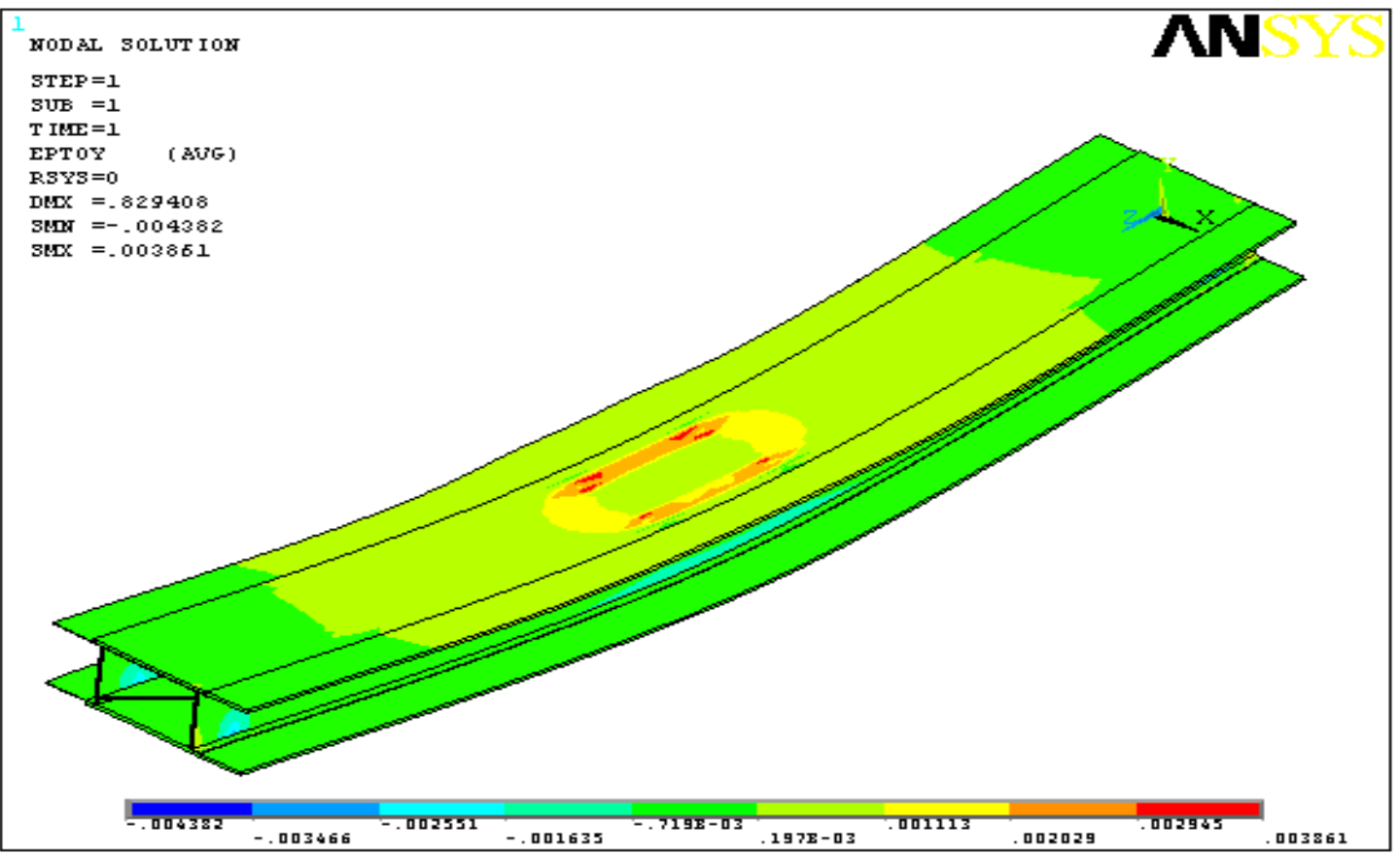

Fig. 5.22 Contour plot of $\varepsilon_{Y}$ for a central patch load of 24 Kips



Fig. 5.23 Contour plot of $\varepsilon_{Y}$ in the side view for a central load of $24 \mathrm{Kips}$ 


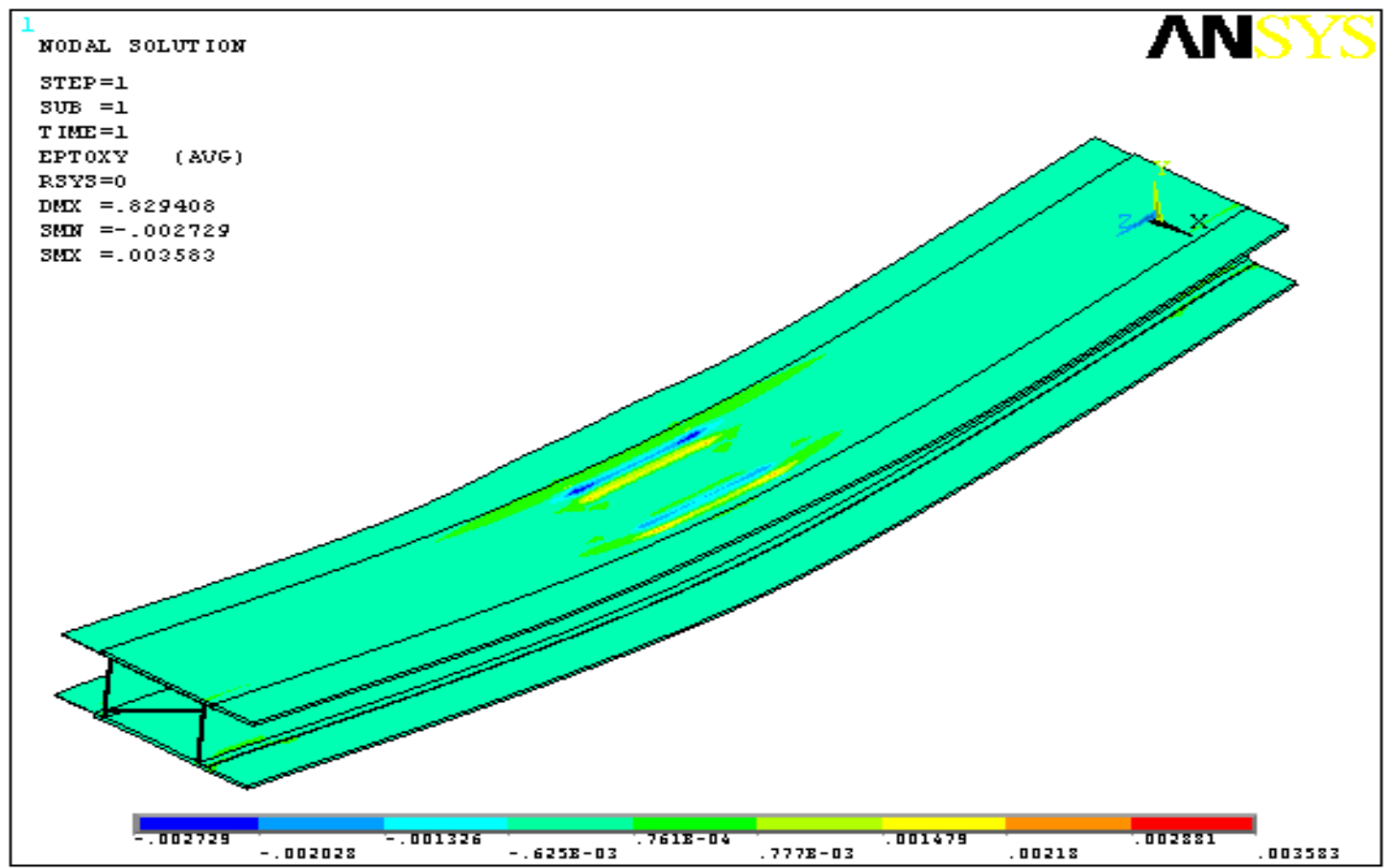

Fig. 5.24 Contour plot of $\gamma_{X Y}$ for a central patch load of 24 Kips



Fig. 5.25 Contour plot of $\gamma_{X Y}$ in the side view for a central patch load of $24 \mathrm{Kips}$ 


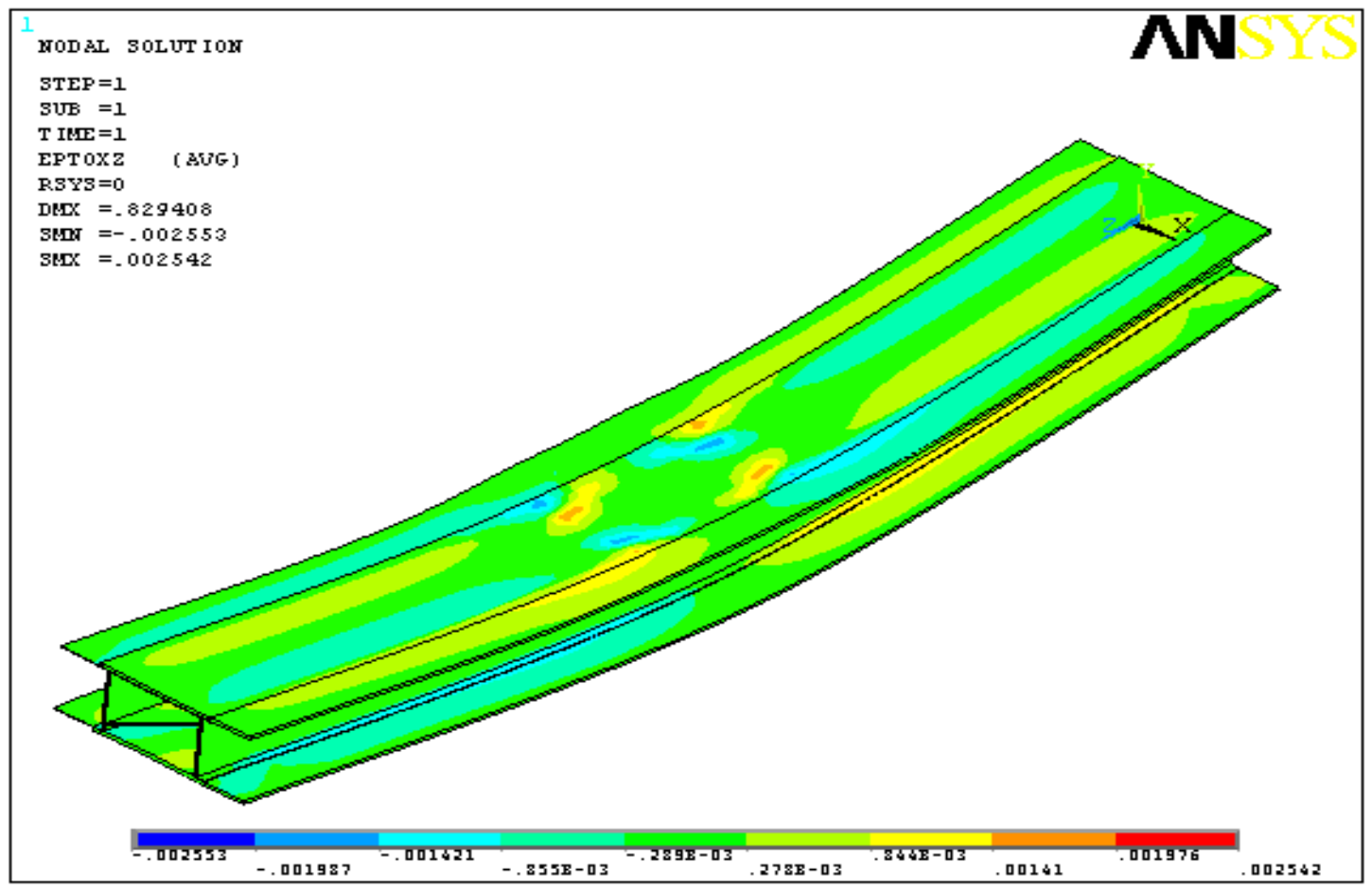

Fig. 5.26 Contour plot of $\gamma_{X Z}$ for a central patch load of 24 Kips

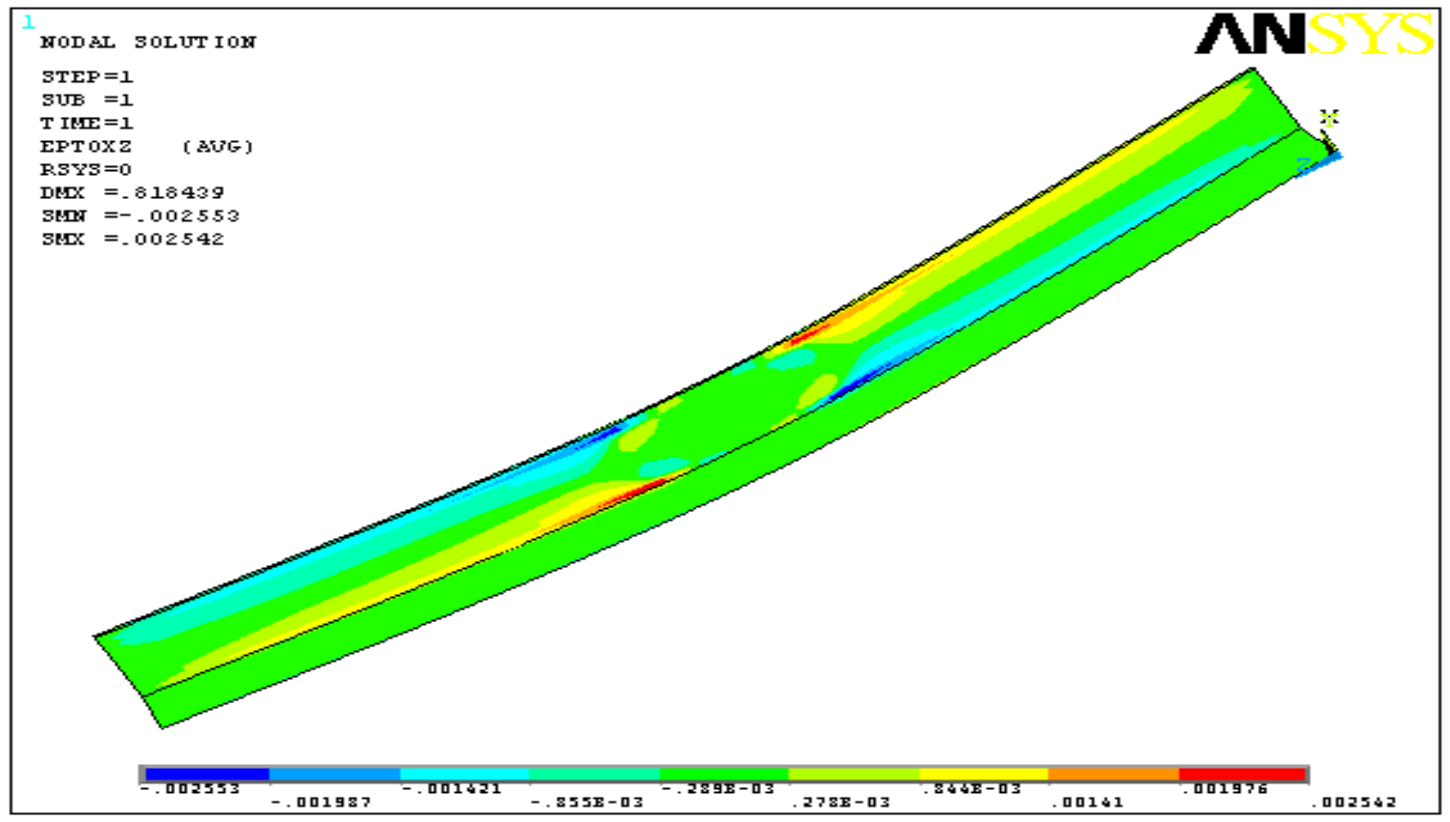

Fig. 5.27 Contour plot of $\gamma_{X Z}$ in the side view for a central patch load of $24 \mathrm{Kips}$ 


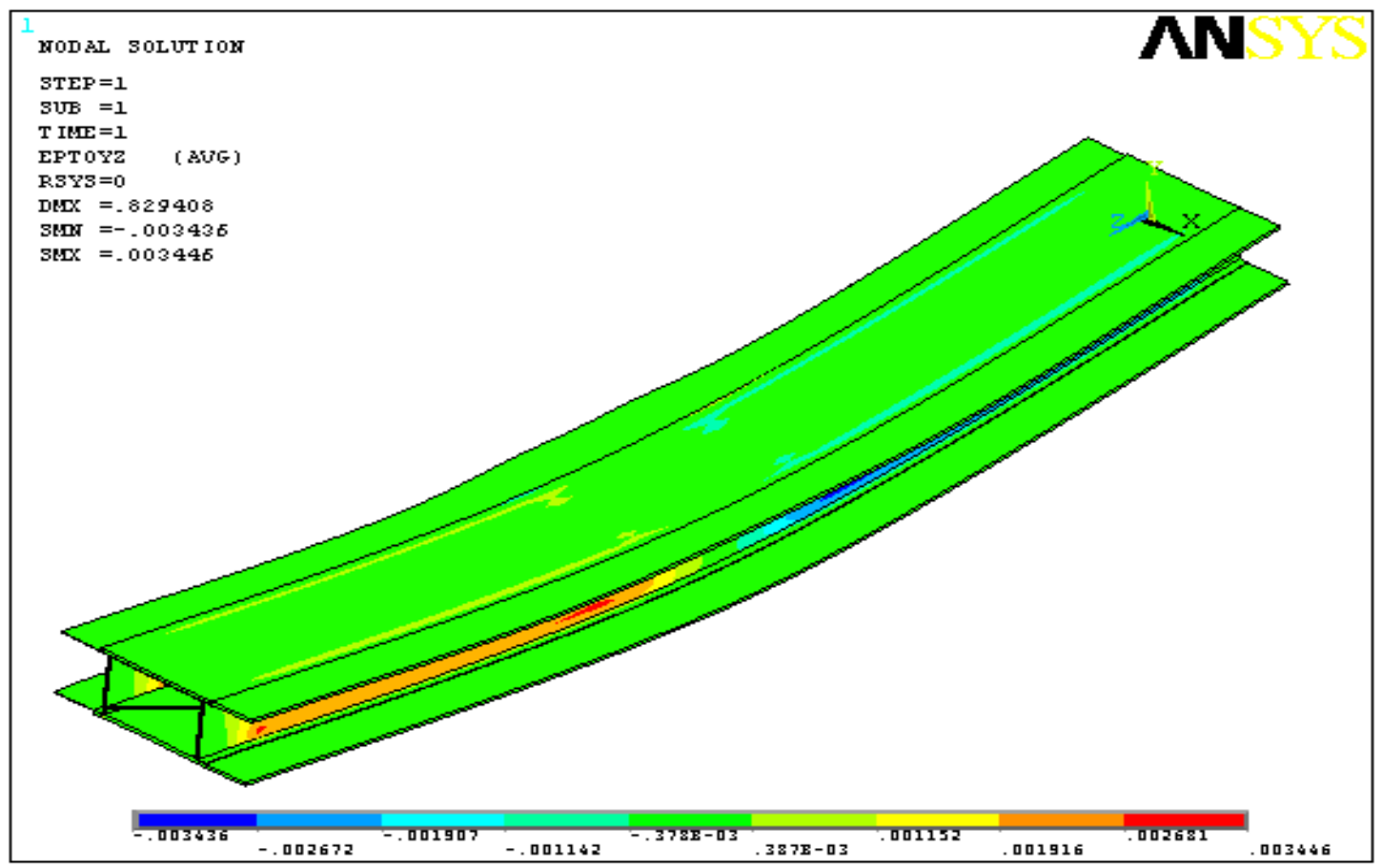

Fig. 5.28 Contour plot of $\gamma_{Y Z}$ for a central patch load of $24 \mathrm{Kips}$

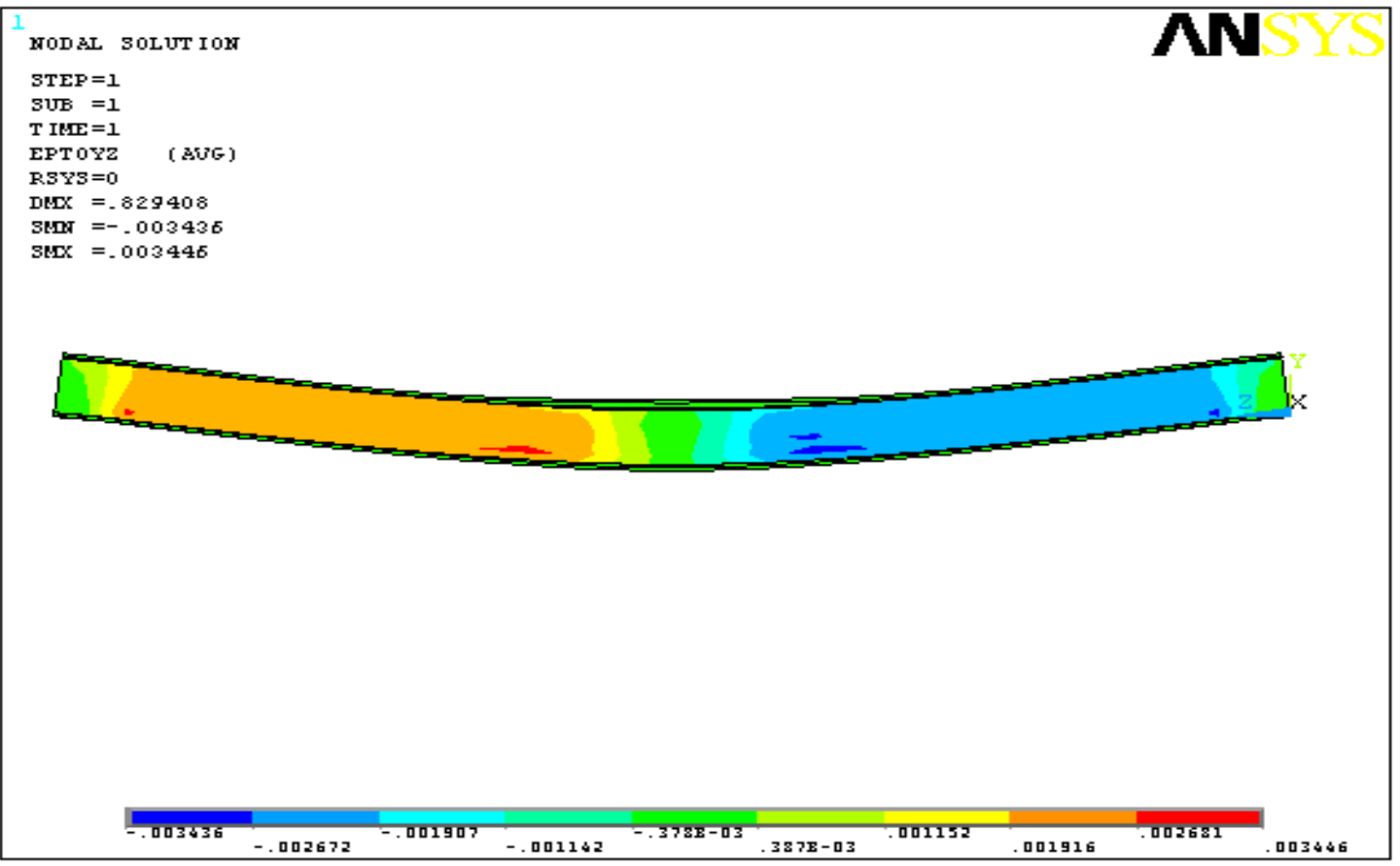

Fig. 5.29 Contour plot of $\gamma_{Y Z}$ in the side view for a central patch load of $24 \mathrm{Kips}$ 


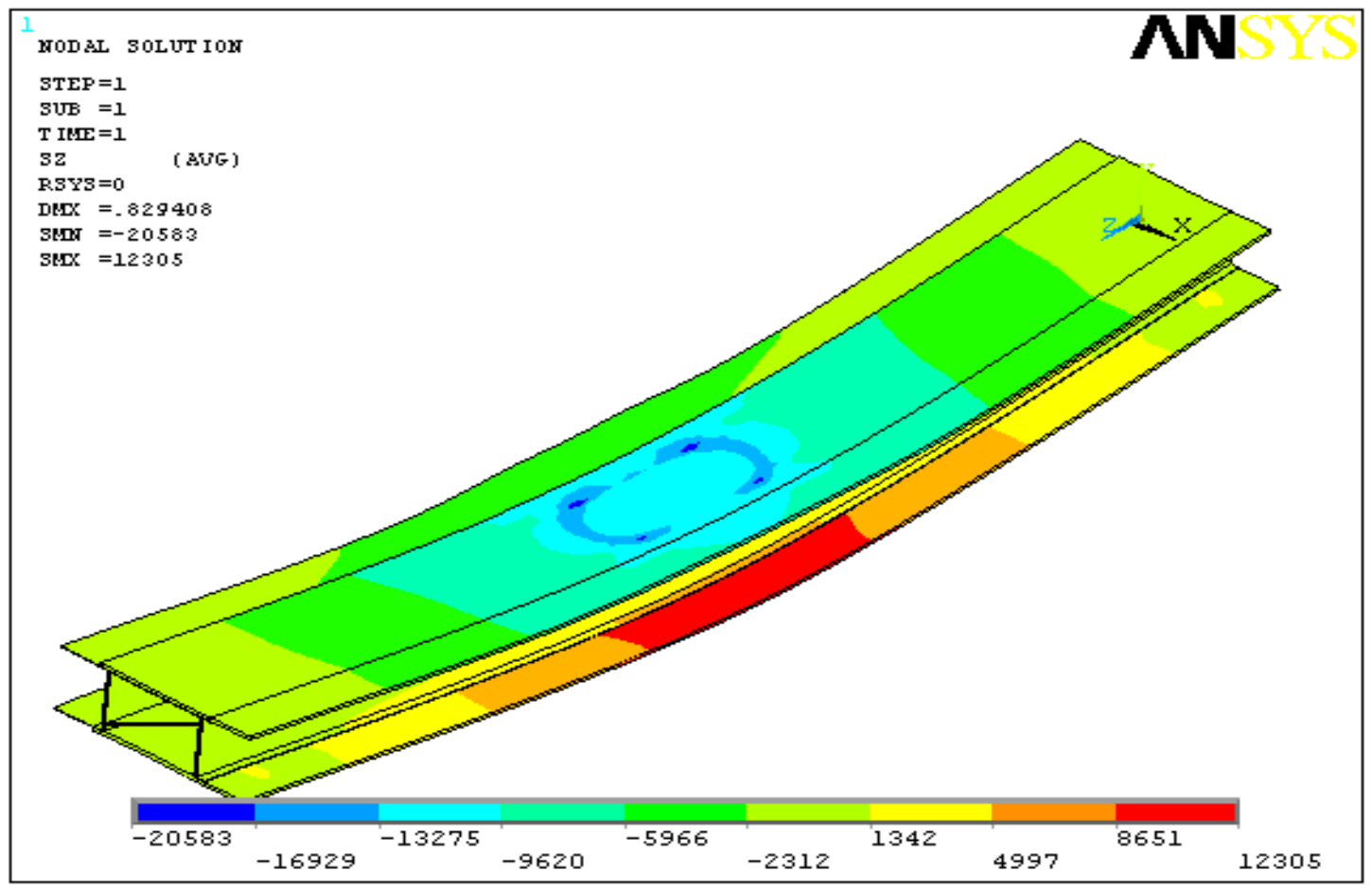

Fig. 5.30 Contour plot of $\sigma_{Z}$ for a central load of 24 Kips

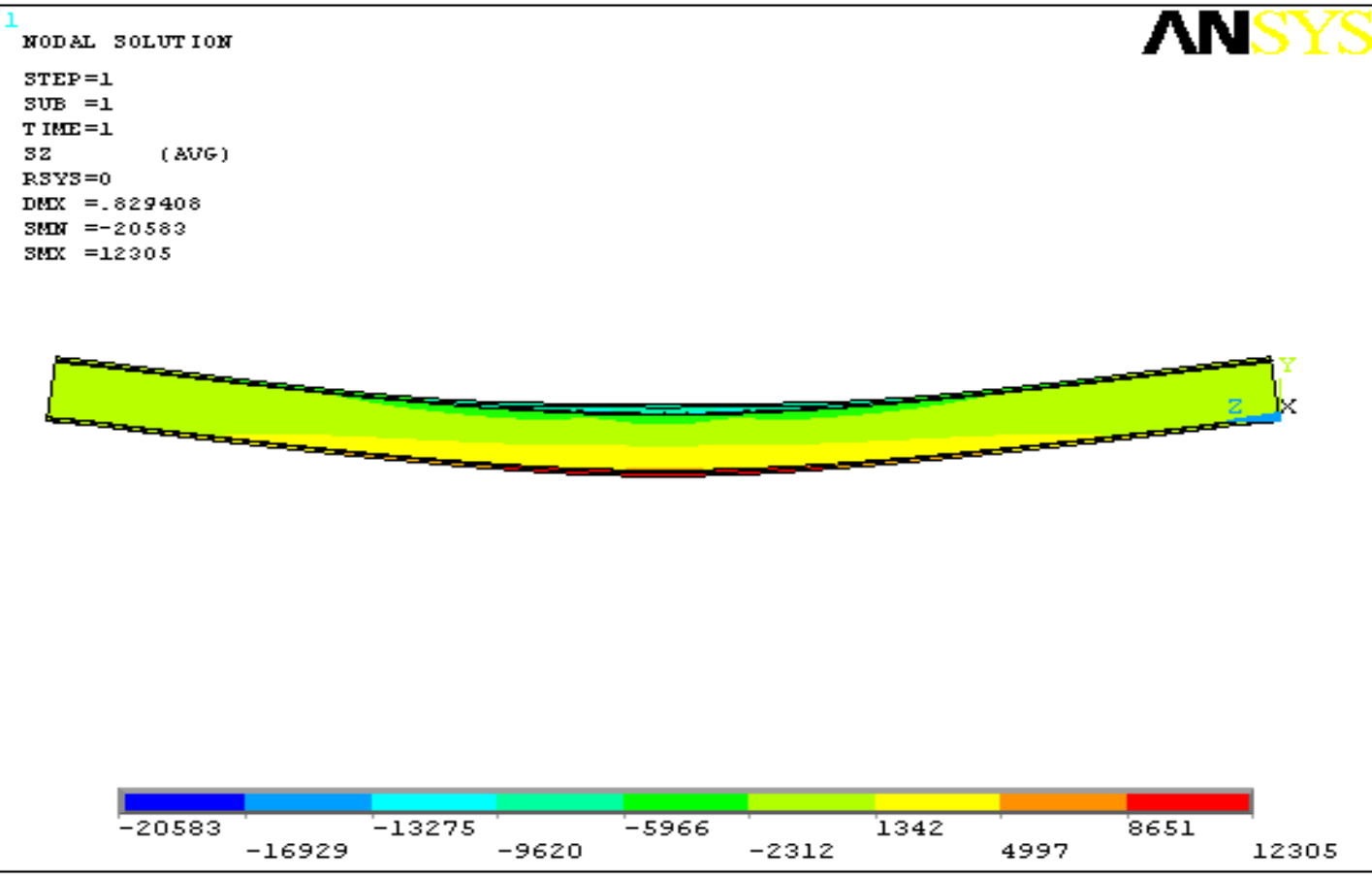

Fig. 5.31 Contour plot of $\sigma_{Z}$ in the side view for a central load of $24 \mathrm{Kips}$ 


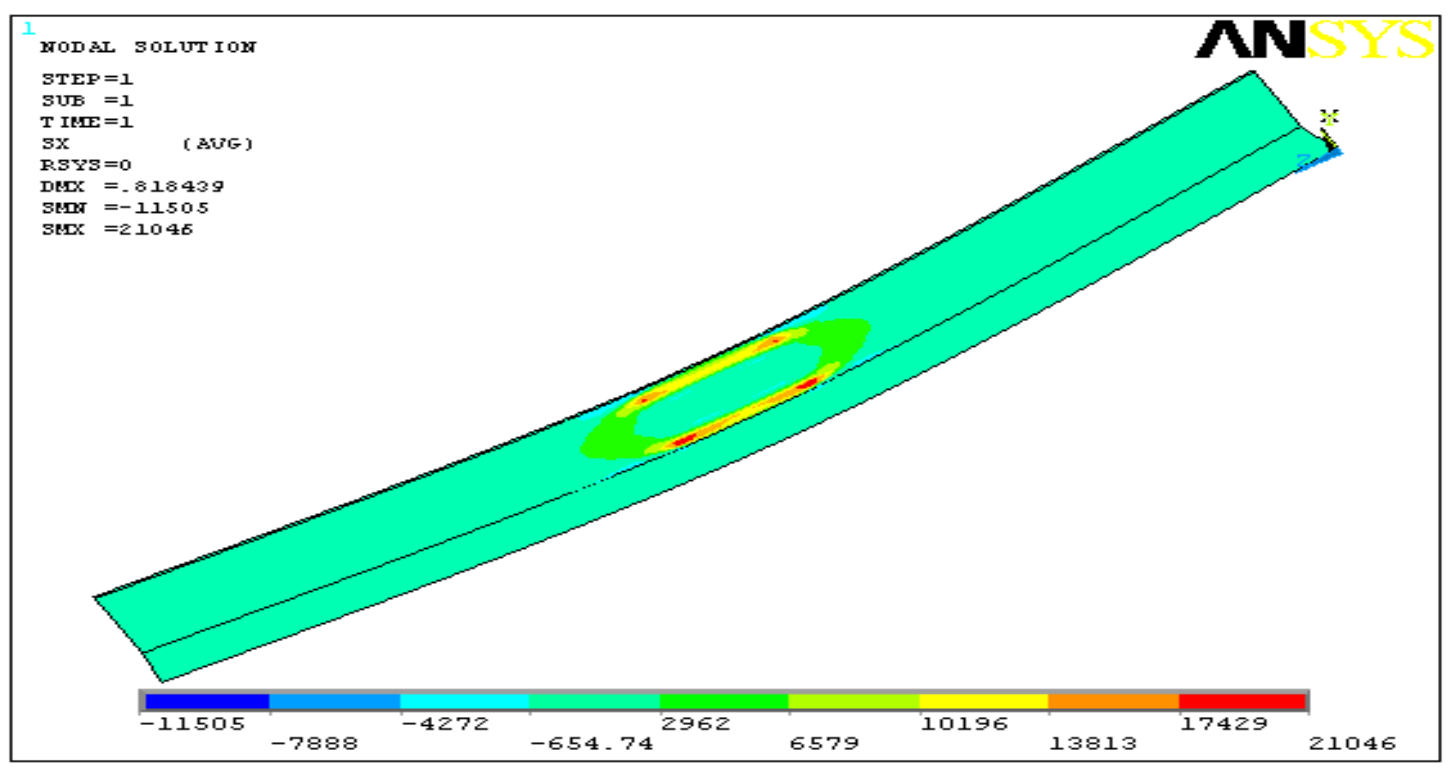

Fig. 5.32 Contour plot of $\sigma_{X}$ in the side view for a central patch load of $24 \mathrm{Kips}$

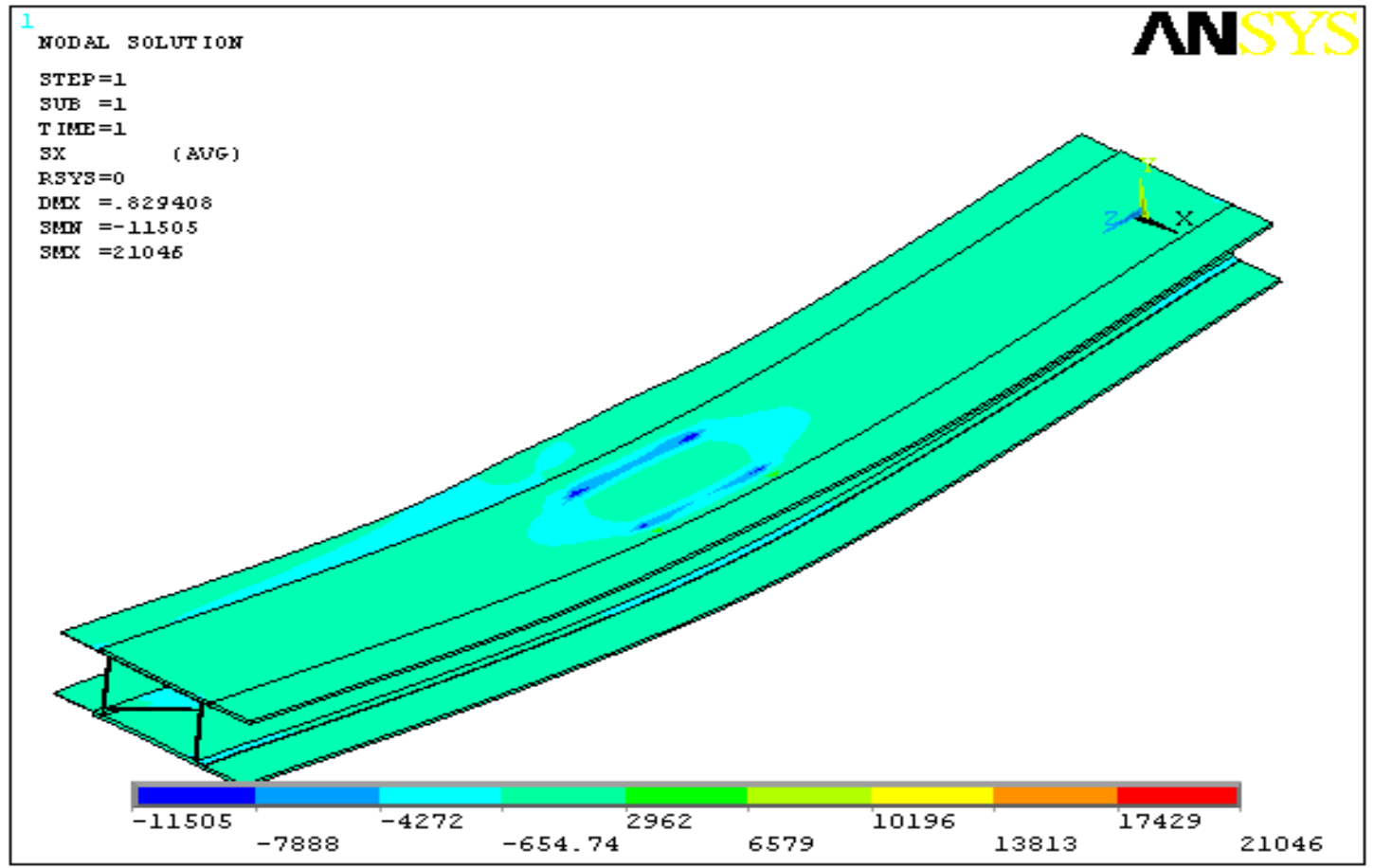

Fig. 5.33 Contour plot of $\sigma_{X}$ for a central patch load of 24 Kips 




Fig. 5.34 Contour plot of $\sigma_{Y}$ for a central patch load of $24 \mathrm{Kips}$

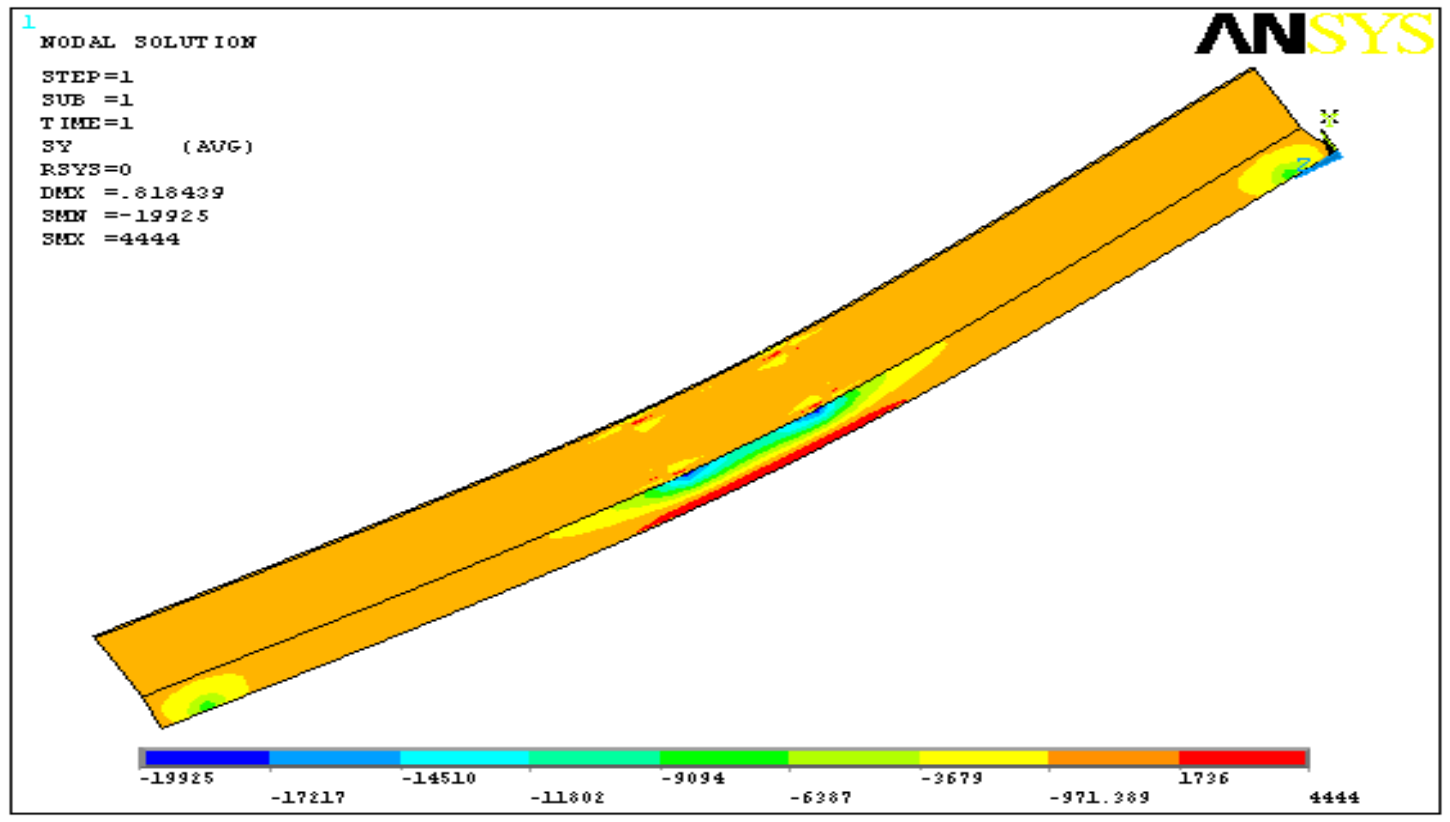

Fig. 5.35 Contour plot of $\sigma_{Y}$ in the side view for a central patch load of $24 \mathrm{Kips}$ 


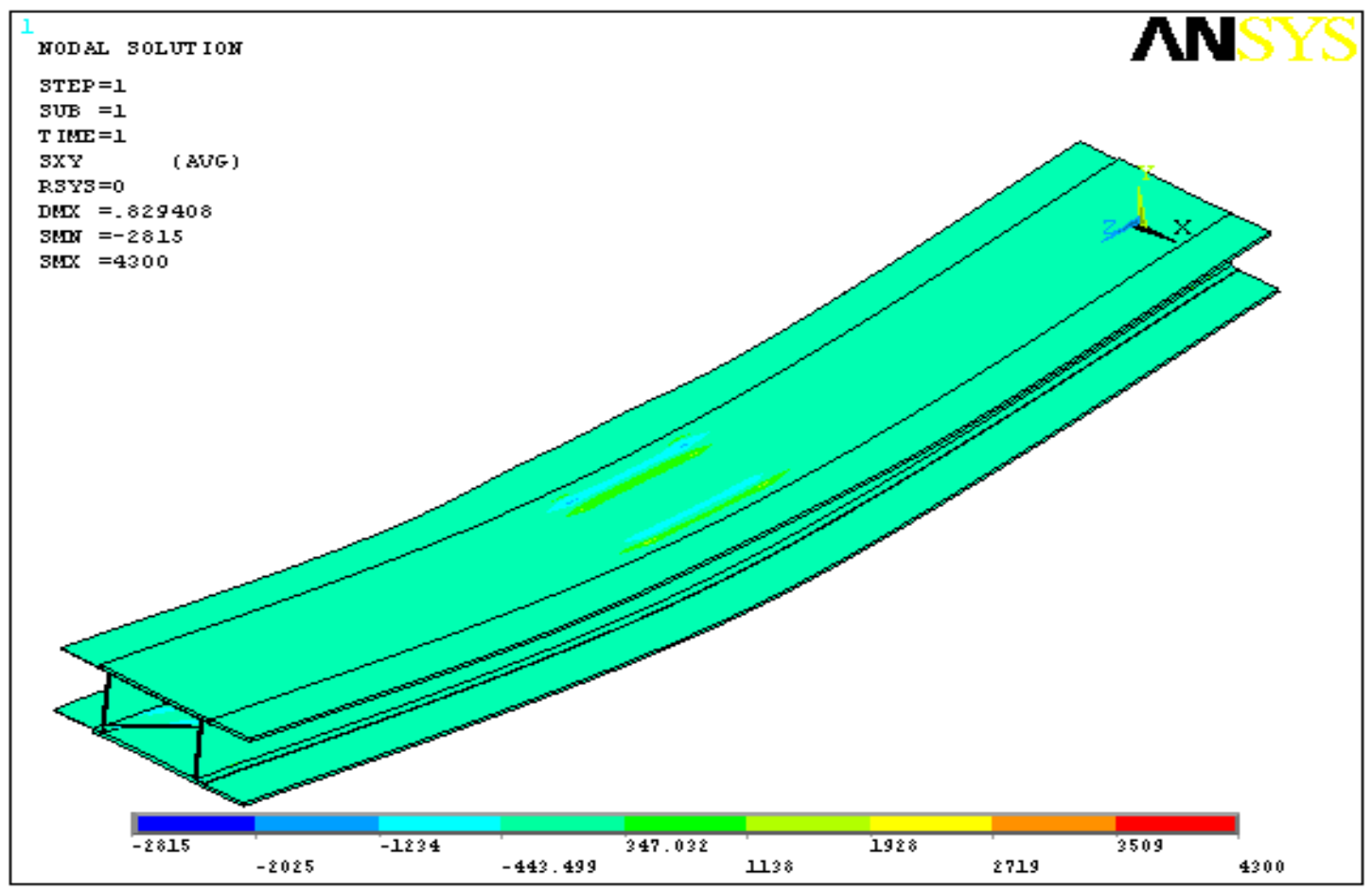

Fig. 5.36 Contour plot of $\tau_{X Y}$ for a central patch load of $24 \mathrm{Kips}$



Fig. 5.37 Contour plot of $\tau_{X Y}$ for a central patch load of 24 Kips 


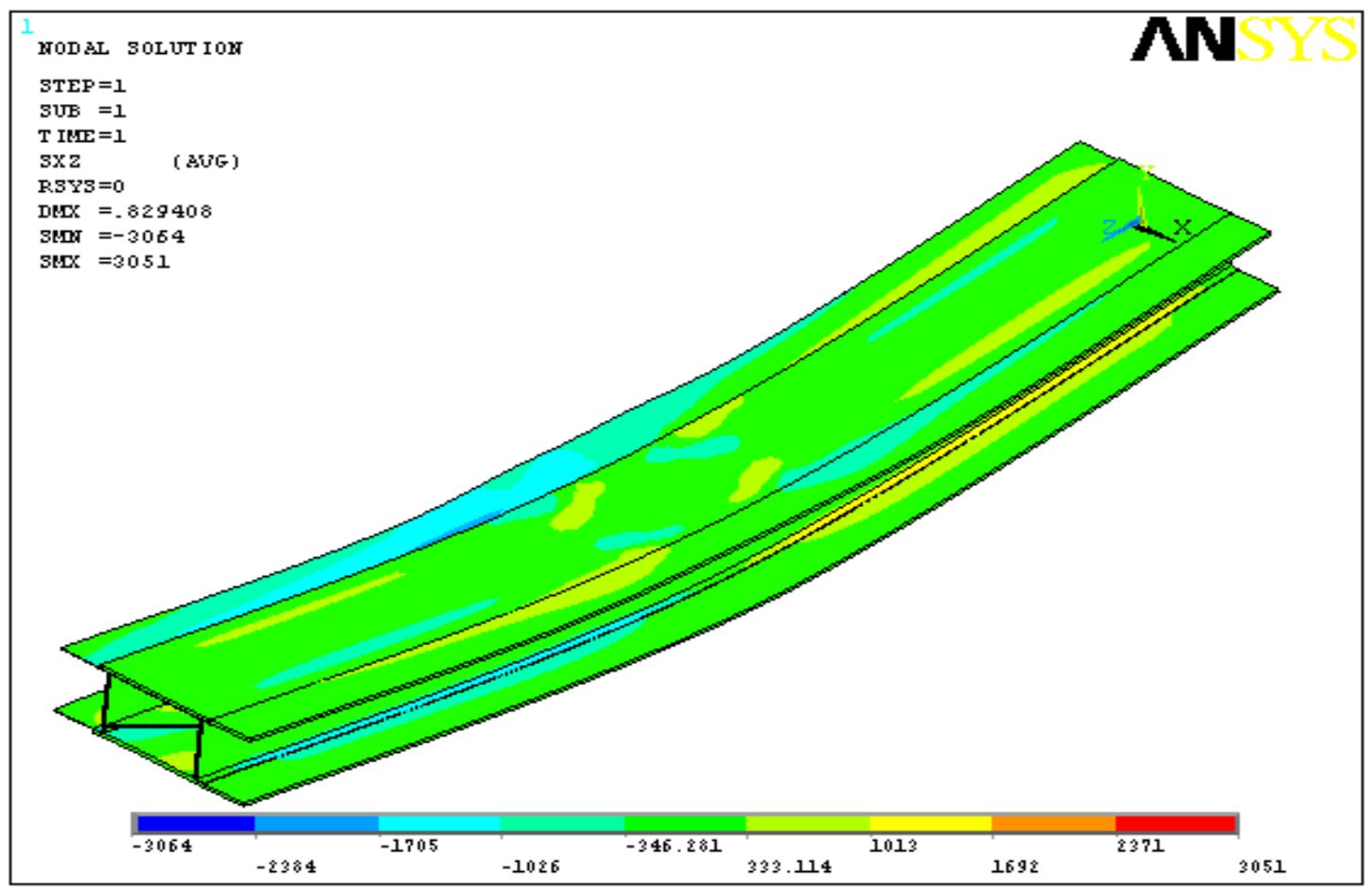

Fig. 5.38 Contour plot of $\tau_{X Z}$ for a central patch load of $24 \mathrm{Kips}$

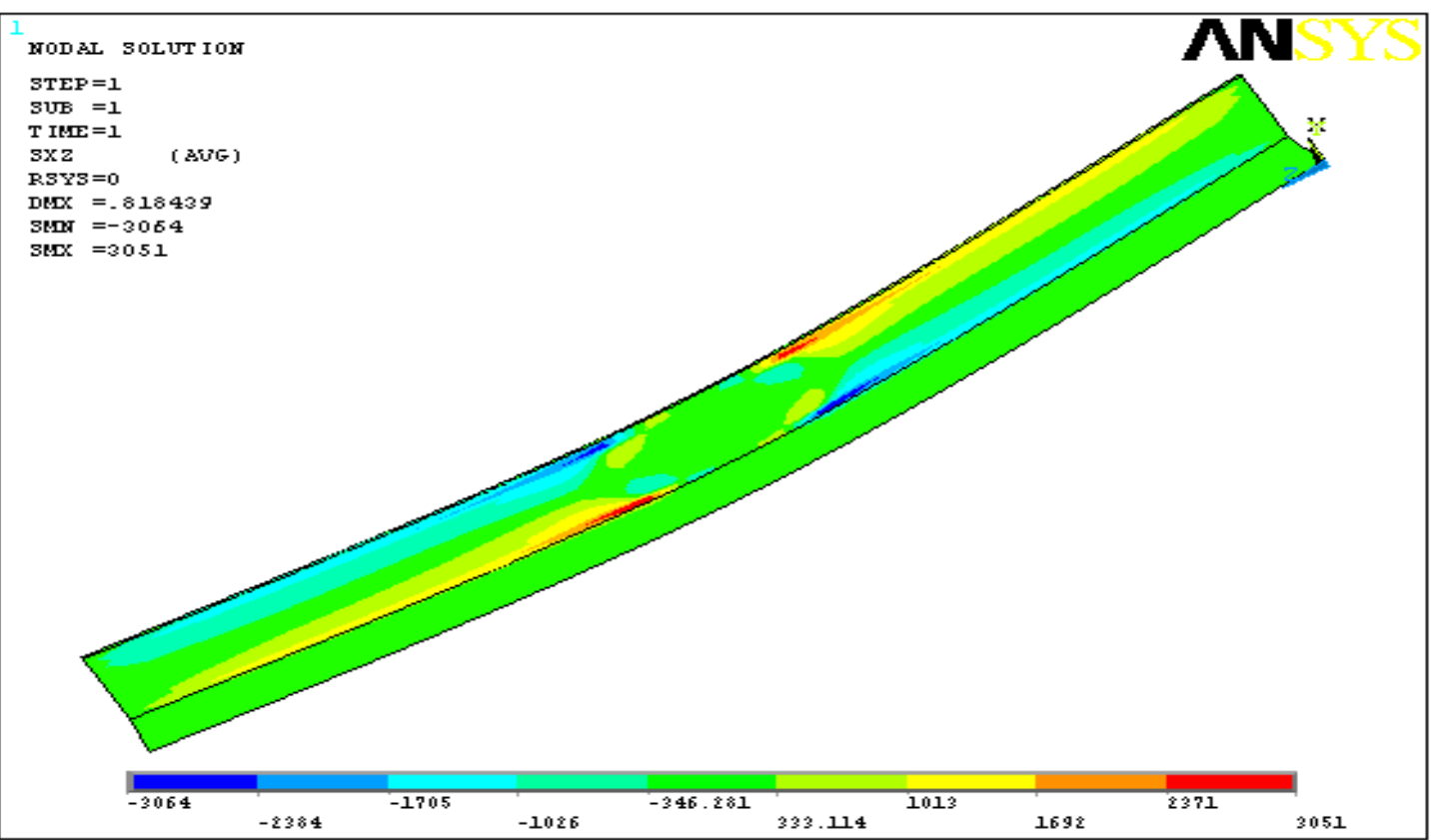

Fig. 5.39 Contour plot of $\tau_{X Z}$ for a central patch load of 24 Kips 


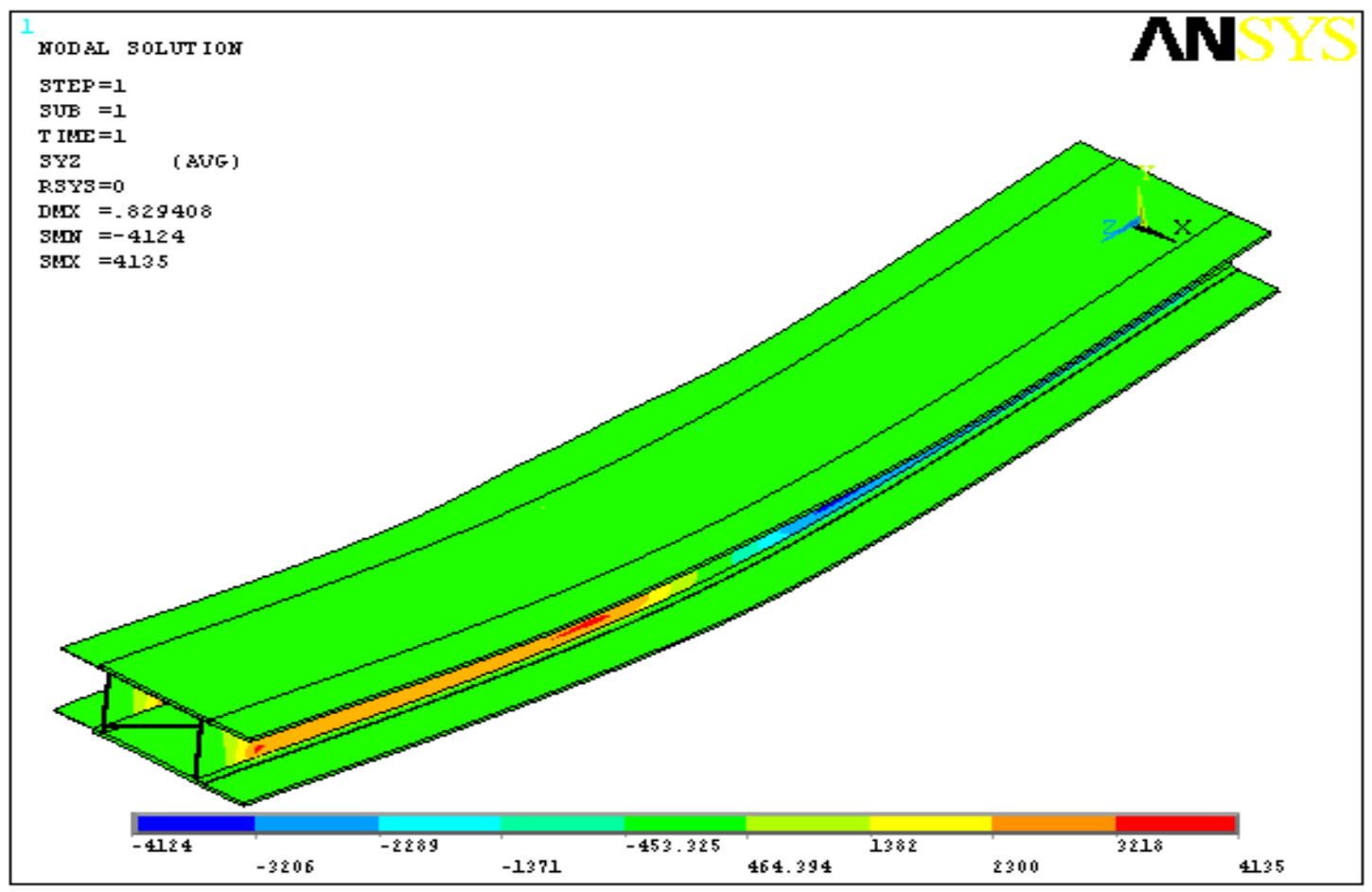

Fig. 5.40 Contour plot of $\tau_{Y Z}$ for a central patch load of 24 Kips



Fig. 5.41 Contour plot of $\tau_{Y Z}$ for a central patch load of $24 \mathrm{Kips}$ 
Contour plots for the strain components $\varepsilon_{X}, \varepsilon_{Y}, \varepsilon_{Z}, \gamma_{X Y}, \gamma_{Y Z}$, and $\gamma_{Z X}$, are presented in Figs. 5.18-5.29. The longitudinal strain $\varepsilon_{Z}$, is represented in Fig. 5.18 as a top view and in Fig. 5.19 as a side view. The phenomenon of top flange in compression, bottom flange in tension, and the maximum absolute strain occurring at mid-span are all as expected. For the applied load of $24 \mathrm{Kips,}$ the maximum compressive strain is 0.002463. The in-plane transverse normal strain $\left(\varepsilon_{X}\right)$ is displayed in Figs. 5.20 and 5.21. While most of the deck undergoes low $\varepsilon_{X}$ values, strain concentration occurs at the corners of the patch load with a maximum value of 0.005971 . Figures 5.22 and 5.23 depict the out-of-plane transverse normal strain $\varepsilon_{Y}$. The maximum positive values occur at the edges of the patch load. The contour plots of the shear strain components $\gamma_{X Y}, \gamma_{Y Z}$, and $\gamma_{Z X}$ are shown in Figs. 5.24-5.29. It is worthwhile to point out that the maximum strain $\gamma_{Y Z}$ due to transverse shear load occurs at the middle of the webs, whereas the components $\gamma_{X Y}$ and $\gamma_{Z X}$ are mainly concentrated near the loading zone. The maximum values of $\gamma_{X Y}$ and $\gamma_{X Z}$ are about 0.0035 while that of $\gamma_{X Z}$ is about 0.0025 .

Figures 5.30-5.41 display contour plots of the normal and shear stress components for a resultant load of 24 Kips. These plots are similar in nature to their strain counterparts. It is seen from Figs. 5.30 and 5.31 of $\sigma_{Z}$ that the maximum compressive stress occurs in the top flange, and the maximum tensile stress in the bottom flange, both at the mid-span of the deck. The maximum absolute value is about 20,500 psi. It is seen from Figs. 5.32 to 5.35 that $\sigma_{X}$ (in-plane) and $\sigma_{Y}$ (transverse) are mostly concentrated at 
the edges of the loading zone with the maximum values around 20,000 psi. The shear stress plots, Figs. 5.36-5.41 indicate that the maximum values are about one-fourth that of normal stress components. Contrast this with the maximum shear strains being nearly of the same value as the normal strains; this affirms the low shear modulus of composites.

\subsection{FAILURE ANALYSIS}

In this section an attempt is made to predict the first ply failure of the Prodeck 8 using the maximum stress criterion, maximum strain criterion and the Tsai-Wu criterion. It should be noted that an automatic progressive ply failure analysis is not featured in ANSYS and thus only the first ply failure is investigated. The failure analysis is performed for patch loads of size 10 "x 20 " and 14 "x 20 ".

Figure 5.42 shows the failure plot for the Prodeck 8 subjected to a patch load of 10 "x 20 " with a resultant load value of 24 kips. The values listed in the failure plots are that of the quality $\xi$, defined in Eq. (4.19), which is the inverse of the strength ratio (R). The maximum $\xi$ value in Fig. 5.42 is 2.372 which implies that according to the maximum stress criterion, the first ply failure occurs at a load value of $P=24 / 2.372=10.11$ kips. It should be noted that first ply failure does not imply failure of the bridge deck. Usually the

first ply fails in the transverse direction but is still capable of resisting higher loads in the fiber direction. Also, the other plies can carry increasing loads as evidenced by the failure load of 36 kips from Howard's (2002) experiments. As seen from Fig. 5.42, the failure seems to occur at the corners of the applied patch load, but this view does not clearly show the actual region where the maximum failure value is reported. As a result, more views are explored to see the regions with maximum failure values. 


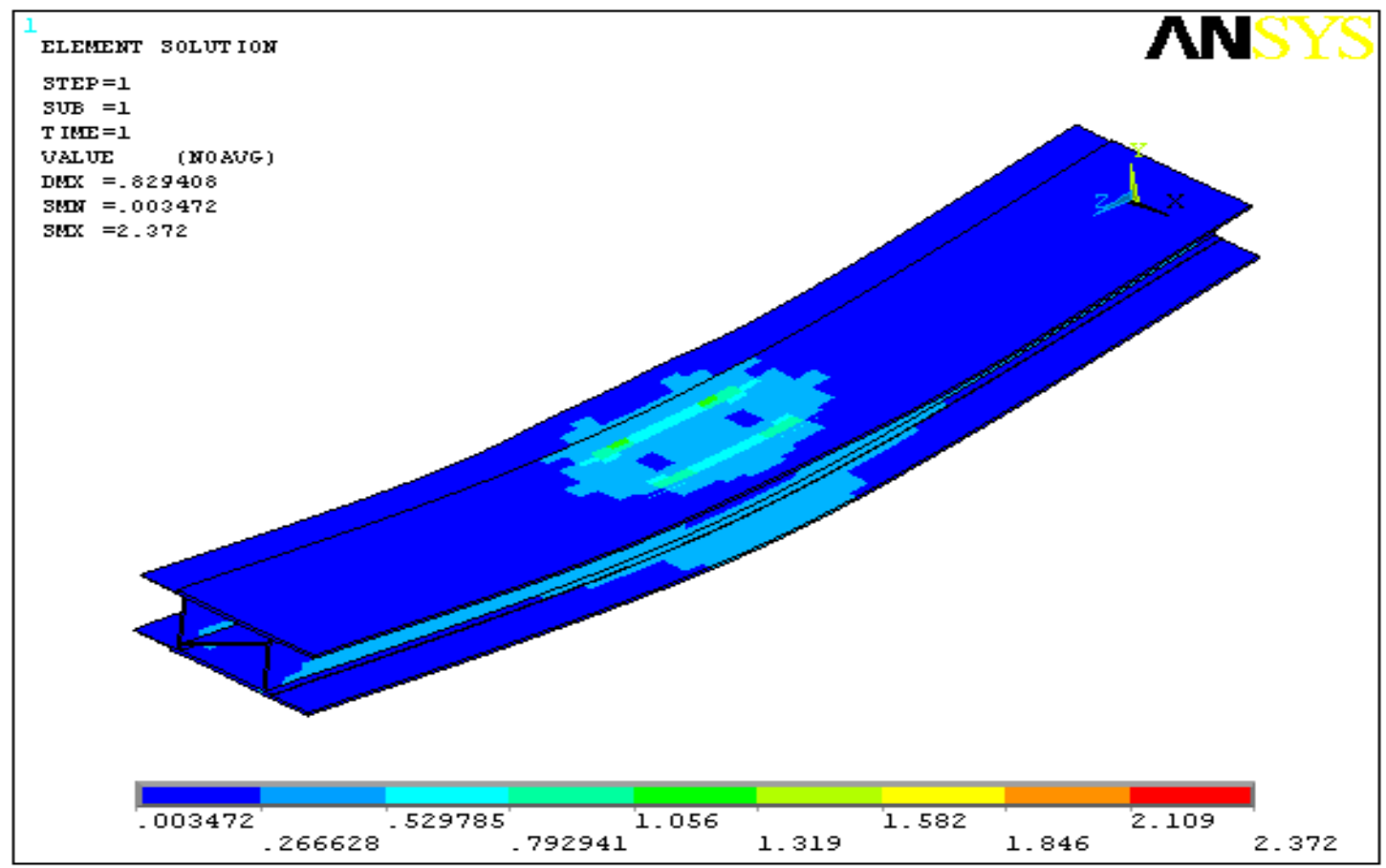

Fig. 5.42 Failure plot of the Prodeck 8 using maximum stress criterion

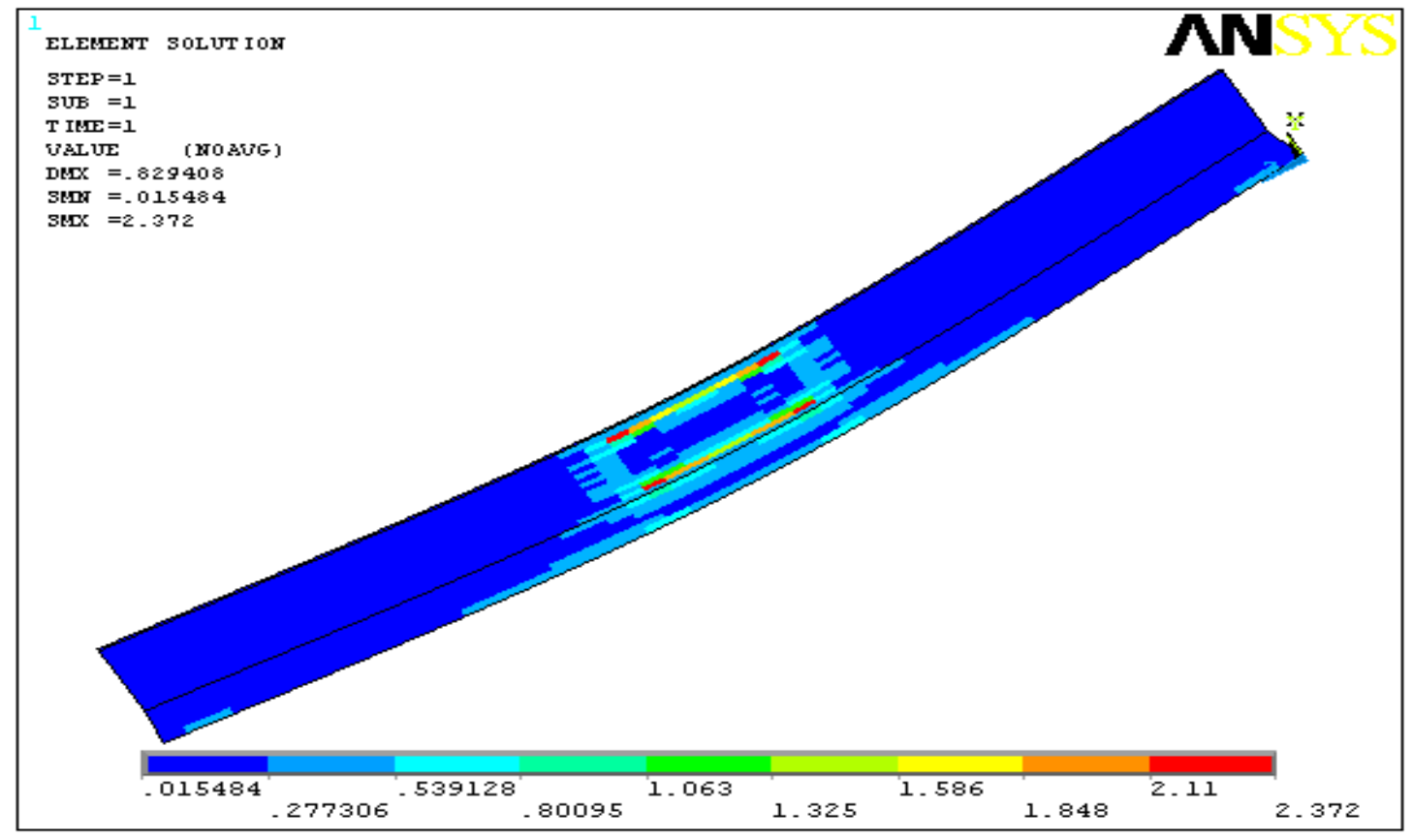

Fig. 5.43 Failure plot for a part of the Prodeck 8 using maximum stress criterion 
Figure 5.43 shows the failure plot for the bottom segment of the top flange and right side of the left web. From Fig. 5.43 we can clearly conclude that the maximum failure value occurs beneath the applied load at the bottom of the top flange. A close analysis of the $\xi$ values of all the layers of the Prodeck 8 indicates that the $0^{0}$ plies (fiber orientation alon the $Z$-axis, longitudinal direction) beneath the applied load at the bottom of the top flange fail first. The ANSYS does not indicate the mode of failure. A careful scrutiny of the stress plots (Figs. 5.30-5.41) along with the strength values (Table 4.2) of the plies indicates that the $0^{0}$ plies fail in the transverse direction. It can be reasonably concluded that failure is due to matrix cracking since the transverse stress $\left(\sigma_{X}\right)$ in the $0^{0}$ plies is tensile and the failure strength, $F_{t 2}$ of 5,900 psi is the lowest among the failure strengths.

The failure analysis is also carried out using the maximum strain criterion and the corresponding failure plots are shown in Figs 5.44 and 5.45.

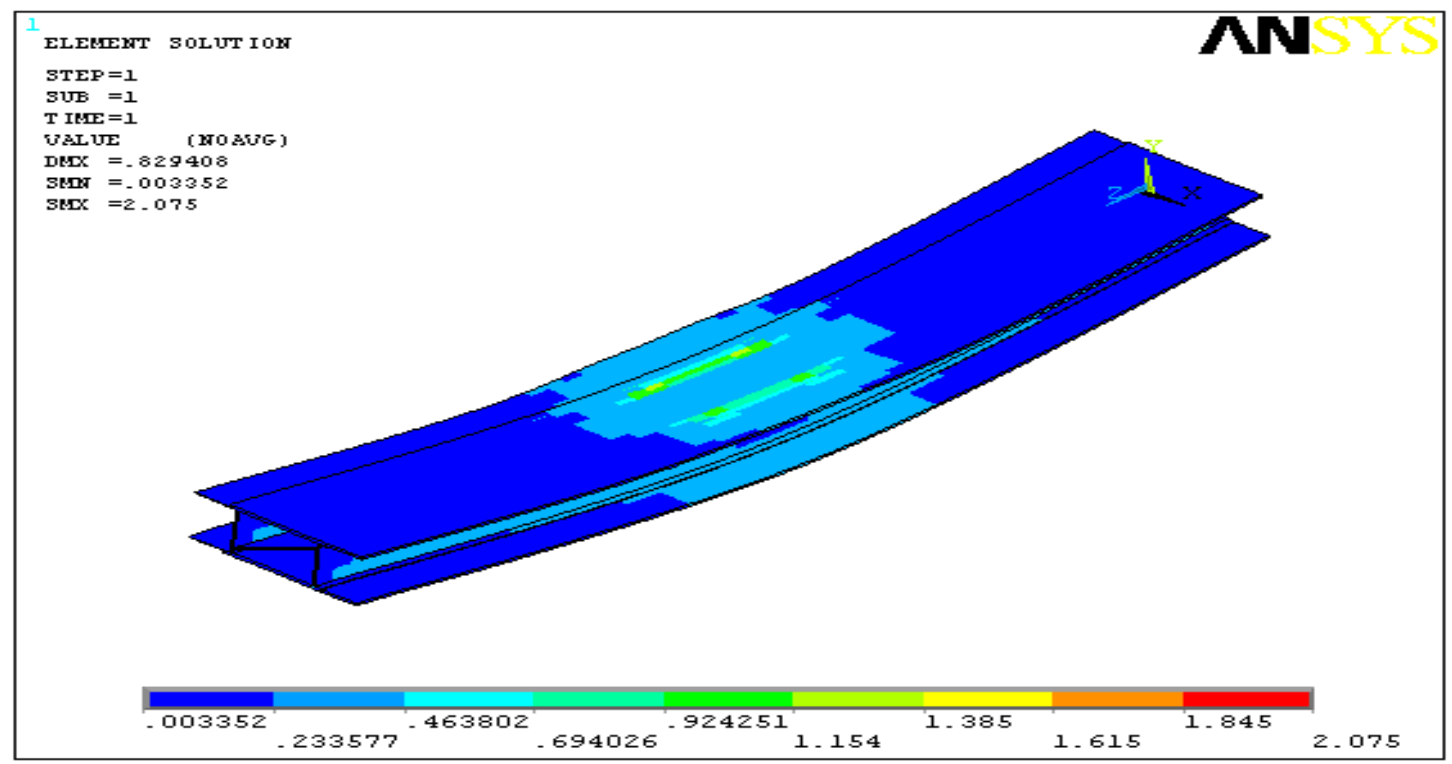

Fig. 5.44 Failure plot of the Prodeck 8 using maximum strain criterion 




Fig. 5.45 Failure plot for a part of the Prodeck 8 using maximum strain criterion

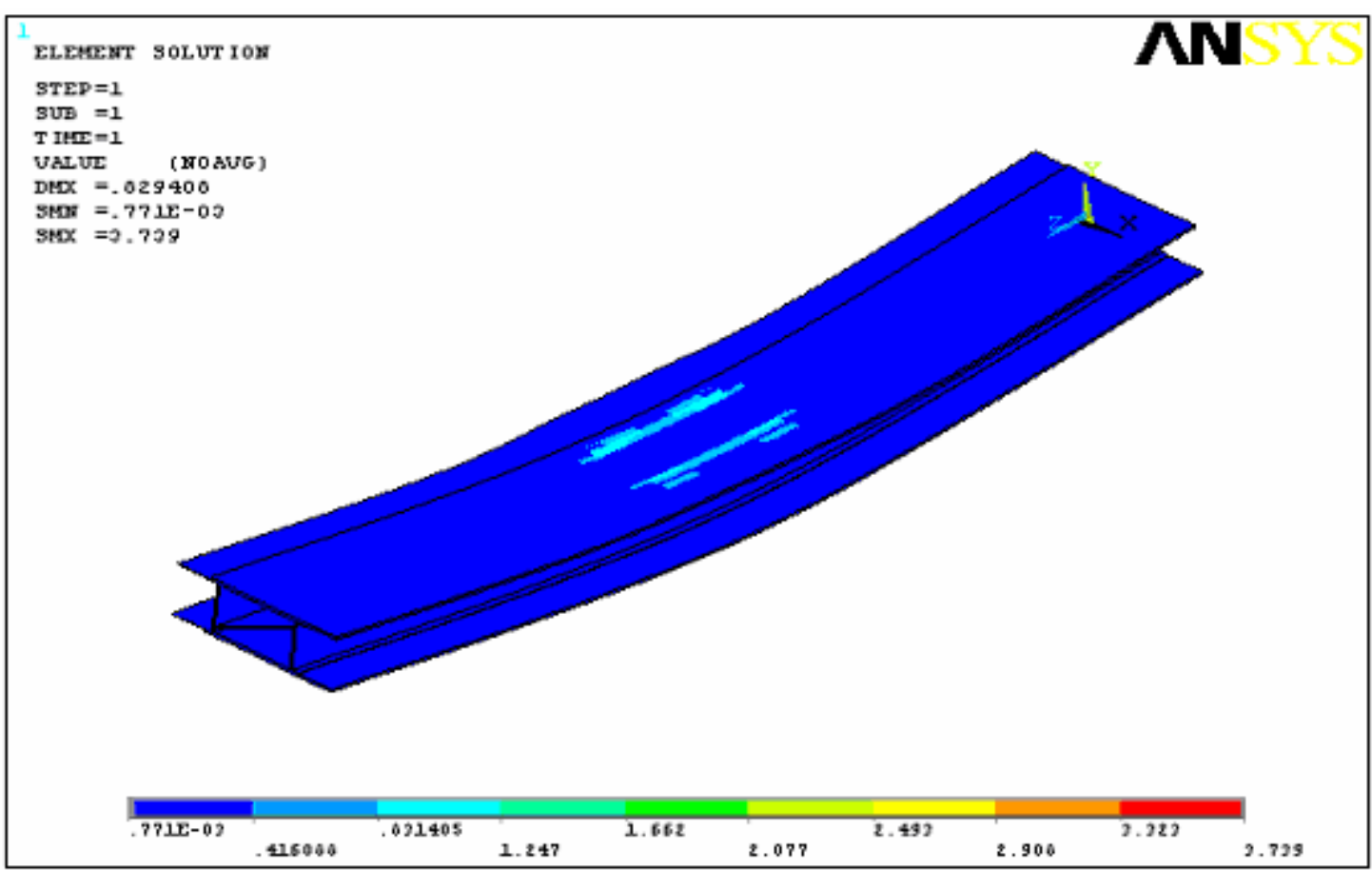

Fig. 5.46 Failure plot of the Prodeck 8 using Tsai-Wu Criterion 


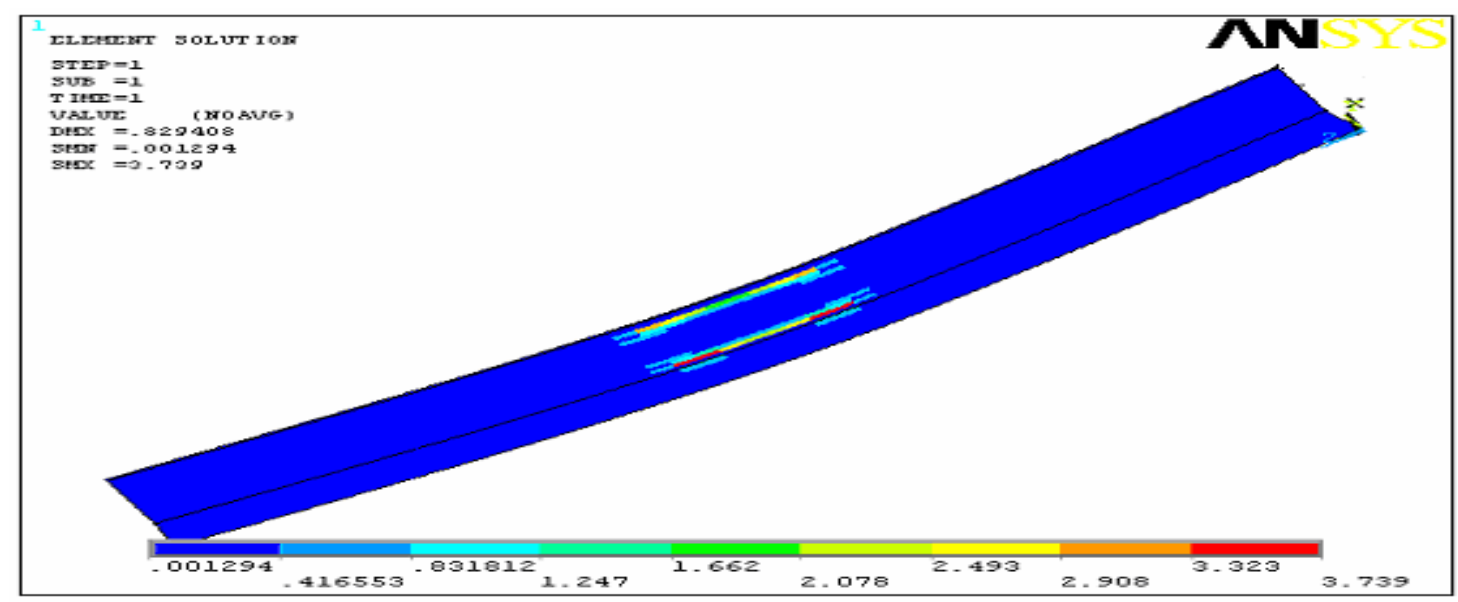

Fig. 5.47 Failure plot for a section of the Prodeck 8 using Tsai-Wu criterion

It is seen from Figs 5.44 and 5.45 that the failure plots using maximum strain criterion are similar to that of the maximum stress criterion with both criterion predicting failure to occur beneath the applied load at the bottom of the top flange. According to the maximum strain criterion, the maximum value of the failure parameter $\xi$ is 2.075 as compared to a value of 2.372 based on the maximum stress criterion. The Tsai-Wu criterion is applied next with the failure plots being as shown in Figs. 5.46 and 5.47. While the failure plots based on the Tsai-Wu criterion are similar to the other two criteria the maximum $\xi$ value of 3.739 is more than one and a half times that of the either of the other two criteria. While the applicability of Tsai-Wu criterion is well established at the coupon level of unidirectional composites, in the current case of a relatively complex structure made of many layers with three different architectures (Fig. 3.3) of 2-D stitched composites, it appears that the Tsai-Wu criterion may not yield accurate results. The experiments conducted by Howard (2002) indicate a Punching shear failure at the edges of the loading plate when the resultant load is about 36 kips. The three theories considered in the present analysis do predict failure in the same region, at least qualitatively. 
The above failure analysis does not indicate the web or the web-flange intersection to be very critical. This may be due to the fact that the patch load of 10 "x 20 " does not span the web locations. To test this hypothesis, the failure analysis is repeated with a patch load of 14 "x 20 " with a resultant load value of 24 kips.

Figures 5.48-5.53 show the failure plots for the Prodeck 8 subjected to a patch load of 14 " $\mathrm{x} 20$ " using the maximum stress criterion, maximum strain criterion and TsaiWu criterion. It can be seen from these figures that that failure is predicted to occur at the web section near the top flange or at the web flange intersection. Howard's (2002) experiments also indicate failure due to web flange separation in the case of the 14 " $\mathrm{x} 20$ " patch load. It should be noted that the maximum $\xi$ values are highest $(0.795)$, implying the first ply failure to occur at a load of $P=24 / 0.795=30.2$ kips for the maximum stress criterion and lowest $(0.519)$ for the Tsai-Wu criterion, implying the first ply failure to occur at a load of $P=24 / 0.519=46.24$ kips.

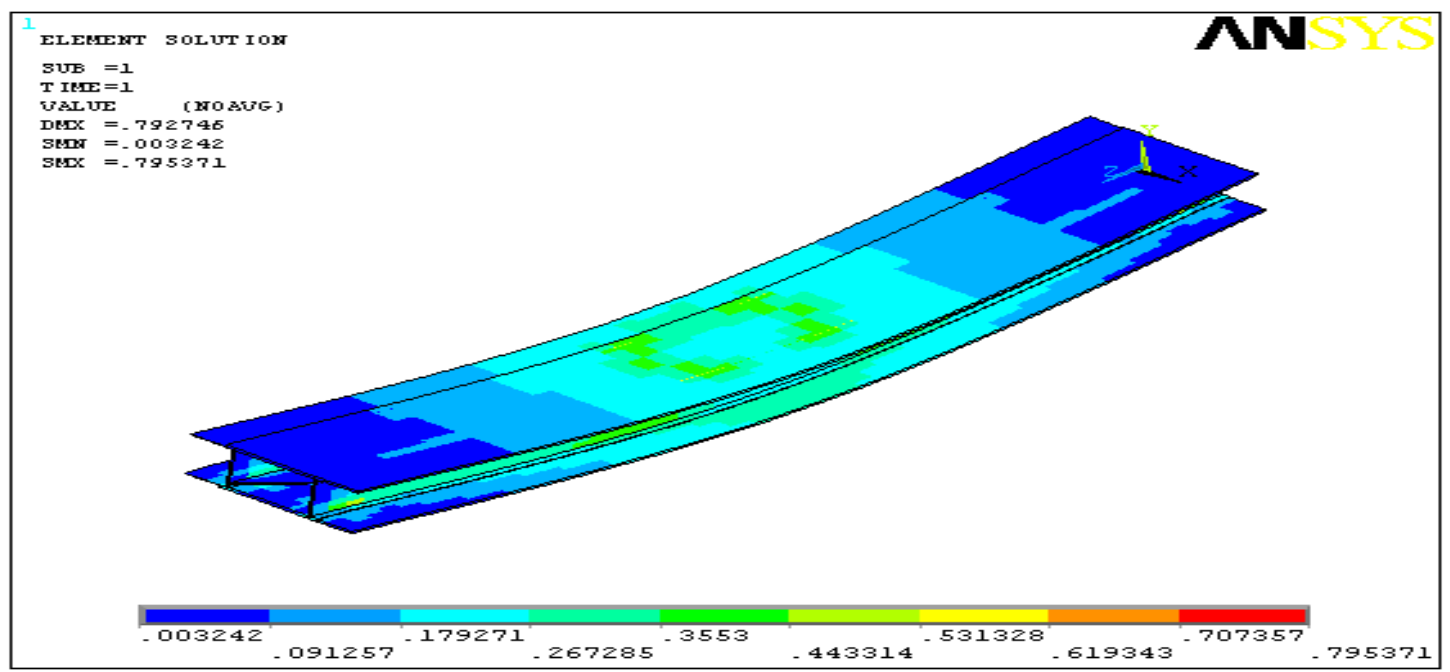

Fig. 5.48 Failure plot of the Prodeck 8 using maximum stress criterion subjected to a patch load of 14"x 20" 




Fig. 5.49 Failure plot for a part of the Prodeck 8 using maximum stress criterion subjected to a patch load of 14 "x 20 "

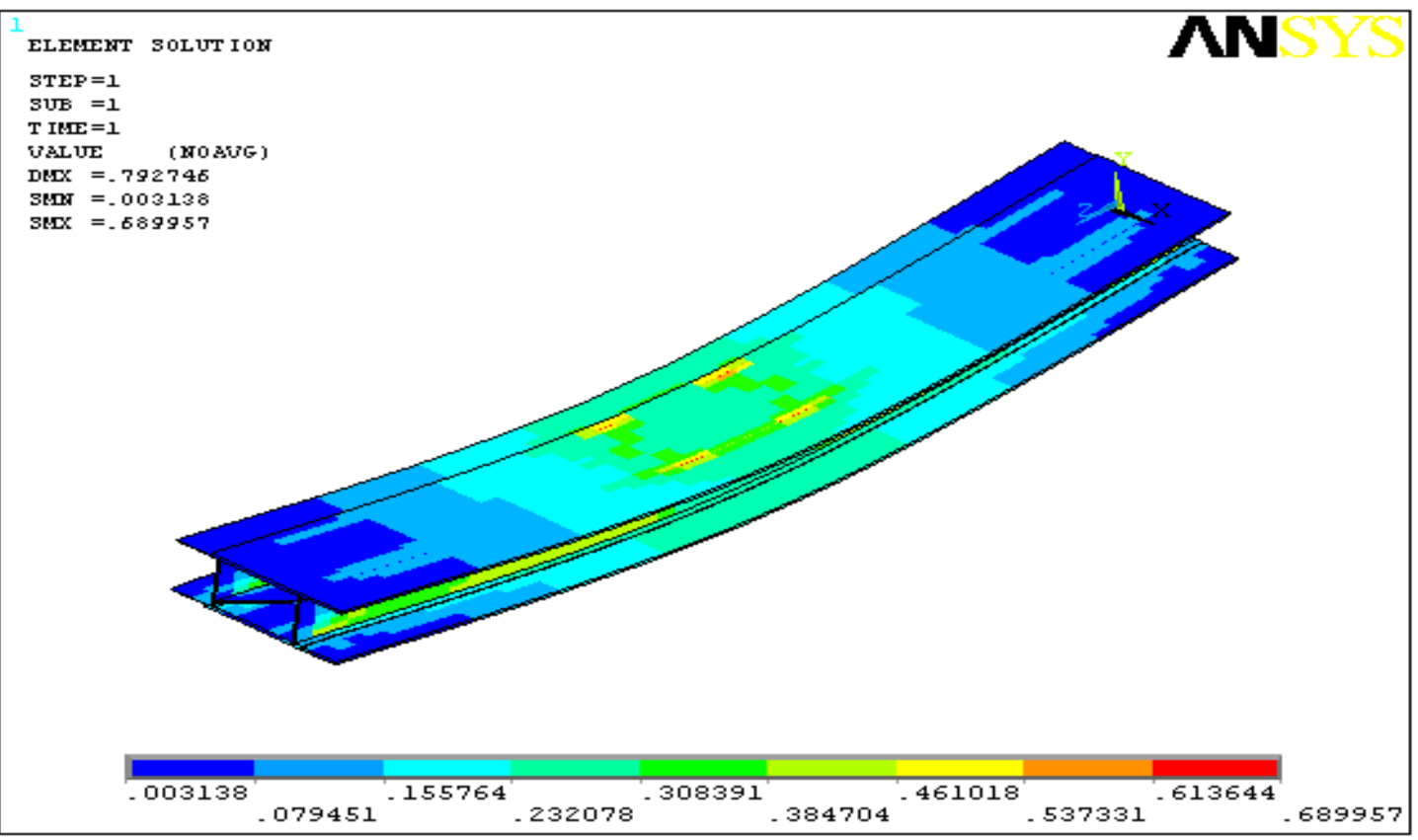

Fig. 5.50 Failure plot of the Prodeck 8 using maximum strain criterion subjected to a patch load of 14 ”x 20" 


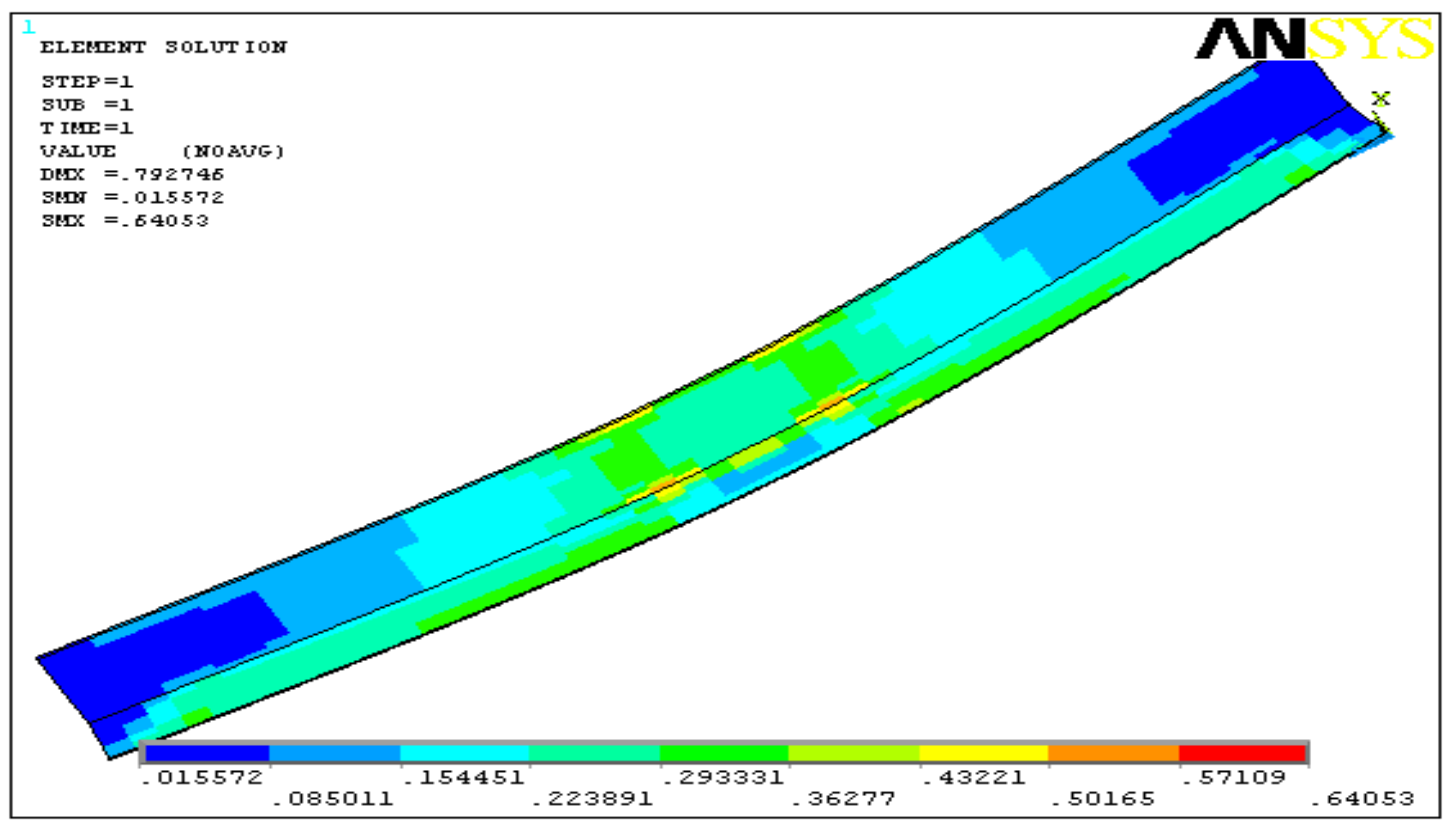

Fig. 5.51 Failure plot for a part of the Prodeck 8 using maximum strain criterion subjected to a patch load of 14 "x 20 "

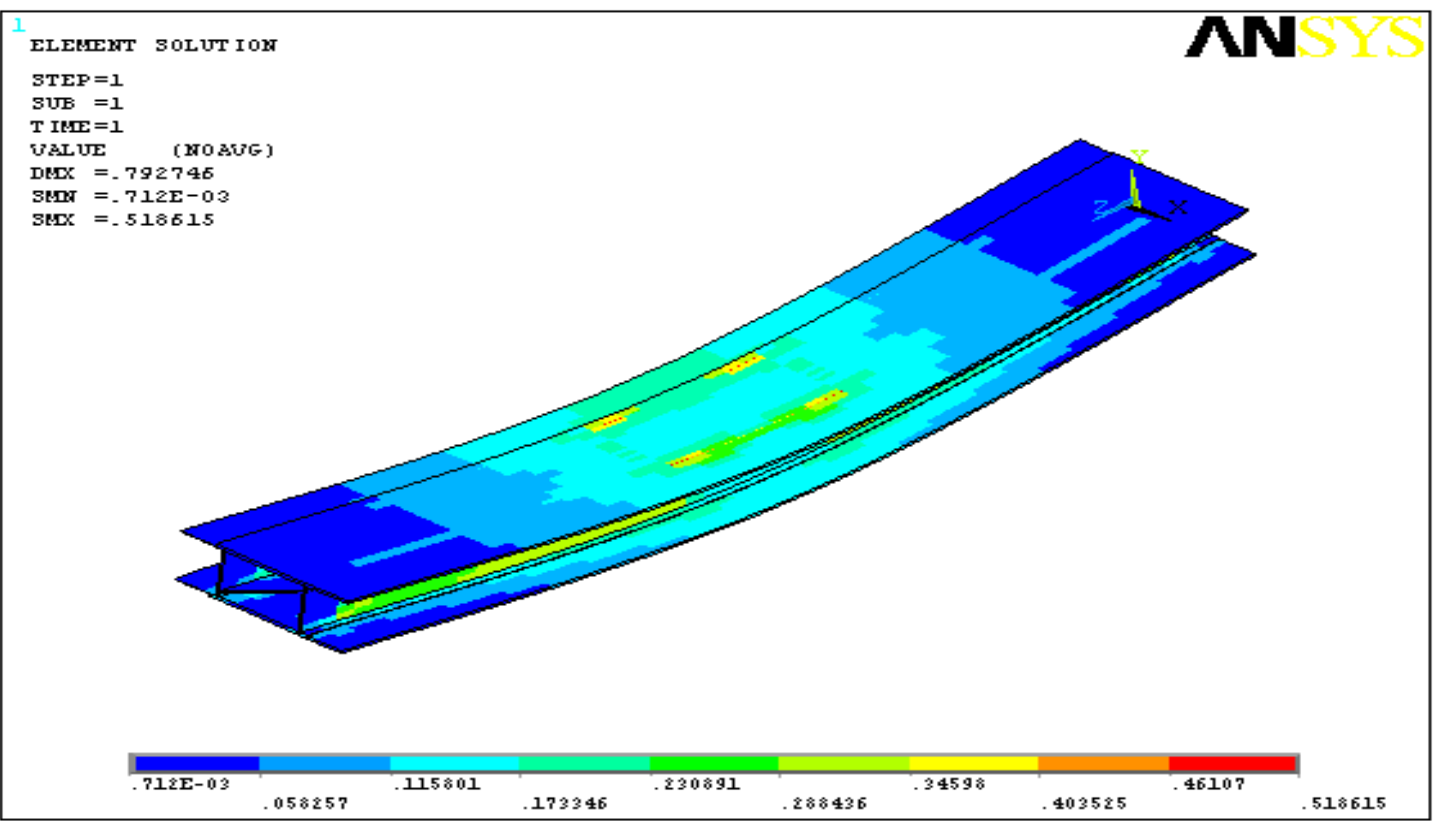

Fig. 5.52 Failure plot of the Prodeck 8 using Tsai-Wu criterion subjected to a patch load of 14 "x 20 " 


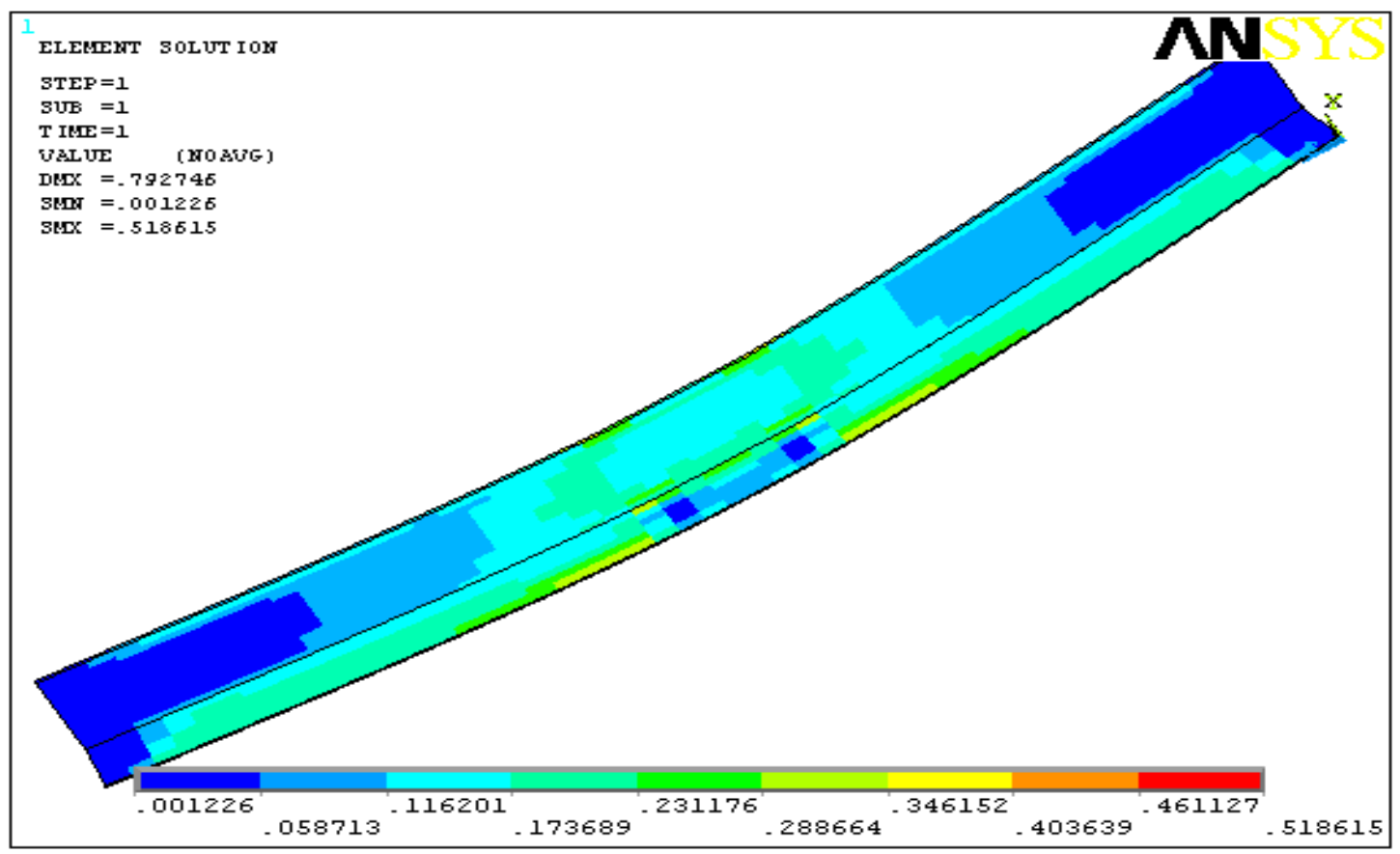

Fig. 5.53 Failure plot for a part of the Prodeck 8 using Tsai-Wu criterion

On detailed observation and analysis of the layers, the conclusion is that the $0^{0}$ fiber fails first. It is believed that this might be due to the matrix cracking in the transverse direction.

\subsection{BUCKLING ANALYSIS}

A buckling analysis is conducted on the present ANSYS model of the Prodeck 8. The Prodeck 8 of 12" length is subjected to a patch load of 12" x 12". The top flange is restricted to have same displacement in the $Y$ direction to achieve pure buckling. Eigenvalue buckling analysis method is used to obtain the critical load for the deck. The buckled shape is shown in the Fig. 5.54. The critical load is found to be 183 kips, which is much larger than the experimental critical load of 45 kips obtained by Howard (2002). Also buckling analysis is carried out on just the web section without the stiffener as shown in the Fig. 5.55. The considered web has dimensions of 0.35 " thickness, 12" 
length and 7" height and is subjected to a load at the top over the area of 12 "x 0.35 ". The critical load for the web section is found to be 33 Kips.

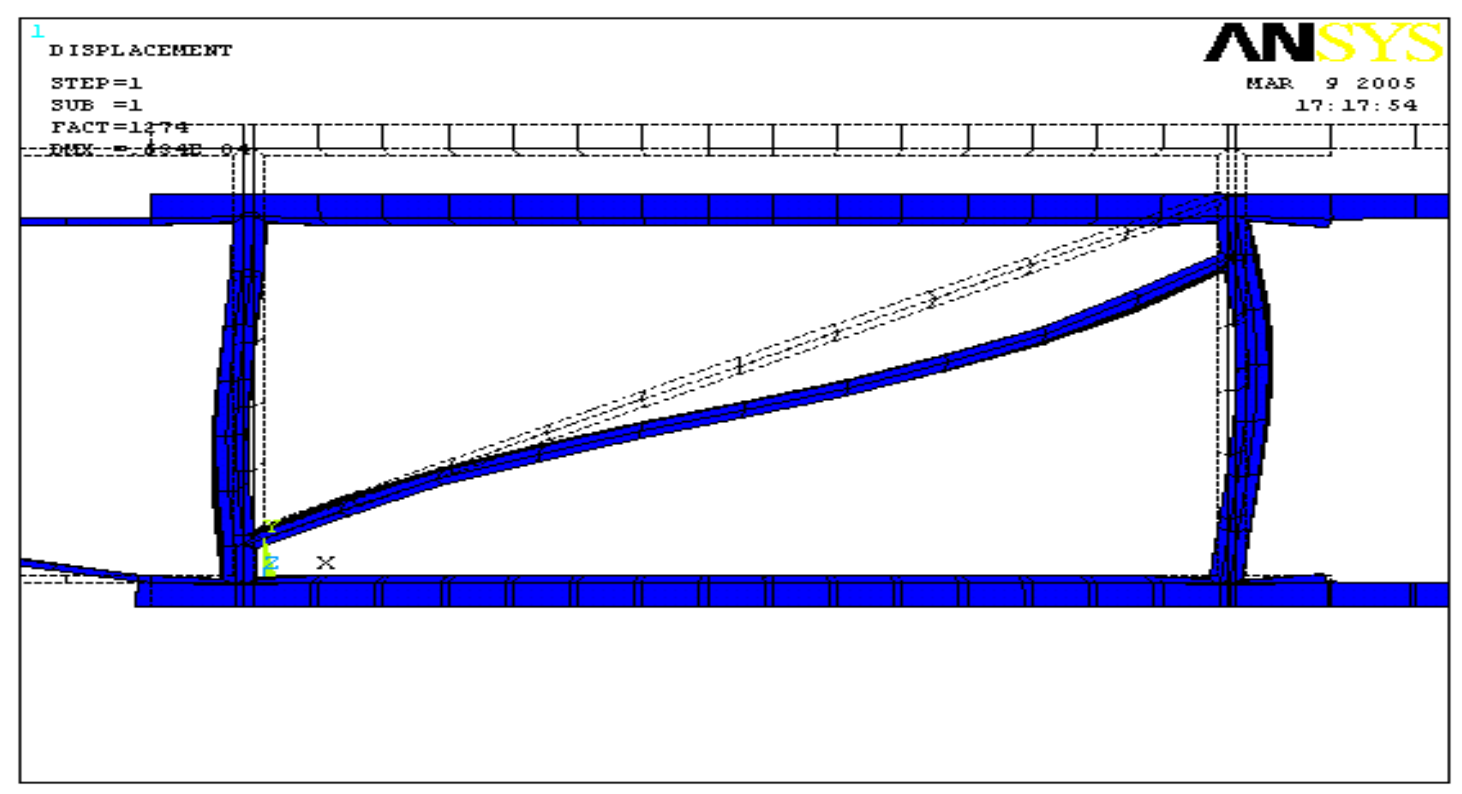

Fig. 5.54 Buckled shape of the Prodeck 8



Fig. 5.55 Buckled shape of the web 


\section{CHAPTER 6}

\section{CONCLUSIONS AND RECOMMENDATIONS}

\subsection{INTRODUCTION}

Prodeck 8 has been evaluated for static response under 3-point bending and buckling load types using the finite-element software ANSYS. Also a first-ply failure analysis has been carried out. This chapter contains conclusions drawn from the current finite-element analysis as well as recommendations on further analysis.

\subsection{CONCLUSIONS}

- $\quad$ Successfully modeled the Prodeck 8 using ANSYS.

- The deflection analysis has showed excellent correlation with experimental results obtained by a previous researcher.

- Comparisons of present strain values at selected locations with previous experimental values has indicated very good correlation.

- The equivalent flexural rigidity and Young's modulus of the prodeck 8 based on a transverse load model are found to be $1.04\left(10^{9}\right) \mathrm{lb} \bullet$ in. $^{2}$ and $3.47\left(10^{6}\right)$ psi.

- When corrected for shear effects, the equivalent flexural rigidity value of $1.007\left(10^{9}\right) \mathrm{lb} \cdot$ in. $^{2}$ was nearly identical to that of the experimentally obtained value of the previous research.

- The equivalent flexural rigidity and Young's modulus of the prodeck 8 based on strain values corresponding to the transverse load case are found to be $1.26\left(10^{9}\right)$ lb x in. ${ }^{2}$ and $4.21\left(10^{6}\right)$ psi respectively. 
- Due to the present limitations of $A N S Y S$, only the first ply failure analysis has been done.

- Based on the failure analysis performed using maximum strain criterion, maximum stress criterion and Tsai-Wu criterion, it is found that the $0^{0}$ fibers at the bottom of the top flange, directly under the applied patch load of 10 "x 20 " are the first layers to fail. And it is believed that the failure occurs due to the matrix cracking in the transverse direction.

- For a patch load of 14 "x 20 " it is found that the failure occurred at the web flange intersection and again it is observed that $0^{0}$ fibers are the first to fail.

- Based on the buckling analysis of the Prodeck 8 , the critical load is found to be 183 kips which is very high compared to the experimentally determined critical load of 45 kips reported by the previous researcher.

- The buckling analysis of just the web section resulted in a critical load of 33 kips.

\subsection{RECOMMENDATIONS}

- Progressive ply failure of the Prodeck 8 can be studied by writing some finiteelement codes to be used with $A N S Y S$ or using another commercially available finite-element software, which is capable of progressive ply failure.

- A thorough study can be carried out to determine the failure modes of the Prodeck 8 under different load types.

- The critical load of the Prodeck 8 should be verified by performing a suitbable buckling analyis. 


\section{REFERENCES}

Ahmad, S.H. and Plecnik, J. M., 1989, "Transfer of Composite Technology to Design and Construction of Bridges," U.S. DOT Report, September.

ANSYS v 7.1, 2004, "ANSYS theory reference manual"

Barbero, E.J., 1998, "Introduction to Composite Materials Design," Taylor and Francis, Philadelphia.

Brown, B.J., 1998, "Design Analysis of Single-Span Advanced Composite Deck-andStringer Bridge Systems," Master's Thesis, West Virginia University, Morgantown, WV.

Chandrashekara, K. and Nanni, A., 2000, "Experimental Testing and Modeling of a FRP Bridge," Final Report, Missouri Department of Transportation, Research, Development and Technology.

GangaRao, H., Thippeswamy, H., Shekar, V. and Craigo, C., 1999, "Development of Glass Fiber Reinforced Polymer Composite Bridge Deck," SAMPE Journal, V 35, n 4.

Henry, J.A., 1985, "Deck Girders System for Highway Bridges Using Fiber Reinforced Plastics," Master's Thesis, North Carolina State University, NC.

Howard, I., 2002, "Development of Lightweight FRP Bridge Deck Designs and Evaluations," Maser's Thesis, West Virginia University, Morgantown, WV.

McGhee, K.K., Barton, F.W and Mckeel, W.T., 1991, "Optimum Design of Composite Bridge Deck Panels," Advanced Composite Materials in Civil Engineering Structures, Proceedings of the Specialty Conference, A.S.C.E., Las Vegas, Nevada,

Mongi, A.N.K., 1991, "Theoretical and Experimental Behavior of FRP Floor System," Master's Thesis, West Virginia University, Morgantown, WV.

Punyamurthula, D., 2004, "Structural Performance of Low-Profile FRP Composite Cellular Modules," Master's Thesis, West Virginia University, Morgantown, WV.

Shekar, V., 2000, "Advancement in FRP Composites Using 3D Stitched Fabrics and Enhancement in FRP Bridge Deck Component Properties," Master's Thesis, West Virginia University, Morgantown, WV.

Temeles, A.B., 2001, "Field and Laboratory Tests of a Proposed Bridge Deck Panel Fabricated from Pultruded Fiber Reinforced Polymer Components," Master's Thesis, Virginia Polytechnic Institute and State University, Blacksburg, VA.

Tsai, S.W., and Hahn, T.H., 1980, "Introduction to Composite Materials," Technomic Publishing Company, Inc. 
Wang, S.D., 2004, “The Elusive Theory for Failures in Composite Materials," Proceedings of a seminar, Drexel University.

Zhou, A., 2002 "Stiffness and Strength of Fiber Reinforced Polymer Composite Bridge Deck Stystems," Ph.D Dissertation, Virginia Polytechnic Institute and State University, Blacksburg, VA.

Zureick, A., 1997, "Fiber-Reinforced Polymeric Bridge Decks," Proceedings of the National seminar on Advanced Composite Material Bridges, FHWA, 1997. 


\section{APPENDIX A}

\section{SHEAR MODULUS AND SHEAR CORRECTION}

\section{A.1 Shear Modulus}

The equivalent shear modulus $G$ of the Prodeck 8 is calculated as follows. First, the angle of twist at the free end of the beam of the web $\left(\theta_{w}\right)$ and that of the flange $\left(\theta_{f}\right)$ from the torsional analysis (Section 5.3) are obtained using Figs. A-1 and A-2 and are found to be

$$
\begin{aligned}
& \theta_{w}=5.026 \times 10^{-4} \mathrm{rad} \\
& \theta_{f}=3.999 \times 10^{-4} \mathrm{rad} .
\end{aligned}
$$

The average angle of twist of the Prodeck 8 is calculated as

$$
\theta=\frac{\theta_{\mathrm{w}}+\theta_{\mathrm{f}}}{2}=4.5125 \times 10^{-4} \mathrm{rad}
$$

The shear modulus of the Prodeck 8 is calculated as

$$
G=\frac{T L}{J \theta}=\frac{1135(128.75)}{342.02\left(4.5125 \times 10^{-4}\right)}=0.9465 \times 10^{6} \mathrm{psi}
$$

Note that the applied torque at the free end is $1135 \mathrm{lb} \bullet$ in. and the length of the deck considered for the torsional analysis is 128.75 in.

\section{A.2 Shear correction in transverse loading analysis}

Using the shear modulus value obtained using Eq. (A-2), the deflection due to shear $\left(\delta_{S}\right)$ is calculated as 


$$
\delta_{s}=\frac{P L}{4 G A}=\frac{24000(120)}{4\left(0.9465 \times 10^{6}\right) 27.04}=0.02813 \text { in. }
$$

Thus the total deflection $(\delta)$, due to shear deflection $\left(\delta_{S}\right)$ and bending deflection $\left(\delta_{B}\right)$ (Section 5.2), is calculated as

$$
\delta=\delta_{S}+\delta_{B}=0.02813+0.8295=0.8576 \text { in } .
$$

The equivalent flexural rigidity and Young's modulus for the Prodeck 8 based on total deflection are calculated as

$$
\begin{aligned}
& E I=\frac{P L^{3}}{48 \delta}=\frac{24000\left(120^{3}\right)}{48(0.8576)}=1.007 \times 10^{9} \mathrm{lb} \bullet \text { in. }^{2} \\
& E=\frac{E I}{300}=3.358 \times 10^{6} \mathrm{psi}
\end{aligned}
$$

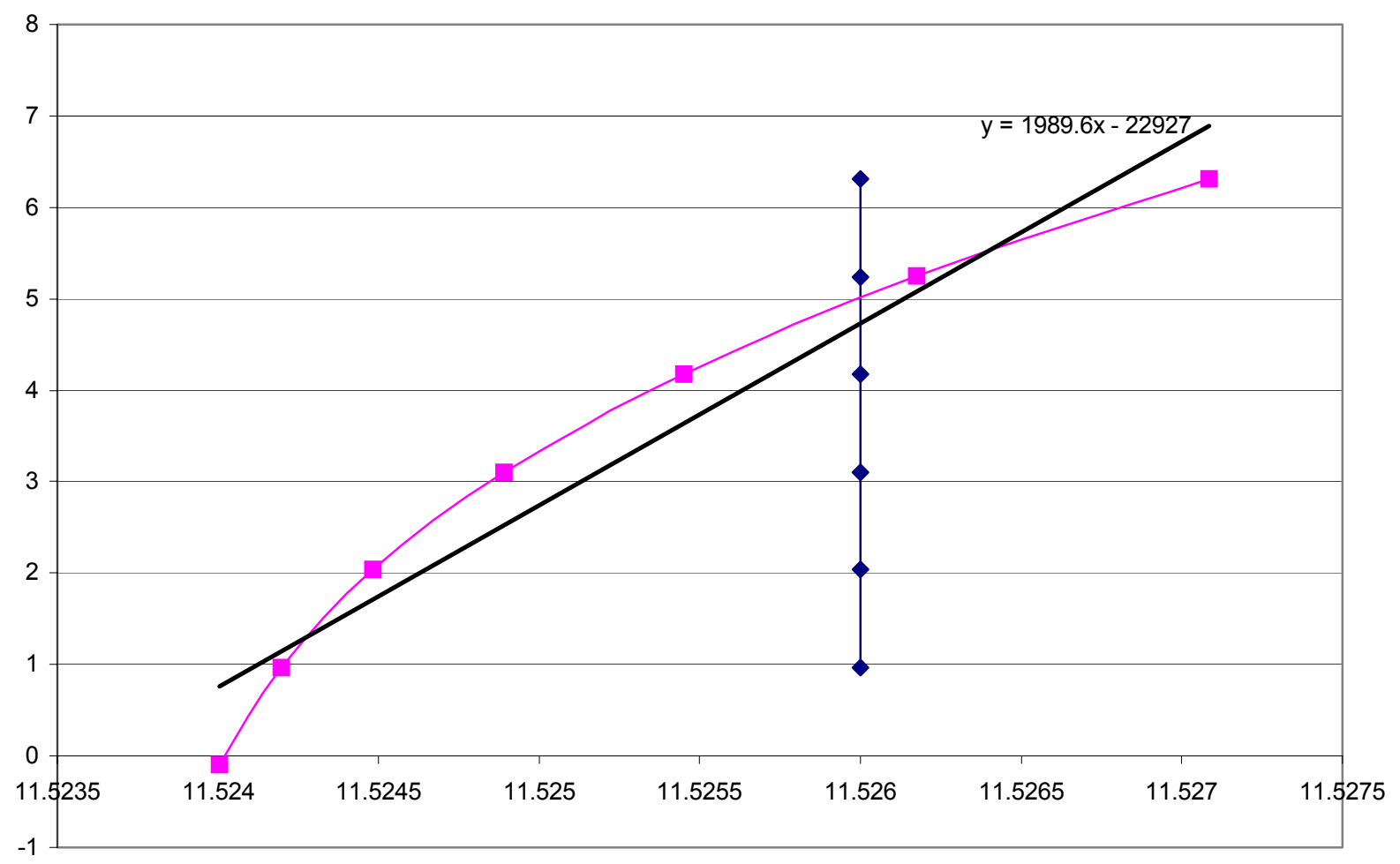

$$
\rightarrow-\text { Undeformed web } \quad-\text { Deformed web Linear fit of deformed web }
$$

Fig. A-1 Linear fit of the angle of twist for the web of the Prodeck 8 


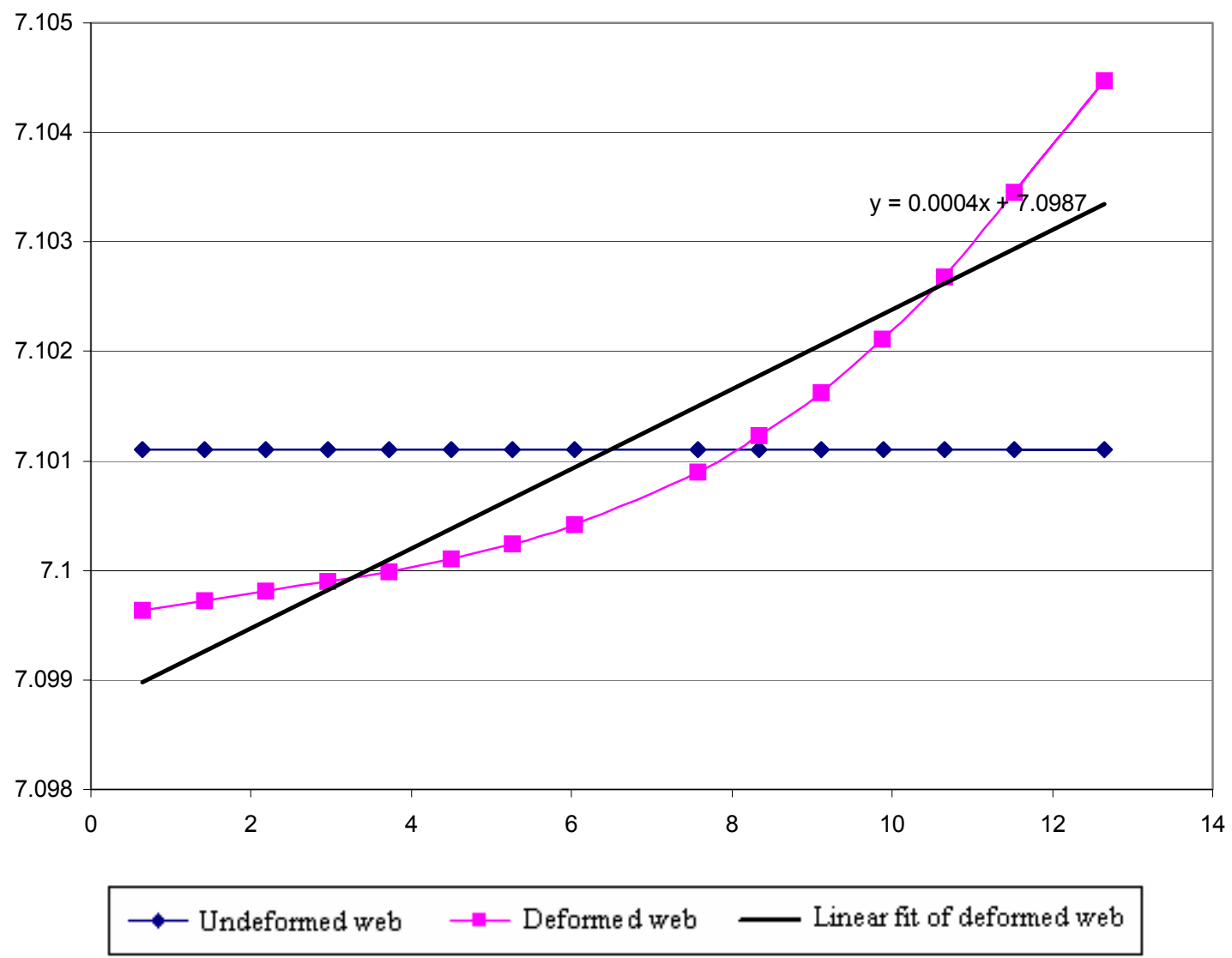

Fig. A-2 Linear fit of the angle of twist for the flange of the Prodeck 8 


\section{APPENDIX B \\ PRODECK 8 SUBJECTED TO PURE BENDING MOMENT}

Figure B-1 shows the boundary conditions and load applied on the Prodeck 8 to achieve pure moment. As shown in the figure, the deck of length $130 \mathrm{in}$. is fixed at one end and on the other end, equal and opposite forces of 120 psi are applied on the top and bottom flanges over an area of 11.55 "x 0.398 ", thus creating a pure bending moment of magnitude $4193 \mathrm{lb} \bullet$ in.

Figure B-2 shows the contour plot of the transverse deflection for the Prodeck 8 under the pure bending moment. The maximum deflection is found to be $0.0278 \mathrm{in}$. and the equivalent flexural rigidity and Young's modulus are calculated as shown below.

$$
\delta=\frac{M L^{2}}{2 E I}
$$

Using Eq. (B-1) the equivalent flexural rigidity is found to be $1.274 \times 10^{9} \mathrm{lb} \bullet$ in $^{2}$ and the Young's modulus is found to be $4.24 \times 10^{6} \mathrm{psi}$. 


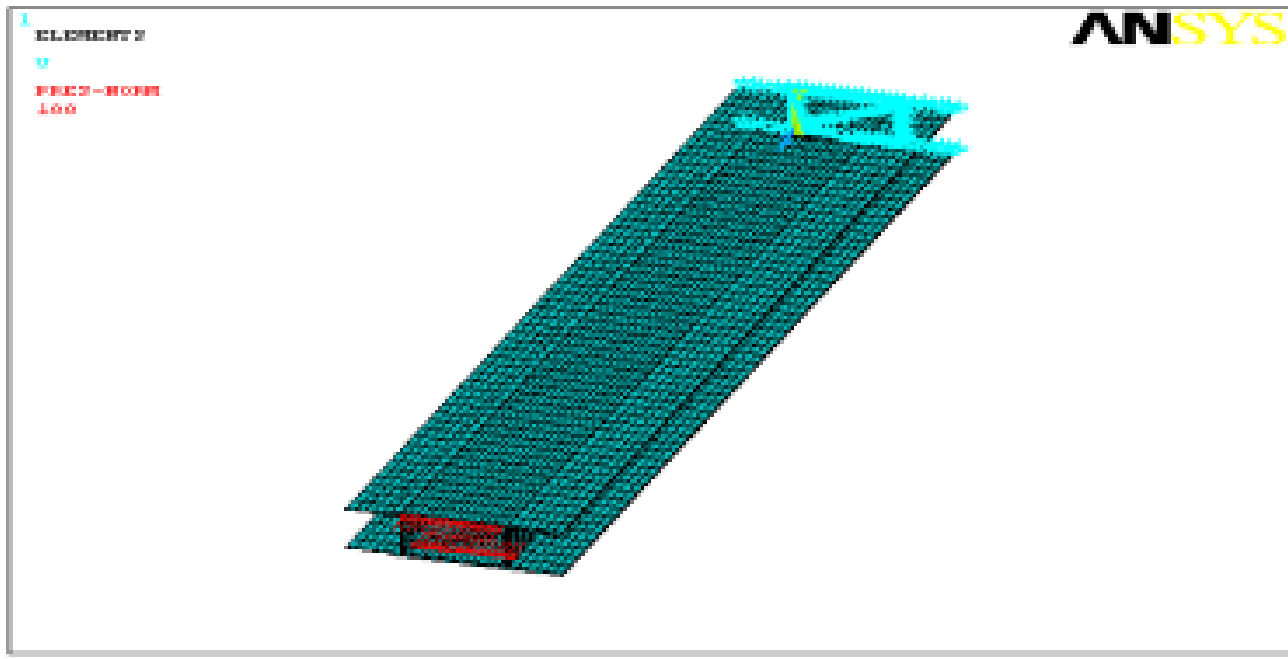

Fig. B-1 Prodeck 8 subjected to pure bending moment

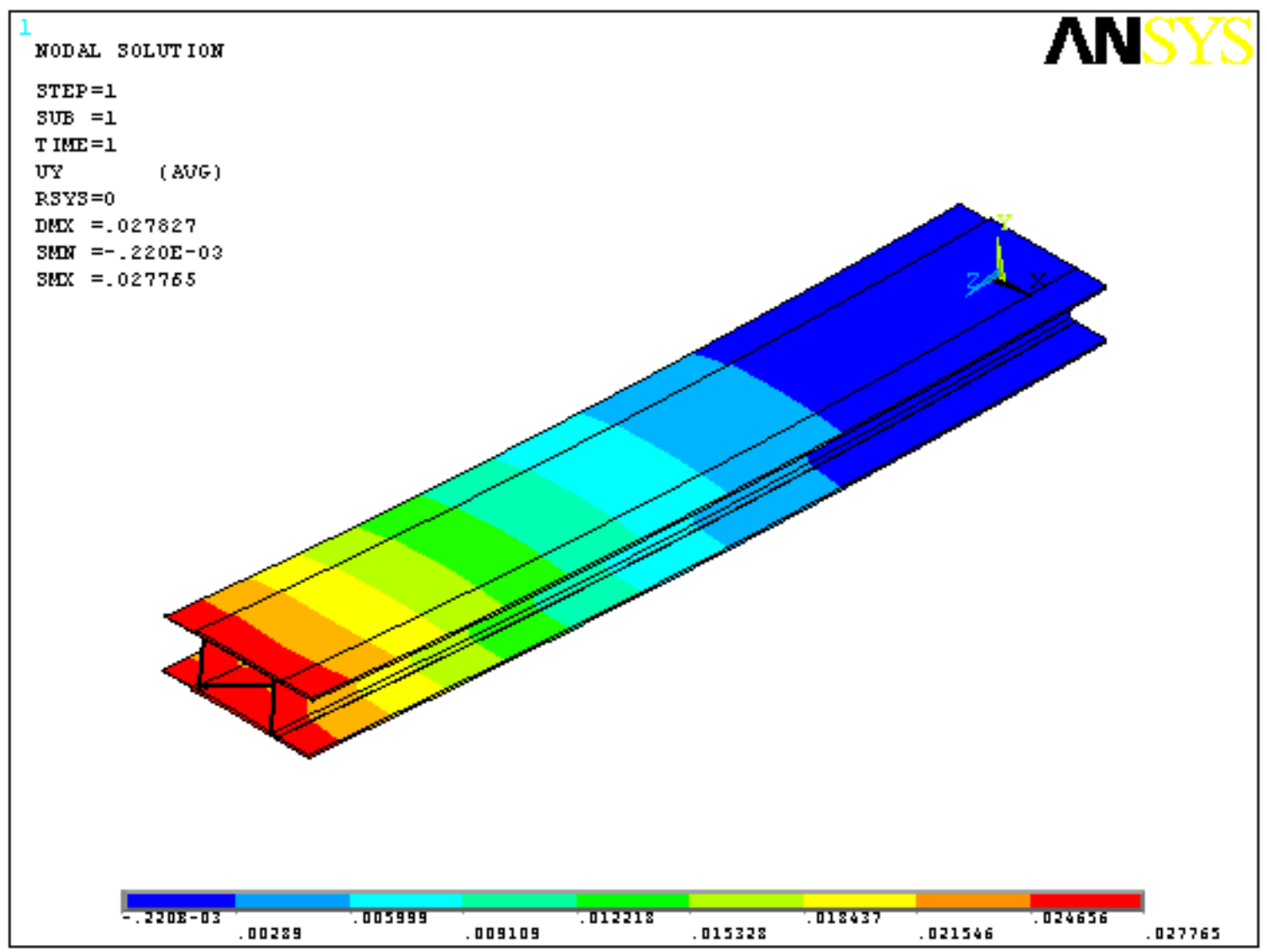

Fig. B-2 Contour plot of displacement in the $Y$ direction 